\title{
Great Lakes Remedial Action Plans (RAPs): Comparing the Hamilton Harbour and Toronto and Region RAPs as Governance Approaches
}

\author{
By \\ Madeleine Martin \\ B.Sc., McMaster University, Hamilton, 2011
}

\author{
A thesis \\ presented to Ryerson University \\ in partial fulfillment of the requirements for the degree of \\ Master of Applied Science \\ in the Program of \\ Environmental Applied Science and Management \\ Toronto, Ontario, Canada, 2014 \\ (C) Madeleine Martin 2014
}




\section{Author's Declaration}

I hereby declare that I am the sole author of this thesis. This is a true copy of the thesis, including any required final revisions, as accepted by my examiners.

I authorize Ryerson University to lend this thesis to other institutions or individuals for the purpose of scholarly research.

I further authorize Ryerson University to reproduce this thesis by photocopying or by other means, in total or in part, at the request of other institutions or individuals for the purpose of scholarly research.

I understand that my thesis may be made electronically available to the public. 


\title{
Great Lakes Remedial Action Plans (RAPs): Comparing the Hamilton Harbour and Toronto and Region RAPs as Governance Approaches
}

\author{
Madeleine Martin, 2014 \\ Master of Applied Science \\ in the Program of \\ Environmental Applied Science and Management
}

\begin{abstract}
This thesis examines and compares the rule instruments, institutions, processes (governance initiatives) and actors engaged in activities that support the remediation objectives of two RAPS: the Toronto and Region and the Hamilton Harbour RAPs. In terms of methodology, the thesis was developed using a combination of a literature review and interviews with key governance personnel. The thesis reveals the diversity of the governance initiatives that further the remediation objectives, and in particular highlights the fact that sometimes the governance is collaborative in nature, but in other cases it takes the form of rivalrous "check and balance" approaches, and that some of the nonstate governance initiatives that further the remediation objectives were developed independently of any government direction or control. The nature of the governance initiatives and actors associated with the two RAPs aligns well with the tenets of the sustainable governance approach described by Webb (2005).
\end{abstract}




\section{Acknowledgements}

I am very grateful for the support, guidance, encouragement, and inspiration of my thesis supervisor, Dr. Kernaghan Webb throughout the duration of my time at Ryerson University. I would also like to extend my acknowledgements to the following members of the Ryerson University community:

Dr. Carolyn Johns

Dr. Alex Wellington

Dr. Ron Pushchak

I would also like to acknowledge the generosity of interview subjects for volunteering their time and expertise, and allowing this investigation to be carried out.

Finally, I was very fortunate to have the support and encouragement of my parents, Stephen and Michelle Martin; my aunt, Patricia Purshouse; and my friends and classmates, Michelle Blake and Shawn Mayhew-Hammond. 


\section{Table of Contents}

Chapter One: Introduction .............................................................................................................1

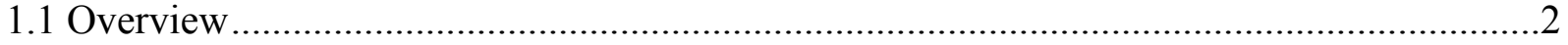

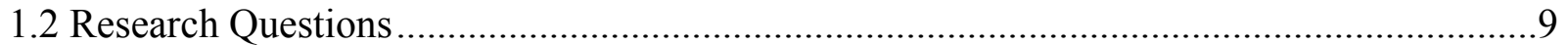

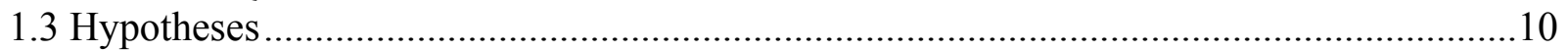

Chapter Two: Research Methods...............................................................................................11

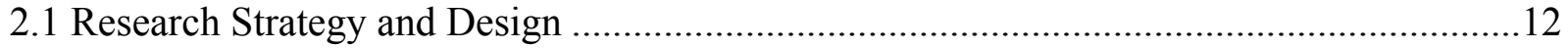

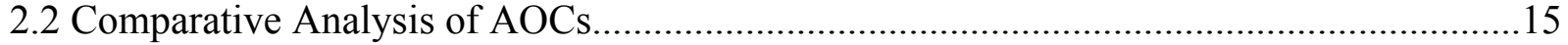

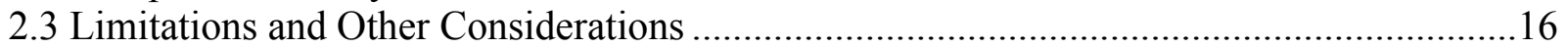

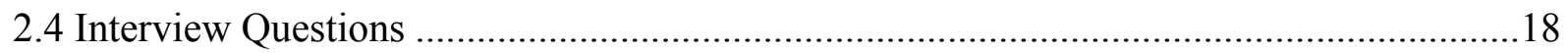

Chapter Three: History and Progress of the RAP Approach ....................................................20

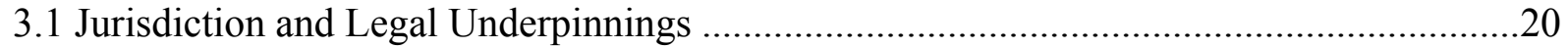

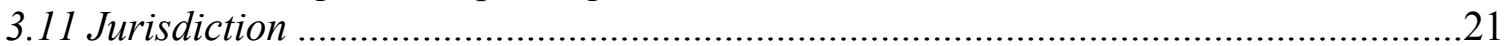

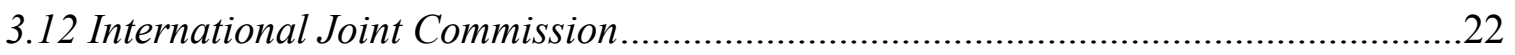

3.13 Great Lakes Water Quality Agreement ..............................................................23

3.2 Current Policy Approach..........................................................................................26

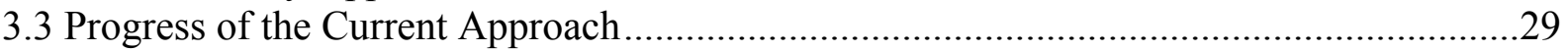

3.31 Progress Towards Delisting ………………….............................................29

3.32 Criticisms of the Approach's Progress ....................................................................

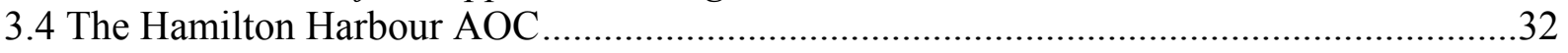

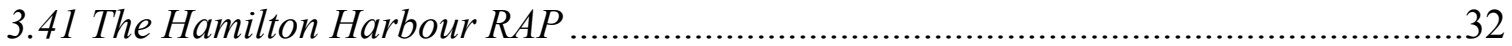

3.42 Organizational Structure of the Hamilton Harbour RAP ..........................................33

3.43 History and Progress of the Hamilton Harbour RAP ...................................................

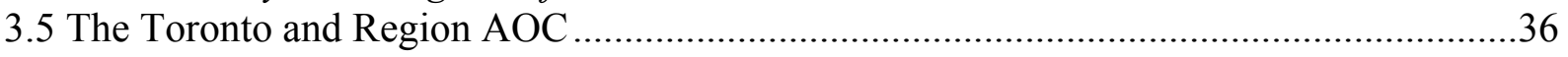

3.51 The Toronto and Region RAP .........................................................................36

3.52 Organizational Structure of the Toronto and Region RAP ........................................38

3.53 History and Progress of the Toronto and Region RAP ..............................................39

3.6 The RAP Approach and New Governance ......................................................................

Chapter Four: Modern Governance Literature Review ..................................................................43

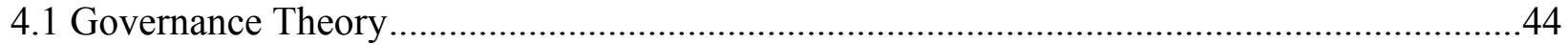

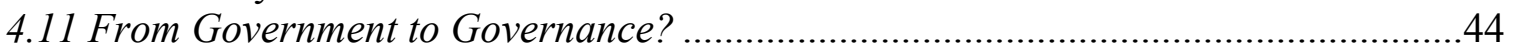

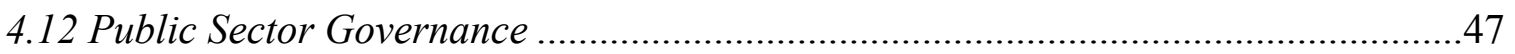

4.13 Civil Society Sector Governance …………………............................................51

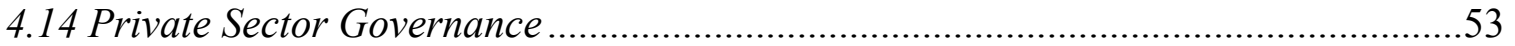

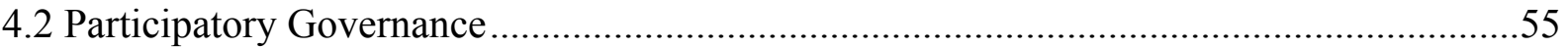

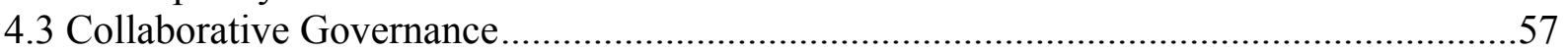

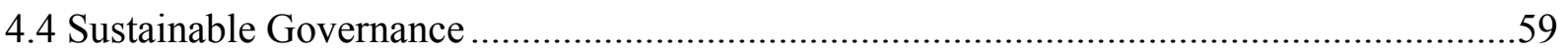

4.5 Evaluating Governance Frameworks .................................................................................62

4.51 Participatory Governance and the RAP Approach .............................................63

4.52 Collaborative Governance and the RAP Approach ................................................64

4.53 Sustainable Governance and the RAP Approach ..................................................65 
4.6 The Tenets of Sustainable Governance.

Chapter Five: Examining the RAP Approach Through the Lens of Sustainable Governance

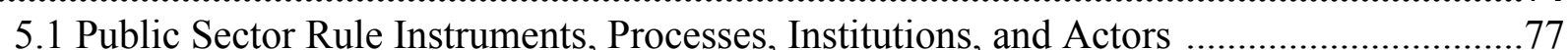

5.11 Binational/Federal Public Sector Rule Instruments, Processes, Institutions, and

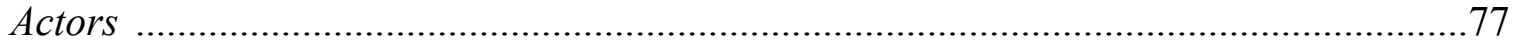

5.12 Provincial Public Sector Rule Instruments, Processes, Institutions, and Actors .....85

5.13 Municipal Public Sector Rule Instruments, Processes, Institutions, and Actors ......89

5.2 Civil Society Sector Rule Instruments, Processes, Institutions, and Actors .....................83

5.21 Bi-national/national Civil Society Rule Instruments, Processes, Institutions, and

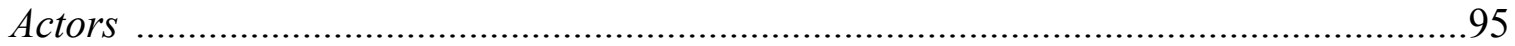

5.22 Regional Civil Society Rule Instruments, Processes, Institutions, and Actors .........95

5.23 Individual and Community Rule Instruments, Processes, Institutions, and Actors 103

5.3 Private Sector Rule Instruments, Processes, Institutions, and Actors ............................111

5.31 Bi-national/national Private Sector Rule Instruments, Processes, Institutions, and

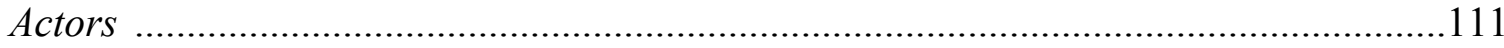

5.32 Local Private Sector Rule Instruments, Processes, Institutions, and Actors ..........113

5.4 Multistakeholder Initiatives Rule Instruments, Processes, Institutions, and Actors ........117 5.41 Binational/Federal Multistakeholder Rule Instruments, Processes, Institutions, and

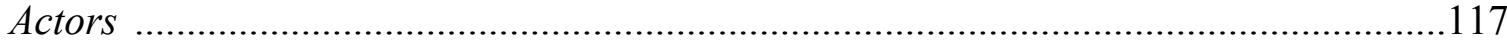
5.42 Local Multistakeholder Rule Instruments, Processes, Institutions, and Actors .....123

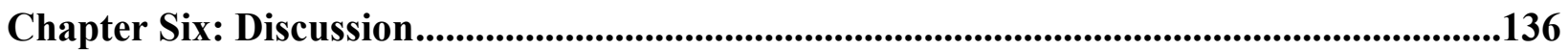

6.1 Revisiting the Tenets of Sustainable Governance.....................................................137

6.2 Learning from the Hamilton Harbour and Toronto and Region RAPs ............................147

Chapter Seven: Concluding Remarks and Recommendations..............................................153

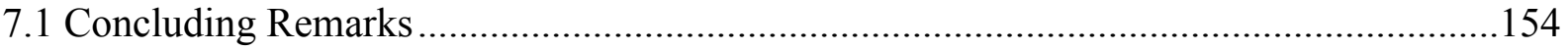

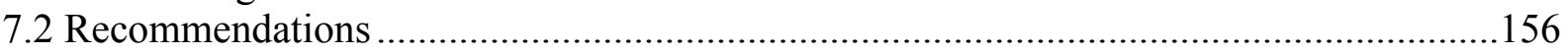




\section{List of Figures}

Figure 1.1 - Governance institutions, processes, rule instruments, and actors applying to Canadian RAPs. Layer 1: Public Sector Dimension.

Figure 1.2 - Governance institutions, processes, rule instruments, and actors applying to Canadian RAPs. Layer 2: Public + Civil Society Sector Dimension.

Figure 1.3 - Governance institutions, processes, rule instruments, and actors applying to Canadian RAPs. Layer 3: Public + Civil Society + Private Sector Dimension.

Figure $1.4-$ Governance institutions, processes, rule instruments, and actors applying to Canadian RAPs. Layer 4: Public + Civil Society + Private Sector + Stakeholder Dimension

Figure 2.1 - The Hamilton Harbour RAP: A Sustainable Governance Perspective

Figure 2.2 - The Toronto and Region RAP: A Sustainable Governance Perspective 


\section{List of Appendices}

Appendix A

Appendix B

Appendix C
Consent Agreement Form

List of Great Lakes Actors, Processes, Rule Instruments, and Institutions

Interview Respondent Key 


\section{List of Acronyms}

AOC Area of Concern

BAIT Bay Area Implementation Team

BARC Bay Area Restoration Council

BUI Beneficial Use Impairment

BWT Boundary Waters Treaty

CIAC Chemical Industry Association of Canada

COA Canada-Ontario Agreement Respecting the Great Lakes Basin Ecosystem

EC Environment Canada

GLWQA Great Lakes Water Quality Agreement

GLSLCI Great Lakes and St. Lawrence Cities Initiative

MOE Ministry of the Environment

MNR Ministry of Natural Resources

TRCA Toronto and Region Conservation Authority

RAP Remedial Action Plan 


\section{CHAPTER 1: INTRODUCTION}




\subsection{Overview}

This thesis examines and compares the rule instruments, institutions, processes (governance initiatives) and actors engaged in activities that support the remediation objectives of two RAPS: the Toronto and Region and the Hamilton Harbour RAPs. In terms of methodology, the thesis was developed using a combination of a literature review and interviews with key governance personnel. The thesis reveals the diversity of the governance initiatives that further the remediation objectives, and in particular highlights the fact that sometimes the governance is collaborative in nature, but in other cases it takes the form of rivalrous "check and balance" approaches, and that some of the nonstate governance initiatives that further the remediation objectives were developed independently of any government direction or control. The nature of the governance initiatives and actors associated with the two RAPs aligns well with the tenets of the sustainable governance approach described by Webb (2005). Research for this thesis reveals that the governance approach for the Toronto and Region RAP differs in significant ways from the governance approach associated with the Hamilton Harbour RAP. This, too, is in keeping with Webb's sustainable governance approach, given that each RAP has associated with it its own unique grouping of rule-instruments, processes, institutions and actors.

The services and benefits conferred by the Great Lakes system are unparalleled, particularly with respect to the economic prosperity, recreational enjoyment, biodiversity, and fresh drinking water enjoyed by the region and communities it houses. At the same time, decades of unfettered pollution by industries situated on the Great Lakes have caused the once pristine freshwater basin to become severely contaminated, resulting in a substantial overall decline in the health of the Great Lakes (Environment Canada, 2003a). The transboundary nature of degradation in the Great Lakes ecosystem has prompted the establishment of a series of inter- 
jurisdictional legislative, regulatory, and policy measures, including the Boundary Waters Treaty (1909), and the subsequent Great Lakes Water Quality Agreement (1978) (GLWQA), which laid the foundation for the current policy approach to restoring the Great Lakes Basin. A 1987 amendment to the GLWQA established the Remedial Action Plan (RAP) as the central policy tool for addressing the environmental degradation present at sites designated Areas of Concern (AOC) (Environment Canada, 2003a). Under this RAP approach, the Great Lakes remediation focuses on 43 designated Areas of Concern (AOCs), categorized based on the presence of severe environmental degradation, which is assumed with the loss of important ecosystem services (Environment Canada, 2003a).

Site-specific RAPs have been developed for each designated site, which are addressing various categories of environmental degradation, referred to as "beneficial use impairments" (BUIs) in Annex 1 of the GLWQA. The IJC defines BUIs as shifts in the "chemical, physical, or biological integrity of the Great Lakes system" that result in any item on a list of 14 impairments, which includes impaired water quality, and diminished wildlife habitat (International Joint Commission (IJC), 2013) (see Chapter 3 for complete list). In spite of this ambitious bi-national government strategy, the actual progress of RAPs has fallen short of initial expectations and goals. To date, only five of the 43 sites categorized as Areas of Concern by the International Joint Commission in 1987 have progressed to the delisting stage: Collingwood Harbour (Canada), Severn Sound (Canada), and Wheatley Harbour (Canada), Presque Isle Bay (United States) and the Oswego River (United States) (Environment Canada, 2010b). The slow progress of the remaining AOCs towards delisting has been the subject of criticism, particularly from the IJC, which serves as a binational regulatory and watchdog entity for the strategy (International Joint Commission, 1998; International Joint Commission, 2009). 
Sproule-Jones (1999) observes that the flexibility of the RAP is such that it can be adjusted to suit the unique characteristics and needs of AOCs and the jurisdictions housing them (e.g., in terms of environmental issues addressed, stakeholders involved, etc.). The author cautions, however, that this flexibility in some cases grants stakeholders a larger amount of discretion with respect to decision making, which has in some cases led to policy deficiencies. This thesis will focus on two sites, the Hamilton Harbour and Toronto and Region AOCs, which, while facing similar urban and environmental characteristics, diverge in terms of the nature and extent of stakeholder involvement in the RAPs, and in other respects. In addition to these perceived characteristic similarities, the two sites were chosen for comparison because they are both Canadian sites, located on Lake Ontario, thus sharing the same legal backdrop. While comparing a Canadian and a U.S. AOC rather than two Canadian AOCs would certainly add an additional layer with respect to the countries' differing legal systems, politics, etc., it was decided that this type of comparison was better suited to a longer term research project (i.e. a Ph.D. dissertation) than a master's thesis.

From its inception, the Toronto and Region RAP has remained largely under public sector control, with key stakeholders selected by government agencies (Sproule-Jones, 1999). As a result, the success of the RAP is chiefly dependent upon sustained government commitment. In contrast, the Hamilton Harbour RAP grew from existing community initiatives, and granted stakeholders considerable authority in decision making (Sproule-Jones, 1999). While using vastly different local governance approaches, both AOCs have experienced implementation difficulties resulting in delays that have hindered the progress of their RAPs (Sproule-Jones, 1999). This thesis aims to examine these difficulties in terms of the sites' distinct governance systems. 
According to Annex 1 of the GLWQA (2012) amendment, the RAPs are to be carried out using a "systematic and comprehensive ecosystem approach," allowing for the participation of stakeholders in both the development and implementation stages (IJC, 2013a). The introduction of this innovative approach was met with much enthusiasm by stakeholders, and was lauded in particular for its inclusion of community members and organizations in the RAP design process (Hartig \& Vallentyne, 1989; Krantzberg, 2003). This aspect of the RAP concept constitutes a distinctive approach to environmental remediation and protection; although its development is a product of top-down actions (i.e. actions stemming from bi-national and federal government initiatives), a good deal of RAP design and implementation decision-making rests in the hands of local stakeholders.

It is this delegation of RAP duties and responsibilities to nonstate actors in the Great Lakes regime that bears resemblance to several emergent governance concepts: collaborative governance, participatory governance, and sustainable governance. Collaborative governance describes a system of governance in which public and private sector members are assembled in "common forums with public agencies to engage in consensus-oriented decision making" (Ansell \& Gash, 2007). It can be considered a broad term for instances of governance in which community members are given a voice alongside government in policy decision making. Participatory governance is similar in its advocacy of increased layperson involvement in policy decision making (Newig \& Fritsch, 2009). It refers to the movement responsible for expanding citizen participation beyond traditional democratic duties (e.g. voting) to a more direct and tangible influence on policy outcomes (Aulich, 2009). Another approach, sustainable governance, emphasizes the ways in which governmental and nonstate resources have begun to be harnessed to create a more resilient and effective system of governance. In its most advanced form, this is 
accomplished through the systematic use of a combination of governmental and nonstate institutions, processes, rule instruments, and actors (Webb, 2005). It is important to note that Webb (2005) uses "sustainability" not in the environmental sense that the term has come to be associated with but rather to emphasize the enhanced resilience, reliability and robustness over the long term of governance systems that include the combination of elements associated with the sustainable governance framework, when compared with other approaches. The sustainable governance framework applies to issues outside of the environment, and is considered separate from the frequently discussed concept of sustainable development.

In spite of possessing unique characteristics and principles, it should be noted that these three governance frameworks (participatory, collaborative, and sustainable governance) are not mutually exclusive; that is, they overlap in terms of operational characteristics. In fact, the sustainable governance framework encompasses many aspects of collaborative and participatory governance. For instance, the participatory governance concept of extending democratic participation beyond voting by writing nonstate actors directly into government initiatives aligns well with several of the tenets of sustainable governance (i.e., increased involvement of nonstate actors in governance). Similarly, the collaborative governance framework's emphasis on consensus is in accordance with, for example, the sharing of the responsibilities, costs, and learning associated with governance with nonstate actors that is central to the sustainable governance theory. What distinguishes sustainable governance from both collaborative and participatory governance is its recognition of the involvement of nonstate actors in governance that can be initiated and operated independent of government, and can be rivalrous or confrontational, in addition to being collaborative and consensus-oriented. This important 
distinction will be emphasized and discussed throughout this thesis, citing numerous examples related to the Great Lakes RAP approach.

At a preliminary stage of research for this thesis, and in subsequent analysis, the position was taken that the sustainable governance approach most closely aligns with the actual activities and characteristics associated with implementation of RAP objectives in terms of remediating the lakes' most severely contaminated sites. The notion of sustainable governance is premised on the recognition that private sector and civil society actors can contribute in terms of governance, sharing the responsibilities, costs, and learning, along with the public sector (Webb, 2005). Although aspects of the Great Lakes remediation approach can be characterized as examples of both collaborative and participatory governance, sustainable governance best captures the diverse conceptual aspects of the approach to governing associated with the RAPs and more accurately explains the ways through which it is achieved. The extent to which the tenets of sustainable governance can be seen to align with governance practices aimed at remediating the Great Lakes ecosystem is a topic that has yet to be explored, and will be undertaken as the chief purpose of this research. In this regard, avenues for the increased involvement of nonstate actors, and subsequent incorporation of their rule instruments, institutions, and processes will be identified.

According to Webb (2005), rule instruments refer to sets of objective criteria intended to guide behaviour and to determine whether an entity or an activity is operating within the bounds of these criteria. Laws, voluntary codes, memoranda of understanding, and standards are all examples of rule instruments. The most familiar forms of rule instruments are government laws and regulations; however, sustainable governance allows for the possibility of nonstate actor rule instruments, independent of government. While the RAP approach has a legislative foundation, 
nonstate rule instruments also make less obvious, innovative contributions to forwarding its goals. This investigation will review both state and nonstate rule instruments that have either been observed to contribute to the approach, or that appear to demonstrate the potential to contribute. In the sustainable governance model, processes describe structured sets of interrelated or interacting activities that enable parties to make significant contributions to decisions concerning issues that they have a stake in. Examples of processes include petitions, funding programs, and dispute resolution (Webb, 2005). In a similar manner, this thesis will examine the (existing and potential) contributions of public, private, and civil society sector processes relevant to the governance of the Great Lakes.

Institutions are described in the sustainable governance approach as an organizational entity of the public sector, private sector, or civil society that performs a public interest governance function (Webb, 2005). Examples of institutions include government ministries or commissioners, or industry councils that perform a public interest rule making or dispute resolution function (Webb, 2005). It is important to note that Webb (2005) uses the term "institutions" in the legal sense, although is frequently used in a different manner in political science literature. Scholars such as North, for example, have defined institutions in such a way that includes formal rules (e.g. laws and regulations) (as cited in Prado and Treblicock, 2009). For the purpose of this study and in keeping with the sustainable governance approach, the word "institution" will adopt the more limited sense of institutions as entities performing a specific public interest function. Webb (2005) employs the word in a manner similar to Prado and Treblicock (2009), who characterize institutions as "bodies (formal and informal) charged by a society with making, administering, enforcing or adjudicating its laws or policies." 
While the participatory and collaborative governance theories appear to share some important characteristics with tenets of Webb's sustainable governance (listed below), a number of unique traits distinguish the framework as best describing the novel, emergent governance trend.

1. In a sustainable governance system, the responsibilities, costs, and learning associated with governance involve the public sector, private sector, and civil society organizations.

2. The energies of these public sector, private sector, and civil society actors are harnessed via the rule instruments, processes, and institutions ("initiatives") they contribute to the resolution of a particular public policy issue.

3. Private sector and civil society initiatives complement, rather than detract from conventional state rule instruments, processes, and institutions.

4. In a sustainable governance system, the value of multiple centres of authority is recognized.

5. The value of multi-sectoral collaborations is recognized.

6. A potential for healthy rivalry between actors exists.

7. In a fully evolved sustainable governance system, public, private, and civil society sector initiatives work together in a systematic way to achieve a common public policy goal.

The participatory and collaborative governance frameworks appear to correspond, for example, with tenets 3., 4, and 5. However, others (e.g. 1, 2, 6, and 7) describe governance characteristics that are unexplained by, or that fail to align with the defining principles of participatory and collaborative governance. It is because the actual activities, instruments, institutions and processes associated with the achievement of the RAP objectives studied in this Masters thesis align more closely with the seven tenets of sustainable governance, that the sustainable governance framework is used as a base for discussion in this thesis. These fundamental distinctions are employed throughout this thesis to categorize and explain various 
aspects and behaviours of actors and initiatives contributing to the objectives of the RAP approach.

Figure 1 summarizes the sustainable governance institutions, processes, rule instruments, and actors contributing to the Great Lakes remediation approach. As is hopefully evident from the figure, there are identified independent roles being played by private, civil society, and multistakeholder actors and their governance initiatives that supplement the more conventional "top down" public sector governance initiatives associated with environmental protection (e.g., command and control regulation). The distinct contributions of these diverse governance initiatives and actors will be explored and discussed in the remainder of this thesis. 


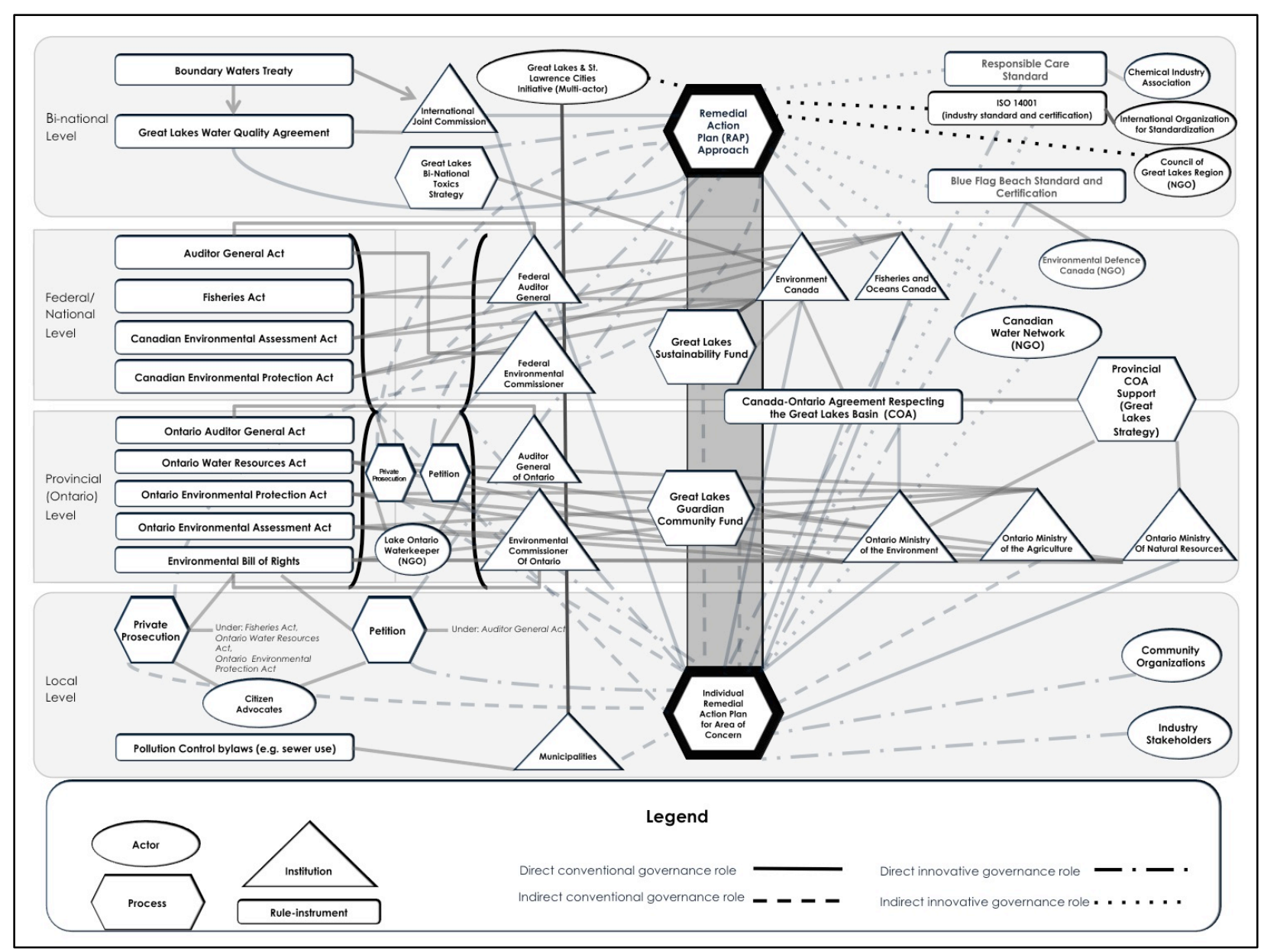

Figure 1. Overview of governance institutions, processes, rule instruments, and actors applying to Canadian RAPs.

\subsection{Research Questions}


The following research questions guide the scope and direction of this thesis, during the literature review, formulation of interview questions, during the interviews, and throughout the analysis of relevant policy documents and interview content:

- How have inter-jurisdictional policies governing the remediation of the Great Lakes been applied at the local scale (i.e. in the Hamilton Harbour and Toronto and Region RAPs)?

- Can the governance initiatives and actors associated with the Toronto and Region and Hamilton Harbour RAP/AOC approaches be considered as furthering the RAP remediation objectives?

- What aspects of the Hamilton Harbour RAP can be considered as furthering the RAP remediation objectives? Which do not?

- What aspects of the Toronto and Region RAP can be considered as furthering the RAP remediation objectives? Which do not?

- Which governance framework or approach articulated by scholars best describes the RAP approach to remediating the Great Lakes?

- To what degree does the RAP/AOC approach align with the tenets of the chosen governance framework?

- What are the respective roles of the public, private and civil society sectors in the RAP approach?

- How might the energies of nonstate actors be further harnessed to fill implementation gaps, in order to achieve a more robust system of governance?

- What are the challenges associated with multistakeholder rule instrument, institution, and process governance? 


\subsection{Hypothesis}

If the diverse challenges associated with the remediation of the Great Lakes are to be adequately addressed, then this will require harnessing of the combined energies and capabilities of public sector, private sector, and civil society actors, using a diverse array of rule instruments, processes, and institutions (the "pillars” of Webb's sustainable governance).

This master's thesis will examine this hypothesis by investigating the alignment of the RAP approach to remediating the Great Lakes with the tenets of Webb's (2005) sustainable governance, listed in Section 1.1. This will be explored through a focused examination of the RAPs of two AOCs (the Hamilton Harbour and Toronto and Region RAPs), drawing on a review of publicly available documents, a review of academic literature pertaining to governance and concerning the environmental regulation of the Great Lakes, and interviews with key public sector, private sector, and civil society actors engaged in actions that support the objectives of the RAPS through use of a diverse array of rule instruments, processes and institutions. 


\section{CHAPTER 2: RESEARCH METHODS}




\subsection{Research Strategy and Design}

This master's thesis tested the veracity of the hypothesis outlined in the previous chapter (1.3) with a focused examination of the Hamilton Harbour and Toronto and Region RAPs using a combination of two methods. First, a review of publicly available documents, and a review of academic literature pertaining to governance and concerning the environmental regulation of the Great Lakes was conducted. This commenced with an exploration of the history of Great Lakes governance and remediation methods, in order to better understand the progress and success achieved by the approach thus far. The goal was to piece together the "story" leading up to the binational RAP approach, including successes, failures, and obstacles to achieving remediation objectives. The "stories" of the two RAPs serving as the focus of this comparative analysis of the implementation of GLWQA commitments at different sites were also compiled.

Transnational, federal, provincial/state, and municipal policy documents, in addition to relevant reports published by nonstate actors, such as industry members, and environmental nonstate organizations was examined. The review of academic works centred on those that provided a general commentary on governance practices, and academic discourse regarding preselected theories (sustainable governance, participatory governance, and collaborative governance), as well as those pertaining specifically to Great Lakes governance. Preliminary research on the topic of governance suggests the Great Lakes regime aligns most closely with Webb's (2005) theory of sustainable governance, which posits that both state and nonstate actors participate in modern governance, filling implementation gaps and serving as a check and balance for each other's policies and behaviours. These actors make contributions to the larger system of governance through a combination of innovative and conventional initiatives in the shape of rule instruments, institutions, and processes (Webb, 2005). Hence, the next step was to 
identify initiatives designed and implemented by public, private and civil society actors that have been developed and/or applied (whether primarily or secondarily), or hold potential for application to the RAP approach. These were taken into consideration when exploring the alignment of current governance practices aimed at remediating the Great Lakes with the principles of sustainable governance.

The second method consisted of open-ended, semi-structured interviews with 28 key public sector, private sector, and civil society actors engaged in actions that support the objectives of the RAPs through use of rule instruments, processes and institutions. The purpose of this second component was to provide the investigation with an additional layer via direct insights from individuals representing actors in the public, private, and civil society sectors. It was determined that interviews were to be used as a means of obtaining further insight into the remediation of the Great Lakes. This method was favoured over other qualitative data collection methods due to its ability to permit interview subjects to shape their responses according to their unique experiences, involvement, and insights. Moreover, interviews allow for greater flexibility in responses from participants and are therefore better suited to the investigation than, for example, a survey, which is far more rigid, and consequently, limited in the type and depth of information that can it can be used to collect.

Qu and Dumay (2011) discuss the merits of using semi-structured interviews, as opposed to fully unstructured or structured interviews. According to the authors, the semi-structure interview consists of a planned set of questions formulated with guidance from pre-identified themes. These are interspersed with unplanned, spur-of-the-moment probing questions intended to prompt the interview subject to provide further detail. The combination of structure and fluidity allows the interviewer to remain on topic while delving more deeply into the subject 
matter, exposing "important and often hidden facets of human and organizational behavior" $(\mathrm{Qu}$ and Dumay, 2011).

Due to the level of knowledge and detail required to properly investigate the research question, interviews were requested only from those considered 'key informants' in the field of research. According to Marshall (1996), "key informants, as a result of their personal skills, or position within a society, are able to provide more information and a deeper insight into what is going on around them." In other words, interview subjects were selected on the basis of their knowledge and expertise regarding their organization's involvement in the RAP approach. These key informants were identified throughout the literature review, as the roles of various actors in the remediation of the Great Lakes were unearthed. The snowball sampling method was used to ensure interview subjects were a representative sample of the approach's numerous actors and stakeholders. According to Handcock and Gile (2011) the snowball sampling procedure is used when the investigation requires information from "hard-to-reach" populations. Given the very small number of individuals well versed in Great Lakes issues, and the even smaller subset of individuals with knowledge concerning the involvement of specific actors, the target population for interviewees certainly fills the requirements for a rare population. Under the snowball sampling method, members of the population are identified, interviewed, and are asked to identify other members of the population, who are in turn interviewed and asked to identify additional individuals in the population. This was accomplished at the end of the interview process, by asking subjects whether they could recommend any other experts who might be able to provide additional, pertinent information or insights. At a certain point in the interview process, individuals began to name experts that had already been interviewed. This suggests that 
at this stage, individuals representing the most prominent, and heavily involved entities had been spoken to.

It should be noted that one challenge inherent in the use of interviews to obtain research insights is that responses given to questions posed tend to be biased in one direction or another depending on the affiliations and convictions of interview respondents and the entities they represent. In the investigation in question, this may, for example, manifest itself as a bias towards views held by whichever sector an interviewee is affiliated with, be it an environmental NGO, government department, stakeholder community, or polluting industry. In order to minimize this potential for bias in information acquired from interviews, it was ensured that individuals representing each of the above sectors were selected as interview subjects, such that a range of opinions and insights are gathered.

As previously discussed, of the governance theories examined, sustainable governance appeared to provide the most accurate backdrop against which to investigate the RAP approach. Thus, the insights and information collected during the literature review and interviews were tested for their alignment with this particular governance theory.

\subsection{Comparative Analysis of AOCs}

Following the data collection phase of research, a comparative analysis of two Areas of Concern (AOC) was conducted. It was thought that reviewing two RAPs would allow for comparisons in terms of the degree of participatory, collaborative, and sustainable governance elements - something that is not possible when only one RAP is examined. After reviewing each of the 43 AOCs, it was decided that the investigation would focus on the Hamilton Harbour and Toronto and Region AOCs. A number of factors were taken into consideration when making this 
decision. First, both AOCs are located in cities experiencing similar environmental difficulties related to urbanization (and being large urban centres), such as development, aging infrastructure, and competition with other pressing demands for government resources. Additionally, because both AOCs are located in Canada, the sites operate under Canadian environmental laws and regulations, allowing a comparison of what can be considered two different manifestations of the fulfillment of Canadian obligations under the GLWQA. Furthermore, it was predicted that this type of comparative analysis would uncover the relative partitioning of government resources at various levels, harnessing of industry and NGO potentials, and the contributions of local groups and community members.

\subsection{Limitations and Other Considerations}

A large number of Great Lakes organizations are currently active, with an expansive range of mandates and agendas. Due to limited time and resources, it is necessary to limit the number of these entities selected for participation in this research project. Rather than attempting to quantify the number of actors, processes, institutions, and rule instruments with any small relevance to this investigation, it was decided that the focus would rest primarily on actors and entities with a significant role in the RAP process. It is thought that this approach would result in a richer, more in-depth analysis than could be accomplished with a comprehensive, but superficial investigation of all possible actors and entities.

For the same reason, this thesis was also limited to investigating the governance of two RAPs, the Hamilton Harbour and Toronto and Region RAPs. Two Canadian sites were selected due to somewhat similar urban contextual characteristics, and their sharing of the same legal backdrop. It was decided that the complexity involved in comparing a Canadian and U.S. RAP 
could not be adequately addressed in a master's thesis, and is better suited to a longer term research project (i.e. a Ph.D. dissertation).

The Ryerson University Ethics Board (REB) requires that all research projects involving human subjects be submitted to the board for ethical review. A consent form was drawn up based on the guidelines put out by the REB (see Appendix A). An application including the consent form and proposed interview questions were submitted for ethical review, and the board granted its approval on December $12^{\text {th }}, 2012$.

Interview subjects will be presented with two options with respect to confidentiality. They could consent to the use of their name and job title in addition to the insights they provided, or remain anonymous. Interviewees that wished to remain anonymous will be referred to as representatives from the entity they are affiliated with. According to the consent agreement, participants are guaranteed that all interview data will be destroyed one year from the date that their interview was conducted.

The chosen method is limited to an extent by the stipulations of the REB. In order to receive ethics approval, the board requires that all participants be asked a common set of questions that are to be submitted for review. This constraint eliminated the possibility of customizing interviews for particular interviewees and the sectors they represent. As a result of this, interview questions were designed to be sufficiently general, so as to be equally applicable to the unique backgrounds and contributions of interview subjects. 


\subsection{Interview Questions}

1. How has your organization contributed to the Areas of Concern/Remedial Action Plan approach to remediating the Great Lakes, whether directly or indirectly?

2. How did your organization become involved in this? Have you initiated or are you affiliated with any-rule instruments, institutions, or processes* ("initiatives") that have contributed to governing the remediation of the Lakes?

3. Would you say the initiative(s) has evolved over time? If so, how?

4. What would you say are the primary strengths of the initiative(s) (if any)?

5. What would you say are the primary weaknesses of the initiative(s) (if any)?

6. Have you managed to measure the success of your initiative? If so, how has this been accomplished? If not, are there any barriers that have prevented this measurement from being taken?

7. Would you say that your initiative supports, improves, or interferes with any other initiative currently in place to address the remediation of the Hamilton Harbour AOC (OR Toronto and Region AOC)?

8. What would you say are the most significant challenges that have arisen and apply to this initiative(s)? Do you have any thoughts on how you would address these challenges?

9. One commentator uses the term "sustainable governance" to describe an approach to environmental protection where a combination of rule instruments, institutions, and processes developed by the public sector, private sector, and civil society work together in a systematic way to improve the environment. ${ }^{1}$ Due to its inclusion of multiple actors and initiatives, this commentator has suggested that this sustainable governance approach may be more "robust" than traditional approaches, since the successful delivery of services is not entirely dependent on government. ${ }^{1}$ Although sustainable governance recognizes the central role of government and conventional regulatory methods, it also encourages a more systematic exploitation of private and civil society sector capabilities, "to assist in governing in the public interest." A sustainable governance approach involves the systematic use of a combination of governmental and nonstate institutions, processes, rule instruments, and actors. ${ }^{1}$

a) Thinking about the Hamilton Harbour AOC, how (if at all) do you see the idea of sustainable governance applying?

b) Drawing on the concept of sustainable governance, can you make any suggestions with respect to how remediation and environmental protection might be improved? 
c) In what way, if at all, do you think the concept of sustainable governance could be problematic (i.e. could interfere or detract from the remediation of the Hamilton Harbour AOC)?

10. Is there anything else you would like to add that was not covered in the above questions?

*Definitions:

Rule instrument: Rule instruments refer to a set of requisite criteria intended to guide behaviour and to determine whether an entity or an activity is operating within the bounds of these criteria. ${ }^{1}$ Voluntary codes, memoranda of understanding, and standards development are all examples of rule instruments. ${ }^{1}$

Process: Processes are mechanisms that enable parties to make significant contributions to decisions concerning issues that they have a stake in. ${ }^{1}$ Examples of processes include citizen-triggered investigations concerning enforcement, dispute resolution processes, and private prosecutions. ${ }^{1}$

Institution: An institution is described as an organizational structure of state, industry, or nonstate organization (NGO) that perform particular governance functions that possess an explicit public interest aspect. ${ }^{1}$ An institution may take the shape of government, industry, or NGO ombudsmen, councils, associations, commissions, etc. ${ }^{1}$

${ }^{1}$ Webb, Kernaghan. (2005). Sustainable Governance in the Twentieth Century: Moving Beyond Instrument Choice. In Eliadis, P., Hill, M., \& Howlett, M. (Eds.), Designing Government: From Instruments to Governance (242 - 280). Montreal \& Kingston: Mcgill-Queen's University Press. 
CHAPTER 3: HISTORY AND PROGRESS OF THE RAP APPROACH 
The Remedial Action Plan (RAP) approach refers to the current inter-jurisdictional policy regime aimed at remediating the Great Lakes basin. Under this approach, the remediation of the lakes focuses on 43 designated Areas of Concern (AOCs), categorized based on the presence of severe environmental degradation, which is assumed based upon the loss of important ecosystem services. This chapter will explore the evolution of the Great Lakes regime, and the subsequent progress of the RAP approach, in addition to reviewing the history and progress of the Hamilton Harbour and Toronto and Region AOCs.

\subsection{Jurisdiction and Legal Underpinnings}

\subsection{Jurisdiction}

Under the Constitution Act (1867), provinces have the direct authority to control and regulate resources contained within their borders (Environment Canada, 2013a). Provinces are assigned the primary legislative power over water resources within their borders, and pollution control concerning these water resources, although some of this power has been delegated to local governing bodies (Greenbaum \& Wellington, 2010). Thus, in Canada, the provincial government has significant authority to address water quality issues in the Great Lakes. However, the continual involvement of the federal government is unavoidable due to the interjurisdictional nature of Great Lakes issues, and the responsibility of the Canadian federal government for the management of relations with other countries (Greenbaum \& Wellington, 2010). This need for federal involvement is apparent in the current bi-national approach to protecting and remediating the lakes, as it requires a high level of commitment from the Canadian and U.S. governments. 
The Boundary Waters Treaty (BWT) (1909) was the first trans-boundary legislative measure addressing Great lakes issues (Botts and Muldoon, 2005). It stemmed from the perceived need for a dispute resolution body to resolve conflicts arising from the sharing of waters by Canada and the U.S., and was "designed to protect the Great Lakes and other boundary waters against unilateral diversions and obstructions to navigation” (Weiss, 1989). The BWT and IJC later expanded their powers to address pollution control (Weiss, 1989).

\subsection{International Joint Commission}

The BWT established the International Joint Commission (IJC), a bi-national administrative group responsible for resolving disputes stemming from the shared use of interjurisdictional water bodies by Canada and the United States (International Joint Commission [IJC], 2013). In spite of the large disparities that exist between the two countries' populations and economies, Canada and the U.S. have equal powers within the context of the IJC, which emphasizes "binational processes and equal sharing of responsibilities" (Botts and Muldoon, 2005). Accordingly, three members represent each country as commissioners (IJC, 2013b).

Botts and Muldoon (2005) note that the IJC serves three functions with respect to the Great Lakes. The first involves the employment of "quasi-judicial power" when applying principles governing water use for projects with the potential to affect the levels and flows of transboundary and boundary waters (Botts and Muldoon, 2005). The Commission's limited authority permits them to issue what are known as 'orders of approval' when these projects are deemed acceptable (IJC, 2013b). The second function of the IJC is chiefly advisory; governments are able to make requests in the form of what is known as a "reference" for the investigation a particular issue, inviting the Commission to recommend solutions (Botts and 
Muldoon, 2005). Finally, the IJC also has a function in dispute resolution, through an arbitral power awarded under Article X of the BWT, although it is one the Commission has yet to invoke (Botts and Muldoon, 2005). The IJC fulfilled their advisory function via the release of annual reports on progress from 1972 - 1978. Since the 1978 Great Lakes Water Quality Agreement amendment, the Commission has released biennial reports, and continues to do so today (Botts and Muldoon, 2005). The reports are chiefly comprised of recommendations for actions required for meeting the goals of the agreement.

\subsection{Great Lakes Water Quality Agreement}

Created in 1972, the interjurisdictional Great Lakes Water Quality Agreement (GLWQA) is, in essence, a standing reference under the BWT (Botts and Muldoon, 2005). The Agreement emerged from a growing environmental movement and public concern regarding the health of the Great Lakes (Botts and Muldoon, 2005). The Canadian federal government had recently established Environment Canada (1971), and the remediation of the Great Lakes was high on the agency's list of priorities (Botts and Muldoon, 2005). This advancement came on the heels of the U.S. government's establishment of the Environmental Protection Agency (EPA), which was founded in 1970 (U.S. EPA, 2013).

The GLWQA (1972) and the accompanying 1978 and 1987 amendments articulate both countries' commitment to the remediation of the Great Lakes, and hold them accountable for their treatment of the shared waters (Bay Area Restoration Council, 2012a). The 1972 Agreement is largely credited with bringing about drastic reductions in phosphorus levels in Lake Erie, not long after being declared "dead" by the media (Botts and Muldoon, 2005). The 1978 renewal of the GLWQA expanded upon the less precise goals of the 1972 Agreement, 
which centered on the restoration and enhancement of water quality via pollution control (Botts and Muldoon, 2005). The 1978 renegotiated version made explicit mention of the use of an ecosystem approach to restoration, and committed signatories to the "virtual elimination" of harmful pollutants (Botts and Muldoon, 2005). In 1987, a Protocol was signed, amending the 1978 agreement. The 1987 amendment emerged in part as a response to the Unfulfilled Promises report published by the non-governmental organization Great Lakes United in 1987. This action by the now-dissolved Great Lakes United has important implications for the application of the sustainable governance framework to the Great Lakes remediation approach; as is perhaps apparent from the multistakeholder, non-governmental status of the Great Lakes United, the establishment of RAPs was a response to the pressures of a nonstate entity. Furthermore, this action was not the work of a simple collaborative or participatory involvement of a civil society organization - it suggests that the foundation for the RAP approach originated from a rivalrous friction (i.e. a civil society group acting as a check and balance on a government rule instrument), not government-private-sector-civil society collaboration. Thus, right from the outset, RAPs had their origin in nonstate action, and right from the outset, the nonstate action took the form of a “check and balance" or challenge function, in keeping with Webb's idea that sustainable governance harnesses the energies of nonstate actors, instruments, institutions and processes.

The report documented the results of hearings held by the group, which exposed public dissatisfaction with government for failing to live up to the objectives of the GLWQA. The report's release opened the door to increased dialogue between community members and Canadian and U.S. government officials (Jackson, 2005). It was the 1987 Protocol that established the Remedial Action Plans (RAP) approach, calling for the design of site-specific remediation plans for 42 designated Areas of Concern (AOCs) in Canada and the United States. 
AOCs were identified by the extent of their environmental degradation according to criteria established in the initial Agreement (Bay Area Restoration Council, 2012a). The excerpt below, taken from Article 2 of the revised GLWQA, lists the agreement's ambitious goals, and conveys the IJC's vision for the future of the Lakes:

The purpose of the Parties is to restore and maintain the chemical, physical, and biological integrity of the waters of the Great Lakes Basin Ecosystem. In order to achieve this purpose, the Parties agree to make a maximum effort to develop programs, practices and technology necessary for a better understanding of the Great Lakes Basin Ecosystem and to eliminate or reduce to the maximum extent practicable the discharge of pollutants into the Great Lakes System.

Consistent with the provisions of this Agreement, it is the policy of the Parties that:

The discharge of toxic substances in toxic amounts be prohibited and the discharge of any or all persistent toxic substances be virtually eliminated;

Financial assistance to construct publicly owned waste treatment works be provided by a combination of local, state, provincial, and federal participation; and

Coordinated planning processes and best management practices be developed and implemented by the respective jurisdictions to ensure adequate control of all sources of pollutants.

The above brief statement of purpose exposes several important messages entrenched in the GLWQA that have carried through from 1978 Agreement to the present-day RAP approach. According to the first requirement, parties (the U.S. and Canadian federal governments) must ban the discharge of toxic substances. Because the document is a bi-national agreement, it is non-binding; thus, no punitive consequences will arise in the case that any signatory fails to comply. In a similar vein, the role of the IJC cannot exceed that of an advisor or watchdog. The commission is therefore limited to making recommendations to signatories for legal and 
regulatory reform, which Canadian and U.S. governments are not obliged to follow. It is important to take note of the second provision, that the financial burden of wastewater treatment be shared by three levels of government, as the partitioning of costs between provincial, federal, and provincial governments surfaced as a point of debate for the sites being examined in this investigation. Finally, the open-ended nature of the third provision speaks to the flexible nature of the approach. The use of versatile phrasing (i.e. "coordinated planning processes" and "best management practices") foreshadows the flexibility that would emerge from the conventional origin of RAPs (i.e. legislation), as the methods used for achieving individual RAP goals were left to the discretion of the signatories, and out of necessity, yielded innovative, ad hoc solutions.

In 2012, the GLWQA underwent yet another renegotiation, largely in response to a widespread perception that the approach was not effective in fulfilling its objectives (Krantzberg, 2012). Aside from reaffirming the commitments of Canada and the U.S. to the previous agreement's vision and objectives, signatories addressed the concerns of stakeholders with the addition of three new annexes tackling pressing, emergent environmental issues: Aquatic Invasive Species, Habitat and Species, and Climate Change Impacts (Environment Canada (EC), 2013a). Addressing the concerns of stakeholders, the 2012 agreement established timelines for signatories' fulfillment of a number of long-term and short-term actions, such as the formation of a lake-wide rapid response plan upon detection of invasive species within 2 years of signing (EC, 2013a).

\subsection{Current Policy Approach}

An area on the Great Lakes Basin is labeled an AOC when it is observed to have undergone an "impairment of beneficial uses" (BUI) producing biological, chemical, andphysical 
changes to the environment resulting in any of the following environmental damages delineated in Annex $1^{1}$, Section 1I of the GLWQA:

- restrictions on fish and wildlife consumption;

- tainting of fish and wildlife flavour;

- degradation of fish and wildlife population;

- fish tumors or other deformities;

- bird or animal deformities or reproduction problems;

- degradation of benthos;

- restrictions on dredging activities;

- eutrophication or undesirable algae;

- restrictions on drinking water consumption, or taste and odour problems;

- beach closings;

- degradation of aesthetics;

- added costs to agriculture or industry;

- degradation of phytoplankton and zooplankton populations; and

- loss of fish and wildlife habitat (IJC, 2003).

If one of the above BUIs is present in "an area within or directly affecting the Great Lakes, connecting channels, or the international section of the Great Lawrence River," a site may be recommended for designation as an AOC (IJC, 1991).

In accordance with the requirements of the GLWQA, Remedial Action Plans (RAPs) tailored to the specific environmental needs of sites designated AOCs are to be designed and carried out by provincial and state governments (Bay Area Restoration Council (BARC), 2010a). According to the Great Lakes Areas of Concern page found on the Environment Canada website, RAPs consist of three stages. During Stage One, the extent and cause of environmental degradation is determined (Environment Canada, 2010a). Causes of environmental degradation vary widely among AOCs, and include issues such as excess nutrient loading, the presence of bacterial or chemical contaminants, or simply a loss of species habitat (Environment Canada, 2010a). Stage Two entails the identification of goals and the recommendation of measures

\footnotetext{
${ }^{1}$ It should be noted that in previous versions of the GLWQA, this information was located in Annex 2. This was modified in the 2012 amendment; the information is now located in Annex 1 of the agreement.
} 
promoting improved ecosystem health (Environment Canada, 2010a). Stage Three involves the implementation of recommended measures, and the periodic assessment of the site's progress towards restoration, until all of the goals outlined in Stage Two have been met. The completion of Stage Three leads to the removal of the site's designation as an AOC, on the condition that its beneficial uses have been restored (Environment Canada, 2010a). This removal of sites from the list of AOCs is referred to as "delisting."

The Canada Ontario Agreement Respecting the Great Lakes Basin Ecosystem (COA) was signed in 1971, preceding the GLWQA. Federal signatories of the Agreement include Environment Canada, Fisheries and Oceans Canada, Health Canada, Natural Resources Canada, Agriculture and Agri-food Canada, and Transport Canada. Provincial signatories include the Ministry of the Environment, the Ministry of Natural Resources, and the Ministry of Agriculture, Food, and Rural Affairs (Environment Canada \& Ontario Ministry of the Environment, 2007). Renewed periodically, it enables the fulfillment of the Canada's obligations under the GLWQA, through its promotion of communication between the federal and provincial governments. In addition to committing to the long-term goal of environmental restoration in all AOCs, COA also includes goals and objectives specific to individual RAPs, such as the goal of completing "priority actions for delisting" for Nipigon Bay, Jackfish Bay, Wheatley Harbour (now delisted), and St. Lawrence River (Environment Canada \& Ontario Ministry of the Environment, 2007). Additionally, embedded within COA objectives is a process for federal and provincial government funding contributions to Ontario RAP projects. 


\subsection{Progress of the RAP Approach}

\subsection{Progress Towards Delisting}

Thus far, only four of the 43 sites categorized as Areas of Concern by the International Joint Commission have progressed beyond Stage Three to achieve delisted status: Collingwood Harbour, Severn Sound, and Wheatley Harbour in Canada, and the Oswego River AOC in the United States (EC, 2010b). One noteworthy factor shared by the Canadian sites is the relatively simple nature of their environmental problems, and the comparatively few listed beneficial use impairments. According to Canada's RAP Progress Report 2003, two major concerns were responsible for the designation of Collingwood Harbour as an AOC; the contamination of sediments with heavy metals, and eutrophic conditions resulting from nutrient loading by a local sewage treatment plant (EC, 2003). Following the introduction of improved technology to the sewage treatment plant, the removal of contaminated sediments using an innovative technique, and improved protective efforts to the ecosystem, the site was delisted in 1994 (EC, 2003).

There appears to be a substantial amount of variation in the degree of environmental degradation causing sites to be designated AOCs. Canada's RAP Progress Report 2003 identifies nine BUIs in the Hamilton Harbour AOC, the majority of which are a consequence of the city's industrial history (EC, 2003). Environmental degradation at the site has been brought about by a wide spectrum of contaminants, including heavy metals, bacteria, nutrients, pesticides, PCBs, and PAHs. Additionally, habitat loss in this area has been extensive, due to the drastic transformation of shorelines (EC, 2003). The Toronto and Region RAP is equally complex, with eight BUIs identified, which are made more challenging by a rapidly growing population and extreme rate of development of the site and surrounding area (EC, 2003). 


\subsection{Criticisms of the Approach's Progress}

Under the 1987 GLWQA, the IJC is tasked with reporting progress towards remediation objectives to the federal, state, and provincial governments. Over the years, the commission has not shied away from vocalizing its dissatisfaction with the progress of various aspects of RAPs in many of its official biennial reports. This is evident, for example, in the $11^{\text {th }}$ Biennial Report, published in 2002, where the IJC acknowledges the stunted progress of the majority of RAPs:

Failures to address the magnitude of the problem and to allocate adequate resources blunt progress. The Commission continues to find that, after more than 15 years of planning and incremental activity, restoring the Great Lakes through remedial actions remains elusive and difficult....Clearly, much more needs to be done, and much more quickly (IJC, 2002).

The Commission attributes this unsatisfactory advancement of RAP goals to a number of factors, including the absence of government accountability, poor planning, lack of leadership for RAP implementation plans, insufficient funding, and failure to follow up on plans after implementation (IJC, 2002). It is perhaps logical that some of the approach's harshest criticisms would come from the group charged with acting as a watchdog. In spite of the large number of RAPs that have yet to be delisted, some commentators suggested that the approach has been more successful than it would appear at first glance. For example, there has been some speculation that this perceived slow progress comes down to the indicators used to gauge improvements in environmental health (Krantzberg, 2003).

In the most recent report, released April 2013, the Commission acknowledges the renewed efforts of the Canadian and U.S. governments in attempting to fulfill their obligations under the GLWQA. The IJC quantifies the progress of GLWQA objectives by examining the 
total number of restored BUIs, observing that approximately $25 \%$ of BUIs in the remaining AOCs have been removed.

In the past quarter century, only four of the AOCs have been restored to the point that they were delisted, and two of them improved enough to be considered areas in recovery. In the United States, 33 of 255 BUIs have been removed. In Canada, 54 of 154 were removed. Currently both governments are working hard to delist more AOCs and further remove BUIs. To accelerate progress toward meeting these objectives, adequate resources need to be made available by both federal governments, and accountability and responsibility need to be assigned to specific agencies (IJC, 2013c).

Others have criticized the use of restored BUIs to track RAP progress towards achieving remediation objectives. George and Boyd (2007), for instance, question the accuracy of quantifying restoration using BUIs. The authors conclude that, decades after their initial detection and labeling, BUIs may no longer be relevant; some have no identified ecological component to be used for measurement, while others require extensive expert interpretation. In short, there appears to be an "intrinsic level of uncertainty associated with some of the BUIs" (George and Boyd, 2007).

Academic commentators have made general criticisms of the Great Lakes regime. McLaughlin and Krantzberg (2012), for example, posit that the governance system is insufficient to address the "diffuse and nonlinear" changes taking place in the Great Lakes, and provide evidence in the form of a list of implementation deficits. Included among these implementation deficits are: inadequate government investment (coupled with unrealistic imposed funding deadlines), the basing of policies on uncertain scientific premises, the absence of a single implementing agency, lack of clarity with respect to objectives and responsibilities of participants, poor communication and coordination among participating agencies, and the failure 
of governing bodies to demand adherence to the "code of conduct" embedded in the GLWQA (McLaughlin and Krantzberg, 2012).

\subsection{The Hamilton Harbour AOC}

Hamilton is a port city in Ontario, located along the shoreline of Lake Ontario. It is historically an industrial city, and at one point in time, the local economy was largely dependent on steel production. In spite of the enactment of legislative and regulatory pollution control measures in recent years, decades of largely unregulated steel manufacturing have resulted in the steady accumulation of a highly toxic cocktail of contaminants in the city's harbour. It was for this reason that the IJC identified the harbour as one of the most severely damaged areas in the Great Lakes Basin, and included it among the 43 Areas of Concern (Hall et al., 2006). The AOC includes both the harbour and Cootes Paradise, a wetland embayment tributary to the harbour (Hall et al., 2006).

\subsection{The Hamilton Harbour RAP}

The Hamilton Harbour was originally classified as an AOC in 1987, in Annex 1 of the GLWQA, due to the presence of the following BUIs:

- Restriction on fish and wildlife consumption

- Tainting of fish and wildlife flavor

- Degraded fish and wildlife

- Fish tumours and other deformities

- Bird or animal deformities or reproductive problems

- Degradation of bethos

- Restrictions on dredging activities

- Eutrophication or undesirable algae

- Restrictions on drinking water consumption or taste and odour problems

- Beach closings 
- Degradation of aesthetics

- Added cost to agriculture or industry

- Degradation of phytoplankton or zooplankton

- Loss of fish and wildlife habitat (Hamilton Harbour RAP team, 1992).

The 1992 Hamilton Harbour RAP Stage 1 Report provided a comprehensive breakdown of the site's environmental state. The assessment identified the following key issues: water quality/eutrophication/water clarity, contamination from trace metals and trace organics, bacterial contamination, stresses on fish and wildlife, aesthetics and access, and planning and coordination (Hamilton Harbour RAP team, 1992).

\subsection{Organizational Structure of Hamilton Harbour RAP}

Although the Hamilton Harbour RAP is federally led, it has been organized in such a way that nonstate entities with a stake in the site's fate have been given an internal role in the decision making process, through their representation on three distinct organizational branches: the Bay Area Implementation Team (BAIT), the Bay Area Restoration Council (BARC), and the Stakeholder Forum (Environment Canada, 2013b). BAIT is an actor responsible for the empirical, evaluative, "hard" science aspect of the RAP. The team has had the advantage of geographical proximity to the Canada Centre for Inland Waters, which has permitted access to top-notch government resources (Environment Canada, 2013b). According to the official Hamilton Harbour RAP website, BAIT represents 18 industry and government stakeholders, and is charged with implementing the remedial actions detailed in the Stage 1 RAP report (Bay Area Restoration Council, 2012f). BARC, on the other hand, can be considered the "voice" of the RAP, due to its watchdog and public outreach responsibilities. The group has taken on an advocacy role, in addition to their other duties, and promotes RAP issues, for example, by 
lobbying city council members. A third, less formal arm of the RAP is the Stakeholder Forum, assembled periodically in response to a perceived need for consultation with community, industry, and NGO stakeholders (Hall et al., 2006). The temporary stakeholder group, consisting of more than 50 agencies from the public, private, and civil society sectors, was amassed specifically for the development of Stage 1 and Stage 2 reports (Hall et al., 2006).

\subsection{History and Progress of the Hamilton Harbour RAP}

RAP officials made use of a community group, Save Our Bay, which predated the site's identification as an AOC in the 1987 GLWQA (Wilson, 2013). The RAP approach harnessed this group's pre-existing enthusiasm and desire for environmental change, to form the presentday Bay Area Restoration Council (BARC) stakeholder group, which was extended to include industry, in addition to community members. Official progress of the RAP is chronicled in BARC's annual publication of the Towards Safe Harbours Report Card, which assigns a letter grade to indicate the progress of each BUI (BARC, 2011). According to the federal government's Hamilton Harbour RAP web page, substantial improvements to the site have been

observed in a number of problem areas identified in the RAP's Stage 1 report: bacterial contamination has decreased substantially; nutrient loading to the harbour has been restricted; urbanization is being managed in order to reduce interference with wildlife habitats, and an additional 340 ha of habitat has been either enhanced or created at the site; the accessibility of the shoreline to the public has increased from 5\% to $25 \%$; and finally, public involvement in restoration projects has increased substantially (Environment Canada, 2010c).

In spite of the improvements made in the areas listed above, the restoration of many of the site's BUIs has yet to be completed. Progress towards the goals of achieving healthy water 
quality and opening beaches at the Harbour's west end received grades of $\mathrm{C}+$ and $\mathrm{D}+$, respectively, in the most recent Towards Safe Harbours Report Card (Bay Area Restoration Council, 2012c). Although the federal and provincial governments have committed a combined \$200 million for upgrading the Woodward wastewater treatment plant, the upgrades have been delayed until 2020 (BARC, 2012), as the Hamilton City Council voted to direct funding towards improving the quality of treated sewage flowing into the harbour, rather than covering their portion of the treatment plant costs (Van Dongen, 2012).

In the most recent Towards Safe Harbours Report Card (2012), progress towards the goal of cleaning up contaminated sediments also received poor reviews, and was assignment a grade of D. Deposition of contaminated sediments by steel industry members in their economic prime caused what is arguably the most contentious environmental issue being addressed by the site's RAP. The 55500 cubic meter coal tar deposit, nicknamed "Randle Reef" by local residents, contains hazardous concentrations of polycyclic aromatic hydrocarbons (PAHs), and is responsible for the presence of more than one BUI (Bay Area Restoration Council, 2012d). Numerous delays have arisen in implementing the remedial actions recommended for Randle Reef in the Stage 2 report, many of which can be attributed to political gridlock surrounding delegation of funds, and discord among stakeholder groups with respect to the chosen solution (Lukasik and Sproule-Jones, 2002). The problem is compounded by the growing cost of the proposed remedial action, which involves encasing the mound in concrete and steel, as shipping activity in the harbour causes the sediments to spread, continually widening the area that must be contained (and subsequently, the quantity of materials needed to contain it) (Lukasik and Sproule-Jones, 2002). 
The prohibitive costs associated with removing the contaminated sediment BUI have been the subject of much debate among government officials over the past two decades. As of September 2013, however, the federal and provincial governments, and the cities of Hamilton and Burlington, in addition to the Hamilton Port Authority and U.S. Steel, have reached an agreement regarding the division of the project's \$138.9 million price tag (Churchill, 2013).

\subsection{Toronto and Region AOC}

\subsection{The Toronto and Region RAP}

The Toronto and Region AOC stretches from the Rouge River in the east to Etobicoke Creek in the west, and is comprised of 6 watersheds: Etobicoke Creek, Mimico Creek, Humber River, Don River, Highland Creek and Rouge River. This 2000 square kilometers area houses over three million people (Environment Canada, 2013c). The site was classified as an AOC in Annex 1 of the GLWQA, based on the suspected presence of the following BUIs:

- Restrictions on fish or wildlife consumption.

- Tainting of fish or wildlife flavour.

- Degradation of fish and wildlife populations.

- Fish tumours and other deformities.

- Bird or animal deformities or reproductive problems.

- Degradation of benthos.

- Restrictions on dredging activities.

- Eutrophication or undesirable algae.

- Restrictions on drinking water consumption, or taste and odour problems.

- Beach closings.

- Degradation of aesthetics.

- Added costs to agriculture or industry.

- Degradation of phytoplankton and zooplankton populations.

- Loss of fish and wildlife habitat (Metro Toronto Remedial Action Plan, 1989). 
In addition to defining the problem and assessing the site's environmental conditions, the RAP's Stage 1 report also emphasizes the need for collaborative community involvement at all stages of the RAP:

Implementation of the remedial action plan will be the joint responsibility of all jurisdictions and interests with a direct responsibility for the area of concern. The RAP needs, therefore, to reflect the priorities and concerns of the community as well as established international, federal, and provincial water quality objectives. It is essential that the local communities in the Toronto area see the RAP as a means of achieving their goals for the area of concern. In order for RAPs to reflect community views, the local public must be actively involved in and consulted during the development of the plan (Metro Toronto Remedial Action Plan, 1989).

It is clear from the above excerpt, which calls to mind the participatory governance framework, that at the time the Stage 1 report was published, governing bodies considered the RAP as a vehicle for public involvement in the remediation of the Toronto watersheds. It is also important to note that the government departments involved in the compilation of the report also expressed their commitment to accepting joint responsibility for the AOC at this point in time. This bears significance considering the loss of funding support from the province that would later take place under the Mike Harris government in the 1990s. These events will be discussed in greater detail in Chapter 6.

The Toronto RAP Stage 2 report, published in 1994, includes a list of 12 goals, such as improved ecosystem health, "fishable, swimmable, drinkable" harbour and watersheds, and reducing discharges of harmful microorganisms or chemicals. The report included specific restoration targets for each goal. For example, the report contained plans to improve ecosystem health by virtually eliminating discharges of persistent, toxic substances (Metro Toronto Remedial Action Plan, 1994). 


\subsection{Organizational Structure of the Toronto RAP}

The RAP process commenced in 1986, and was directed by the federal and provincial governments with contributions from local and regional municipalities, the Toronto and Region Conservation Authority, the Waterfront Regeneration Trust and a Public Advisory Committee (PAC) composed of representatives from a variety of sectors (Environment Canada, 2013). The PAC consisted of stakeholders from a variety of sectors, including agriculture, business/industry, community groups/individual advocates, education, recreation and tourisms, and municipal (Metro Toronto Remedial Action Plan, 1994). It is important to note that many potential members shunned the PAC because it was considered a state substitute for meaningful community involvement (Beierle and Konisky, 2001). The Science and Technical Advisory Committees (SAC and TAC) are responsible for carrying out testing and implementation requirements, and are primarily made up of government officials from Environment Canada, the Ontario Ministry of the Environment, the Ontario Ministry of Natural Resources, the Toronto and Region Conservation Authority, and relevant local and regional departments (Metro Toronto Remedial Action Plan, 1994).

The Toronto and Region Conservation Authority (TRCA) is currently the "principal partner in the RAP's implementation and advocacy" (Environment Canada, 2013c), where Environment Canada, and the Ontario Ministry of the Environment work through a memorandum of understanding (MOU) with TRCA, to ensure the continued development and implementation of RAP goals. Under the MOU, the MOE and EC are committed to the implementation of federal and provincial government recommendations, providing scientific expertise, the acquisition of necessary funds, and providing general direction (EC, 2013d). 
TRCA in turn acts as a platform for reporting of progress, and coordination of public consultation, while bearing responsibility for the following items:

- Raising political and public awareness of the RAP goals;

- Providing a forum for exchange of information and report on progress;

- Coordinating RAP communications including progress reporting;

- Focusing on RAP implementation activities on an individual watershed basis;

- Providing technical expertise; and

- Continuing with cleanup activities such as stormwater management and control, shoreline restoration and habitat development (EC, 2013d).

When it comes to implementing Toronto RAP goals, there appear to be a wide variety of actors taking part. Nonstate community groups, for example, such as the watershed councils for the Etobicoke-Mimico, Humber, and Don watersheds and the Rouge Park Alliance, play a role in implementing RAP goals (EC, 2013d). These watershed councils have also been instrumental in public education, advocacy, and restoration. It appears that often RAP goals are achieved through indirect methods; projects developed by municipalities housing parts of the RAP, TRCA, and separate federal and provincial initiatives, for instance, make contributions to achieving remediation objectives (EC, 2013d).

\subsection{History and Progress of the Toronto RAP}

The Toronto and Region AOC has made significant progress towards fulfilling the RAP's goals. For example, a watershed-based framework has been developed for the RAP, and RAP objectives have been integrated into City of Toronto initiatives, including the Wet Weather Flow Management Plan, which addresses stormwater runoff (EC, 2013d). Additionally, the Toronto Waterfront Aquatic Habitat Restoration Strategy has been developed, addressing BUIs related to habitat and wildlife (EC, 2013d). Efforts such as these have resulted in the marked improvement of a number of BUIs. For instance, water quality in the city's eastern beaches has improved 
substantially. As of the summer of 2013, eight of the city's eleven beaches were in possession of an internationally recognized Blue Flag award, which is only bestowed in cases where beaches have met a stringent set of criteria related to water quality and aesthetics (City of Toronto, 2013a). Furthermore, an additional twenty hectares of new waterfront habitat have been created, resulting in an increase in aquatic species diversity and biomass (EC, 2013d). Also, new parks and trails have been created to promote public use of the natural area. Finally, concentrations of lakewide pollutants have declined, and controls on industrial spills and discharges to sewers have improved (EC, 2013d).

The Toronto RAP's 2010 Status of Beneficial Use Impairments Report indicates that more work is required in a number of areas. Combined sewer overflows (CSOs) are a large problem for heavily urbanized areas like Toronto, and are the culprit for several of the site's BUIs (City of Toronto, 2013b). CSOs refer to the single system of pipes that both storm drains and sanitary drains flow into, discharging directly into rivers or the lake (City of Toronto, 2013b). During precipitation events, dilute sewage and stormwater enter the watersheds through the city's 71 remaining CSOs. CSOs are considered to be a significant source of contaminants, including bacteria, metals, organic compounds, and nutrients (City of Toronto, 2013b). Implementing the Combined Sewer Overflow and Treatment Strategy would help restore more than one BUI, including eutrophication/undesirable algae, and beach closings (Toronto and Region Remedial Action Plan, 2010).

\subsection{The RAP approach and New Governance}

From the 1987 GLWQA renegotiation onwards, the RAP approach places a clear emphasis on public participation, which is one of the hallmarks of the 'new governance' 
movement. New governance describes a system in which the conventionally governmental capacity to guide societal behavior has been displaced in the direction of private, and civil society sector members (Jordan et al., 2005), where these nonstate actors contribute regulatory mechanisms in addition to those that have been put in place by government (Steurer, 2013). It appears as though the RAP approach described in this chapter characterizes this paradigm shift, in that nonstate actors to some degree share in the duties and responsibilities involved in governing the Great Lakes. This shift from "government to governance," as it is often referred to in academic literature (Boyer, 1990), and its relevance to the Great Lakes regime will be explored in greater detail in Chapter 4.

It is also important to note that the direct and intentional involvement of nonstate actors in government initiatives (for example, in the Hamilton Harbour RAP's Bay Area Implementation Team) related to the RAP approach is in keeping with ideas found in the literature concerning participatory and collaborative approaches to governing. However, this chapter highlighted two important facts that distinguish the approach from the collaborative and participatory frameworks, which suggest that the approach aligns with the second "noncollaborative" dimension of sustainable governance framework: first, the RAP approach was developed as a response to a critical report compiled by a civil society organization (Great Lakes United); second, the public outreach/decision making arm of the Hamilton Harbour RAP stemmed from a community organization (Say Our Bay) that predated the RAP approach. The former piece of information can be viewed as an example of the rivalrous friction, or the confrontational type governance approach that is considered to be unique to the sustainable governance framework (Webb, personal communication, 13 December, 2013). Likewise, the latter provides evidence of the presence of another unique characteristic of sustainable 
governance in the RAP approach; that is, the establishment of nonstate governance initiatives independent of government (Webb, personal communication, 13 December, 2013). Chapters 5 and 6 will review state and nonstate initiatives that have made explicit contributions to the RAP approach (both through collaborative or confrontational governance methods), in addition to those that contribute to the remediation of the Great Lakes indirectly (i.e. without being explicitly written into the RAP approach). 
CHAPTER 4: REVIEWING MODERN GOVERNANCE FRAMEWORKS 


\subsection{Governance Theory}

\subsection{From 'Government to Governance’?}

It has been observed that traditional governance modes are no longer sufficient to address the overabundance of complex policy issues faced by government in the $21^{\text {st }}$ century (Webb, 2005). In 1990, Boyer identified a need to address the "growing obsolescence of the nation-state", as the lines separating various sectors and jurisdictions had begun to blur, and the world had begun to operate as a single unit. Boyer recognized that continuing to consider environmental, technological, and economic issues separately was futile, as these sectors are so closely interlinked in modern times. This movement is often described to as a shift from "government to governance," due to its emphasis on the sharing of public sector duties and responsibilities with nonstate actors (Boyer, 1990). Webb (2005) defines governance as the methods used for the management of public policy issues by actors from both the private and public sectors, in addition to those from civil society. It is important to note that this rise in the prevalence of nonstate approaches to environmental protection by no means suggests that traditional regulatory methods are being replaced; it rather marks the emergence of "a series of heterogeneous shifting links" among a variety of public and private authorities (Wood, 2003).

There has been some academic debate concerning the definition of modern governance (Rhodes, 1996). Jordan et al. (2005) remark that the bounds of governance have yet to be demarcated, as no consensus has been reached regarding a particular set of criteria or practices that indicate its presence. Some suggest that the emergence of modern governance methods has resulted in a diminished capacity for government to guide societal behavior (Jordan et al., 2005), which has led to civil society and private sector actors coming forward with innovative policy 
initiatives to fill gaps in government approaches (Jordan et al., 2005). Accordingly, the authors establish a simple typology of governance types, in which either government or society are charged with selecting the "means of policy", and either actor may also be responsible for the end result/societal outcomes. Considering the diversity of existing and innovative governance mechanisms, which span the full spectrum of the private and civil society sectors, and the potential for cross-sectoral collaborations (including public-private, and public-civil society partnerships), however, this is perhaps an oversimplification.

Steurer's (2013) breakdown of the typology of new governance is more expansive. The author identifies categories of regulatory instruments contributed by each sector, in addition to multi-actor initiatives. Government regulation consists of both 'hard' and 'soft' methods, named for their differential levels of bindingness. Hard regulations refer to those that are mandatory, including laws, decrees, and directives. Economic instruments, such as taxes and fees, are also considered examples of hard regulations, because "while hard law represents the hierarchical mode of governance, hard economic instruments make use of both steering hierarchically and via market forces" (Steurer, 2013). Soft government regulation refers to initiatives that are voluntary, and not legally binding, using persuasive rather than coercive methods to bring about compliance (Steurer, 2013). Stuerer (2010) observes that hard legal and economic instruments can also take on characteristics of soft instruments. Informational instruments (i.e. studies, campaigns), and non-mandatory economic instruments (i.e. subsidies) fall into this category. Regulation within the private sector can also be divided into two categories; industry self-regulation, which refers to standards, codes, and certification schemes adopted by a group of industry members or a trade organization; and firm self-regulation, which describes internal codes of conduct and restraints imposed by business partners at the level of a single firm (Steurer, 2013). The Chemical 
Industry's Responsible Care Program is an example of industry self-regulation. Civil society has also jumped on the new governance bandwagon, having established regulatory methods (independent of government) that often take the shape of standard setting. In terms of the Great Lakes regime, the Blue Flag beach award (headed by Environmental Defence NGO in Canada) is considered an example of a formal civil society regulatory rule instrument. Civil society can also contribute to regulation informally. Lake Ontario Waterkeeper is an example of a civil society group that is actively involved in the monitoring and reporting of Great Lakes water quality issues. This type of civil society involvement is considered confrontational or rivalrous because it performs a function also carried out by government, and is therefore in a position to identify shortcomings in government methods.

This shift from government to governance is frequently discussed in literature on the topic of environmental governance, as private sector members increasingly adopt voluntary environmental stipulations, and the civil society sector expands in response to the surfacing of pressing global environmental issues such as climate change. In the environmental sector, these novel governance initiatives are often referred to as New Environmental Policy Instruments (NEPIs) (Tollefson et al., 2012). Jordan et al. (2005) found that increases in the number of NEPIs in nine jurisdictions failed to correspond with a diminished role of government. In fact, the authors found that NEPIs are often reliant on government resources (Jordan et al., 2005); hence, the continued involvement of the public sector is crucial for the 'new governance' movement in the environmental sector (Tollefson et al., 2012). Lemos and Agrawal (2006) capture this in the following definition of environmental governance:

The set of regulatory processes, mechanisms and organizations through which political actors influence environmental actions and outcomes. Governance is not 
the same as government. It includes the actions of the state and, in addition, encompasses actors such as communities, businesses, and NGOs.

It is important to note that in spite of their acknowledgement of its involvement of nonstate entities, the authors' definition of governance suggests that government actors retain their status as primary directors in spite of the shift away from conventional command-and-control methods. Indeed, even in the face of emerging innovative nonstate initiatives, the continued relevance of government in modern governance approaches is not disputed.

\subsection{Public Sector Governance}

While this shift in the paradigm of governance has certainly moved some of the spotlight away from the public sector, government continues to play a central role in the development and implementation of public policy. As Jordan et al. (2005) conclude, government and governance should not be considered separate entities; they are rather two opposite poles on a "continuum" of governing options. The overwhelming majority of literature on the governance of water quality in the Great Lakes makes criticisms and recommendations that fall into the realm of conventional state methods (e.g. identification of policy deficits and suggested modifications to state management of the approach), or innovative state-lead collaborative arrangements (e.g. Public Advisory Councils). Mclaughlin and Krantzberg (2012), for example, identify "management pathologies" (i.e. shortfalls in policy implementation and monitoring) in the Great Lakes remediation approach, such as the closed cultures of state-led RAP teams, which causes resistance to input from external, nonstate organizations. The authors suggest that these management pathologies can be overcome in part using collaborative governance processes that encourage civic engagement in all aspects of the policy in question and the programs stemming from it. In a similar manner, Johns and Sproule-Jones (2009) acknowledge the central role of 
government ministries in water resource disputes, observing that these public sector institutions have "extensive discretionary powers permitting them to act like owners and proprietors to manage, lease, include, and exclude users." Citing the example of the Hamilton Harbour RAP's Randle Reef (introduced in Chapter 3), the authors remark that civil society advocacy groups (e.g. Ecojustice, Environment Hamilton) made direct attempts to influence government decision making with respect to the culpability of steel industry members. The above authors focus on the direct and explicit (i.e. state-sanctioned) role of nonstate actors; the potential indirect and rivalrous initiatives (e.g. petitions, private prosecutions, etc.) of nonstate groups such as Ecojustice and Environment Hamilton, however, are often omitted from discussions surrounding Great Lakes remediation policies. The sustainable governance framework encompasses these government-created roles for the private and civil society sectors, in addition to acknowledging the importance of independent governance practices that are not necessarily collaborative in nature (e.g. independent check and balance mechanisms). This idea of confrontational nonstate governance methods (as it relates to the Great Lakes remediation approach) will be explored in greater detail in subsequent chapters.

Trubek and Trubek (2007) identify three ways in which new governance and traditional law operate within the same policy sphere: complementarity, rivalry, and transformation. Simply put, complementarity refers to cases in which the two systems work (separately) towards a common goal. Complementarity may occur in situations in which a single form of intervention (whether legal or otherwise) is not sufficient to address a complex social problem. Rivalry emerges between the coexisting systems when the new governance mechanisms are designed to perform the same tasks as legal regulation, and are thought to be more effective; alternatively, rivalry might be said to be a result of the presence of a necessary choice between systems. An 
example of a rivalrous coexistence occurs when new governance mechanisms are designed with the intention of becoming the primary solution to a given issue, yet pre-existing laws remain in place (Trubek and Trubek, 2007). Transformation, on the other hand, refers to situations in which the relationship between new governance and law surpasses complementarity, as the two systems merge into a single hybrid system, in which each reinforces the successful operation of the other. This may occur, for example, in cases where the law provides a "safety net" for new governance processes "designed to foster collective problem-solving by stakeholders in a policy domain" (Trubek and Trubek, 2007). Although Trubek and Trubek's conceptualization of the relationship between innovative and conventional governance approaches resembles Webb's sustainable governance framework, it requires new governance and traditional law to either exist harmoniously, or to compete with the intention of extinguishing one another. In contrast, Webb's concept of rivalrous friction (in the sustainable governance framework) recognizes the coexistence of confrontational nonstate governance methods alongside conventional initiatives, operating independently without development of a new law. Sustainable governance in no way calls for the replacement of conventional governance mechanisms with innovative, nonstate ones; rather, it acknowledges the potential for nonstate governance initiatives to act as reinforcements and as a check and balance (Webb, 2005). With respect to the Great Lakes remediation, this is apparent, for example, with the simultaneous existence of state rule instruments governing water quality and the Blue Flag certification and standard.

Another aspect of new governance frequently discussed in literature is the multi-level nature of many of these innovative public sector government arrangements (Tollefson, 2012). Considering the international and binational nature of many public policy issues (e.g. the remediation of the Great Lakes), it is not surprising that government departments in different 
jurisdictions have begun to collaborate. Hooghe and Marks (2003) remark that the sharing of governance responsibilities across the boundaries of various jurisdictions results in greater flexibility than if governance is concentrated in a single jurisdiction. The authors comment on the benefits of increased efficiency that is achieved when employing multi-level governance to address local and regional environmental issues:

Efficiency requires that a policy's full effects - positive and negative - be internalized in decision making. Externalities arising from a policy to impede global warming encompass the entire planet, but those involving waste management, water quality control, nature preservation, or urban planning, for example, are local or regional. Under multi-level governance, jurisdictions can be custom designed with such variation in mind (Hooghe and Marks, 2003).

Howlett (2009), for example, uses a multi-level nested model to describe the policy instrument choice and policy design elements of conventional governance. The model is predicated on the observation that functional policy instrument choices at the ground level stem from pre-established general aims or goals formulated at the highest level. At the highest, "macro" level of governance, policy goals are most heavily influenced by changes in prevailing political actors, ideas and institutional rules in the jurisdiction housing policy deliberation. Here, abstract policy goals are generated, and implementation modes are discussed (Howlett, 2009). At the meso governance level, concrete policy objectives are determined, and implementation mechanisms are selected. In liberal-democratic countries such as Canada, this often takes the shape of market governance (Howlett, 2009). At this level, governments typically develop what are called "policy regime logics," which refer to the governmental propensity for grouping preferred specified policy tools with relatively generic sets of policy objectives. At the micro or local level, where implementation occurs, policy instrument choices are limited by previously 
determined macro level implementation modes and meso level policy regime logics (Howlett, 2009).

Given the inter-jurisdictional nature of the issues of remediating the Great Lakes, it is clear that a multi-level governance structure is ideal. The involvement of actors spanning international, national, provincial/state, regional, and local scales has allowed for the custom design of site-specific RAPs, which has been acknowledged as a benefit of a the multi-level governance approach to environmental protection and remediation (Hooghe and Marks, 2003). The inter-jurisdictional Great Lakes regime corresponds with Howlett's (2009) multi-level nest model, in that although the long-term goals for remediation were established by the IJC, U.S. EPA, and Environment Canada in the GLWQA, these goals have trickled down and materialized into concrete policies at the local RAP scale. The duties and responsibilities of the various levels involved in the fulfillment of GLWQA commitments will be explored in greater detail in Chapters 5 and 6.

\subsection{Civil Society Governance}

The term civil society is generally used to describe non-profit and voluntary organizations, and is considered to be separate and distinct from the public and private sectors. According to Parekh (2004):

As an area of uncoerced associative life, civil society includes such associations as the family, trade unions, universities, the press, professional bodies, churches, nonstate institutions (NGOs) and social movements. It excludes the state, which is seen as an inherently and exclusively coercive institution.

Scholte's (2001) definition extends beyond "formally organized, officially registered and professionally administered "NGOs"' to include groups not often considered to be at the 
forefront of civil society (e.g. clan and kinship circles, women's networks, ethnic lobbies, and consumer advocates). Tandon (2002) underscores the important function of civil society as a pillar of "good governance," a term used to describe the conjunct presence of efficient provision of public services, rule of law, and effective management of macroeconomics. This is accomplished through the promotion of the inclusion of individuals previously barred from participation, and the inspection of government performance in the areas of service delivery, fiscal management, and policymaking (Tandon, 2002).

Steen-Johnsen et al. (2011) observe that civil society stands out from other sectors in that internal governance (in-house organizational aspects) and external governance (larger-scale governance processes) are so closely interlinked, and exert such large influences on each other, that the two dimensions are most effectively conceptualized as a unified entity. This is evident, for example, when a civil society organization adopts a grassroots-type internal governance structure, which promotes public participation and a particular framing of issues of public concern Steen-Johnsen et al., 2011). Alternatively, internal governance tending towards professionalist-style or managerialist styles may result in a civil society organization taking on an authoritative role in external governance (Steen-Johnsen et al., 2011).

Globalization is a recurrent theme in literature dealing with civil society governance. Scholte (2001), for instance, argues that the twenty-first century trend of globalization calls for a shift in perspective regarding the definition of democracy, raising questions of the role of civil society in this reconfigured democratic system. Three distinct functions are identified: the enhancement of democracy in global governance via public education endeavors, providing less visible demographics with a voice through which their concerns can be channeled, and the spurring of candid debate within the system of governance (Scholte, 2001). In a discussion of 
global governance and civil society, Castells (2008) remarks "it is the interaction between citizens, civil society, and the state, communicating through the public sphere, that ensures that the balance between stability and social change is maintained in the conduct of public affairs." Bearing in mind that environmental issues rarely can be contained within the confines jurisdictional boundaries, and the lack of effective legal authority beyond the national level, civil society would appear to play an important role in global governance.

\subsection{Private Sector Governance}

Industry self-regulation refers to initiatives taken by the private sector in which members voluntarily commit to following behavioural guidelines that they are under no legal obligation to comply with. Particularly in the early years, self-regulation was met with suspicion, as critics were loath to credit industry members with making earnest attempts to improve their behavioural standards. Industries members practicing self-regulation were often accused of having ulterior, selfish motives. In 1995, Gunningham observed:

...Self regulation has an extremely tarnished image, and is often reviled by conservationists, consumer organizations, and other public interest groups for being little more than a sham - a cynical attempt by self-interested parties to give the appearance of regulation (thereby warding off more direct government intervention) while serving private sector interests at the expense of the public.

Although these denunciations have lessened somewhat in response to the success of several prominent examples of successful industry self-regulation, critics continue to question the legitimacy and relevance of private sector-initiated regulatory schemes in recent years. For example, Gamper-Rabindran and Finger (2013) reported that participation in a popular, highly regarded self-regulation mechanism (the Chemical Industry's Responsible Care Program) did not result in a significant reduction in pollution emitted. In fact, the authors found that participants polluted more than non-participants, which corresponds with the results of an investigation 
conducted by King and Lennox (2000) that examined the same self-regulation mechanism. King and Lennox (2000) caution against establishing a reliance on self-regulatory mechanisms without "an iron fist of explicit sanctions," as coercive forces generally relied upon in cases of self regulation do not allow for policing of opportunism.

Yet, when revisited within the context of a larger system of new governance, the weight of the above criticisms is considerably diminished. It is likely that a given proportion of industries participating in self-regulatory schemes are driven by less than altruistic motives. It is, however, important to recall that voluntary self-regulatory mechanisms typically make demands on their private sector participants that exceed the stipulations enforced by government regulations. Hence, it is worth considering their potential to serve as a separate regulatory medium existing alongside public sector command-and-control mechanisms. This will be discussed in further detail in Section 4.5.

Private sector governance approaches frequently take the shape of voluntary codes, which are defined as the non-legislatively required commitments of participating individuals or organizations to modify behaviour (Webb, 2004). In contrast with legislative and regulationbased governance, voluntary rule systems tend to be flexible, less expensive, and more efficient in their development and amendment (Webb, 2004). Additionally, these rule instruments can bypass jurisdictional issues that constrain governmental programs, and benefit from the potential to exploit the market in a positive manner. On the other hand, unlike laws and regulations, they are often criticized for having lower visibility, credibility, and public accountability, with a reduced likelihood for incorporating stringent criteria (Webb, 2004). It is clear from the above strengths and weaknesses that the exclusive use of either governmental or voluntary initiatives constitutes a sub-optimal approach to environmental governance. In the context of new 
governance, voluntary initiatives can be viewed as an opportunity for the growth of a novel kind of relationship between regulators, industry, and civil society, which "emphasizes flexibility, efficiency, partnership, and market incentives rather than the perceived rigidity and inefficiency of conventional 'command and control' regulation” (Wood, 2003).

\subsection{Participatory Governance}

The term 'participatory governance' is often employed to describe the extension of the democratic roles of actors beyond the traditional, standard duties (i.e. voting in elections). Heinelt (2010) remarks on the ambiguity of the identity of said actors in relevant literature, speculating whether this call to participation is directed solely towards citizens, or if it includes civil society and private sector actors. The author observes that the body of literature on the subject of participatory governance reveals "an unclear understanding of whose participation is being referred to in different contexts, and in which sphere or sector of a political system and level of decision making it should refer to." Hogl et al. (2012) highlight the important role of citizens in participation, while allowing that participation "can extend from informal modes of interaction that are raised bottom-up by civil society to formally institutionalized forms of participation imposed by the state ('top down').” The authors characterize participatory governance as the direct involvement of nonstate actors into the various stages of the policy cycle, including agenda setting, implementation, and the policy evaluation phase.

The concept of participatory governance (and its purported effectiveness as a governance approach) is grounded in democratic theory; that is, the "natural" right of individuals influenced by a decision to be allowed to participate in the deliberations preceding that decision (Heinelt, 2010). Individual participants may not necessarily affect the final outcome, but they are 
empowered by having their voices heard. It is conceptually rooted in Lindblom's (1965) theory, "intelligence of democracy," which suggests that individuals invited to participate in political decision making may possess knowledge that is necessary to achieve a given political outcome, or may improve the quality of that outcome (as cited in Heinelt, 2010). Newig and Fritch (2009) examined the use of multi-level participatory governance strategies to address environmental issues, on the basis that "participatory governance is expected to contribute to improving the 'quality' of decisions by incorporating locally held knowledge and opening up the political arena for environmental interests. "Moreover, participation improves stakeholder acquiescence and increases compliance and implementation success (Newig and Fritsch, 2009).

In practice, participatory governance has translated into a marked increase in multi-sector dialogue. This is evidenced, for example, in Edwards' (2001) discussion of the redefinition of the role of government, industry, and community members stemming from the adoption of a participatory governance model in Canada and Australia. It resulted in the establishment of a secretariat in the government of Canada Privy Council Office for the purpose of communicating with the voluntary sector, supported by 'joint tables' of government officials and voluntary sector representatives (Edwards, 2001).

Dissenting voices question the impact of participatory governance on policy decisions beyond improving "civic skills and social capitol" (Geissel, 2009). Raymond (2002), for instance, notes the reservations of skeptics, who fear the use of grassroots and participatory governance rhetoric as a ploy to promote the exclusive, private interests of particular groups at a cost to the public. The author goes on to emphasize the need to distinguish between "local" and "private" interests; private interests refer to those concerns that are separate from the collective interests of the political community. In contrast, the promotion of local concerns simply 
advocates for "greater political influence for certain actors based on some standard of geographic proximity" (Raymond, 2002).

\subsection{Collaborative Governance}

Collaborative governance shares several key traits with participatory governance. Both approaches are premised on bringing nonstate actors into ongoing policy discussions. However, while participatory governance literature underscores the value of participation in the form of multi-actor dialogue regardless of the outcome on the final policy decision (Heinelt, 2010), collaborative governance emphasizes consensus-based decision making (Conley and Moote, 2003). Ansell and Gash (2007) note that it is a term often used frivolously in literature referencing individual case studies in which stakeholders are included in public forums, in an attempt to avoid the repetition of previous governance failures. The authors developed the following more precise definition:

A governing arrangement where one or more public agencies directly engage nonstate stakeholders in a collective decision-making process that is formal, consensus-oriented, and deliberative and that aims to make or implement public policy or manage public programs or assets.

It is important to note that the definition extends beyond casual arrangements between public sector agencies and interest groups, although the term "collaborative governance" is frequently misapplied to describe these cases (Ansell and Gash, 2007). In actuality, the concept refers to formal collaboration, in which governmental and nonstate entities commit to following through with decisions resulting from the collaboration (Ansell and Gash, 2007).

This lack of clarity regarding the meaning of collaborative governance stems from the approach's origin as an ad hoc solution to past implementation failures; the approach grew out of the recognition of a need for authentic dialogue between actors with potentially conflicting 
interests (Ansell and Gash, 2007; Innes and Booher, 2003). It addresses the increased blurring of lines between sectors, which reflects the emergence of multi-layered, complex social issues requiring consultation from more than one sector (Gravelle et al., 2008). This type of dialogue is difficult to achieve between entities (stakeholder groups and public agencies) that have a history of divergence. Stakeholders are "accustomed to concealing their interests and engaging in positional bargaining rather than in discursive inquiry and speculative discussion or interestbased bargaining. They tune out those with whom they assume they disagree rather than explore for common ground" (Innes and Booher, 2003). Facilitators may be useful in overcoming this obstacle. The chief message is that collaborative dialogue is not something that materializes effortlessly; it is rather the result of skills, training, and a conscious effort made by both parties to subdue inclinations towards defensiveness and inflexibility (Innes and Booher, 2003).

Criticisms of collaborative governance mirror those made of participatory governance, centering on whether collaboration does in fact increase levels of cooperation between sectors, or if it is simply a case of "all talk, no action" (Lubell, 2004). Rosenbloog and Gong take these criticisms a step further, cautioning that without the right preemptive measures, collaborative approaches are susceptible to corruption (2013). Governance arrangements relying on collaborative interactions often result in the contracting out of public services, which places them in danger of nepotism, favouritism, and kickbacks (Rosenbloog and Gong, 2013). For the same reason, there is also a greater potential for misuse or abuse of government property, equipment, or authority. The authors argue that performance contracting relies upon the assumption that companies being contracted to are providing honest advice and service. Coproduction "between governments and citizens in defending against the misuse and abuse of authority and resources as well as in producing public goods and services" is recommended for minimalizing the possibility 
of corruption (Rosenbloog and Gong, 2013). Under a governance system employing coproduction, "public services are the product of the activities of the public and of government officials and employees. Rather than agents presenting "finished products" to citizens, agents and citizens together produce the desired outcome" (Rosenbloog and Gong, 2013).

\subsection{Sustainable Governance}

Webb's description of sustainable governance provides what is by far the most in-depth portrayal of this new system of governance of the three approaches examined. Webb (2005) notes that there is an increasing recognition in the public sector of the limitations of traditional command and control, regulatory methods of governance. "Bureaucratic, centralized, 'top-down' approaches to governing do not necessarily capture the full range of energies and actors that are available and could be harnessed in support of public-interest objectives" (Webb, 2005). There is acknowledgement of the role of innovative, collaborative approaches as a supplement to the command and control approach (Hartig \& Vallentyne, 1989). In the past, stakeholder incorporation into individual RAPs has been accomplished through the establishment of public advisory councils (PAC) by state officials. The type of stakeholder involvement made possible by PACs appears to align very closely with the participatory and collaborative governance frameworks, as these committees exemplify the direct and intentional involvement of nonstate actors in a state policy approach. As previously mentioned, a key aspect of Webb's sustainable governance framework, which distinguishes it from collaborative and participatory governance frameworks, is its recognition of the important role of independent nonstate rule instruments, institutions and processes that act either as supplements to conventional governance approaches or rivalrous check-and-balance mechanisms (Webb, personal communication, 13 December, 
2013). While participatory and collaborative governance approaches aim to reduce this type of rivalry (e.g. between private sector members and NGOs) in a formal assembly of state and nonstate actors, sustainable governance allows for the development of public and civil society sector governance initiatives that are separate and distinct from government mechanisms (Webb, personal communication, 13 December, 2013).

Sustainable governance is used to describe a system in which the responsibilities, costs, and learning associated with governance involve the public sector, private sector, and civil society organizations. Due to its inclusion of multiple actors, the suggestion has been made that it can be more "robust" than traditional approaches, as the successful delivery of services is not entirely dependent on government (Webb, 2005). Although sustainable governance does incorporate the use of conventional regulatory methods, it recognizes the underexploited potential of the private and voluntary sectors, and of individuals, "to assist in governing in the public interest" (Webb, 2005). This is accomplished through the use of a combination of both governmental and nongovernmental institutions, processes, instruments, and actors (Webb, 2005).

According to Webb (2005), rule instruments refer to a set of objective criteria intended to guide behaviour and to determine whether an entity or an activity is operating within the bounds of these criteria. Laws, voluntary codes, memoranda of understanding, and standards are all examples of rule instruments. Voluntary codes, memoranda of understanding, and standards development are all examples of rule instruments. Applying the sustainable governance definition of rule instruments to the Great Lakes remediation approach, these may take the shape of governmental laws, regulations, and agreements (e.g. GLWQA, COA, CEAA, etc.), private 
sector self-regulation (e.g. Responsible Care), or civil society-driven standards and guidelines (e.g. Blue Flag Beach Award).

Processes, on the other hand, are described as mechanisms that enable parties to make significant contributions to decisions concerning issues that they have a stake in. Examples of processes include citizen-triggered investigations concerning enforcement, dispute resolution processes, and funding programs. An institution is described as an organizational structure of state, industry, or nonstate organization (NGO) that perform particular governance functions that possess an explicit public interest aspect. An institution may take the shape of a government ministry, industry self-regulatory body, or civil society council.

It is important to emphasize that a sustainable governance approach allows actors other than government to develop their own rule instruments, independent of government. One example of an industry rule-innovation is the Chemical Industry Association of Canada's (CIAC) Responsible Care Program (Webb, 2005). Since its establishment, the program has grown to include a comprehensive code of behaviour, a multidisciplinary advisory group, the monitoring of facilities, and public disclosure of results (Webb, 2005). Although both the federal government and Ontario provincial governments have entered into memoranda of understanding with the CIAC regarding the program, it was initiated and developed in the absence of government instruction or input, and has facilitated the transformation of "an industry association from a lobbying organization into a rule-making and self-policing body concerned with the behaviour of its members" (Webb, 2005). 


\subsection{Evaluating Governance Approaches}

The Great Lake Remedial Action Plan (RAP) approach allows for a substantial degree of involvement from stakeholders, often through their membership in what are known as public advisory committees (PAC), which typically consist of 20 - 30 members from local industries, interest groups, and local government officials (Beierle \& Konisky, 2001). In this regard, it might be said that actors other than government are being involved in the governing process, although their role in the decision making process has been observed to be largely advisory, and of limited influence (Beierle \& Konisky, 2001). However, the high level of stakeholder involvement and influence at some individual RAPs (such as the Hamilton Harbour RAP introduced in Chapter 3, and that of the delisted Collingwood Harbour AOC) suggests otherwise. As previously discussed, the Hamilton Harbour RAP official public outreach arm, the Bay Area Restoration Council (BARC), in fact stemmed from an existing community group, which predated the RAP, and continues to play a key role in decision making and public outreach. Similarly, Krantzberg (2003) cites engagement and participation of community leaders in the site's PAC as important factors leading to the delisting of the Collingwood Harbour AOC.

Based on the above evidence, it appears that the RAP approach aligns in a general way with the trend towards "governance" rather than just "government." There has been a concerted effort to include nonstate actors at various stages in the policy cycle addressing the remediation of the Lakes. Given, however, the unique theoretical basis and attributes of the governance models reviewed, it is worth applying each model to the RAP approach, in order to determine which demonstrates the best fit. 


\subsection{Participatory Governance and the RAP Approach}

Conceptually, participatory governance encapsulates one of the greatest assets of the Great Lakes regime; that is, the numerous occasions for participation granted to stakeholders throughout the various stages of the policy cycle. In fact, Beierle and Konisky (1999) refer to the Great Lakes Region as a "laboratory of democracy," due to the rigorous efforts that have been made to engage community members in environmental decision making. Both at the bi-national and the local scale, nonstate actors are provided with ample opportunity to partake in policy formulation, and to voice their questions and concerns regarding the progress of these policies. This is evident, for example, in the 2012 review of the GLWQA, during which citizens and other stakeholders were invited to come forth with their input. The revised Agreement was also amended to increase avenues for public participation in the resolution of Great Lakes issues (U.S. EPA, 2012). A similar call for stakeholder participation is also apparent at the local scale, where governing bodies of the Hamilton Harbour RAP periodically summoned civil society and private sector stakeholders to partake in the Stakeholder Forum. Stakeholder participants are "not a decision-making body but an advisory group representing the community and providing input and best advice to the federal and provincial governments overseeing the AOCs" (BARC, 2012a).

Although it accurately represents the explicit involvement of nonstate stakeholders as participants in the RAP process, the concept of participatory governance fails to capture many of the system's participatory nuances. It does not explain, for example, the indirect, unconventional ways in which organizations established with a mandate that does not overtly include the Great Lakes remediation still manage to forward the goals of the GLWQA (i.e. the watchdog role of Lake Ontario Waterkeeper, citizen petitions to the Office of the Auditor General, private civil action). Participatory governance, as outlined in relevant literature, is conceptually restricted to 
the intentional and deliberate involvement of nonstate actors in an open dialogue with the public sector.

\subsection{Collaborative Governance and the RAP Approach}

Collaborative governance refers to a decision making process that is "formal, consensusoriented, and deliberative" (Ansell and Gash, 2007). This description implies the presence of an atmosphere in which stakeholder opinions are not simply considered when discussing policies, but one in which a compromise must be reached in order to reach a decisive outcome. Under a collaborative system of governance, it might be said that stakeholders are allowed more than the usual political clout. In particular, the emphasis on reaching consensus suggests the elevation of stakeholder influence, perhaps even to the level of government. It is difficult to ascertain the degree to which nonstate stakeholders are able to contribute to the RAP Approach. As mentioned

previously, although stakeholder opinions are certainly considered at the binational level, there is little evidence of a formal, consensus-based deliberation process. At the national and state levels, stakeholders are given no additional powers (i.e. in excess of those awarded by democratic rights) beyond what they hold for any given political issue. At the scale of individual RAPs, this appears to vary considerably depending on the community. Krantzberg (2003) notes that for most of the AOCs, community stakeholders formed some sort of advisory council or committee in order to foster dialogue with government representatives and scientific experts. The Collingwood Harbour AOC, considered a major success due to its early delisting, is said to have achieved a consensus-based approach by establishing a public advisory committee with candidates selected based on their capacity to bring about change in the sectors they represented (Krantzberg, 2003). The Hamilton Harbour RAP website mentions consensus-based decisions as the goal outcome of the Bay Area Implementation Team multi-stakeholder group (BARC 2012b). 
It is important to question whether this formal, consensus-based governance approach provides an accurate portrayal of the wide range of interactions between stakeholders and government entities addressing the remediation of the Great Lakes, both within and across jurisdictions. The potential for collaborative governance certainly exists at the local level, as evidenced above. However, the Great Lakes remediation approach is comprised of numerous governance mechanisms (both formal and informal, direct and indirect), and the concept of collaborative governance fails to account for many of these.

\subsection{Sustainable Governance and the RAP Approach}

Webb (2005) has observed that many jurisdictions are moving in the direction of a sustainable governance approach; the review undertaken here of the evolution of the RAP approach suggests that this appears to be the case with respect to Great Lakes governance. Indeed, when one considers the roles of environmental nongovernmental organizations, private sector members, community groups, and individual citizens in the design and execution of RAPs and the remediation of the Lakes as a whole, the approach's alignment with many of the concept's precepts is highly probable. Hence, of the three emergent governance trends examined, sustainable governance best captures the full range of policy innovations and non-conventional interactions between actors, both within and across sectors interacting in the RAP approach.

Sustainable governance can be considered quite flexible in terms of its application to a particular public policy issue, due to the virtually limitless combinations of interactions it allows between sectors and jurisdictions, and its progressive view of the types of mechanisms that constitute governance initiatives. Because of this, the concept of sustainable governance exceeds the limited potentials of participatory and collaborative governance, though its acknowledgement 
of the filling of perceived gap in traditional governance models by the indirect efforts of nonstate actors. In fact, although they fail to adequately account for the depth and pervasiveness of the new governance movement, it might be said that the alternate governance concepts discussed represent what are potentially important components of a system of sustainable governance; the concept in question undoubtedly encompasses the consensus-based approaches central to collaborative governance, and the intentional, deliberate involvement of nonstate actors required for participatory governance.

\subsection{The Tenets of Sustainable Governance}

In order to assess the alignment of the Great Lakes Remedial Action Plan approach with sustainable governance, the concept's defining principles, or "tenets," must be firmly established. The explicit delineation of these tenets provides a set of benchmark criteria for sustainable governance, against which to compare the governance of the Great Lakes. Drawing on the work of Webb (2005), the following tenets of sustainable governance have been developed:

1. In a sustainable governance system, the responsibilities, costs, and learning associated with governance involve the public sector, private sector, and civil society organizations.

In the twenty-first century, governments are faced with a multitude of complex, often inextricable challenges. These include variable public interest in an issue, the looming possibility of budget cuts, demand for economic growth, political willpower that varies with every election, and conflicting public demands to lower taxes while continuing to deliver optimal levels of administration and enforcement (Webb, 2005). As a result of these challenges, the delivery of effective responses to public policy issues has begun to exceed the limits of government capabilities. According to Webb (2005), "multivariate, multiparty governance approaches have a 
better likelihood of success in such choppy waters because they harness the energies and experience of multiple parties and perspectives," yielding a more robust system of governance than can be achieved by government alone. This appears to align well with the Great Lakes remediation approach, which (through the intentional involvement of nonstate actors and initiatives) can be considered a large-scale multi-stakeholder approach, and in addition to involving numerous smaller scale innovative multi-stakeholder approaches.

2. The energies of these public sector, private sector, and civil society actors are harnessed via the rule instruments, processes, and institutions ("initiatives") they contribute to the resolution of a particular public policy issue.

Webb (2005) refers to these rule instruments, processes, and institutions as the "building blocks of sustainable governance". In this type of system, conventional state governance methods (governmental rule instruments) are one of many governance tools in a collection that includes a wide range of private, public, and civil society initiatives. In the context of the Great Lakes remediation approach, a multitude of nonstate and public sector actors contribute to policy objectives through direct or indirect, and collaborative or confrontational initiatives. It is important to note that a wide range exists for what constitutes a particular category; for instance, Webb's terms incorporate local to global scales. As a result, the binational Responsible Care standard and certification falls into the same category (i.e. private sector rule instruments) as the local scale Hamilton-Halton Homebuilder's Association behavioural guidelines.

3. Private sector and civil society initiatives complement, rather than detract from conventional state rule instruments, processes, and institutions.

In a sustainable governance system, state and nonstate initiatives work in tandem towards a common public policy objective. Although private sector and civil society actors may 
participate to some degree out of self-interest (i.e. industry members may seek economic benefits associated with participation in an environmental initiative), the overarching effect of multisectoral involvement is the advancement of the policy goal in question, which serves the public interest (Webb, 2005). In terms of the Great Lakes remediation, there are instances where opposition or "friction" certainly exists between actors (e.g. community activists submitting a petition to the Office of the Auditor General); however this type of rivalry between actors is considered to be a healthy component of a sustainable governance system, which ultimately helps to further the public policy objective.

4. In a sustainable governance system, the value of multiple centres of authority is recognized.

The concept of sustainable governance recognizes that government is no longer the singular authoritative voice in the public sphere; rather, it views private sector and civil society members as having authority over the innovations they contribute to the governance system. An example of an alternate centre of authority in relation to the Great Lakes remediation approach is the NGO's (Environmental Defence) assessment of beach water quality to determine whether criteria for the Blue Flag certification is being met. The civil society organization performs this assessment independent of government direction or approval. As the results of the Blue Flag application are made known publicly (i.e. through the awarding or retraction of Blue Flag award), the organization is considered to act as an additional centre of authority with respect to Great Lakes water quality. 
5. The value of multi-sectoral collaborations is recognized.

While sustainable governance allows nonstate actors to develop their own initiatives, independent of government, this does not preclude the possibility of the establishment of collaborative initiatives between the public sector and private or civil society sectors (Webb, 2005). Numerous multi-stakeholder initiatives make contributions to the Great Lakes remediation approach, including the Council of Great Lakes Region, Great Lakes and St. Lawrence Cities Initiative, and the International Organization for Standardization's ISO 14001 standard and certification. The contributions of these initiatives to the remediation of the Great Lakes will be discussed in greater detail in Chapters 5 and 6.

6. A potential for healthy rivalry between actors exists.

Building upon the observation made by Trubek and Trubek (2007) that rivalry may emerge from the coexistence of new governance mechanisms and legal regulation, Webb (2005) posits that this type of conflict can in fact be advantageous. In fact, the rivalry that emerges between the rule instruments, processes, and institutions put forth by different sectors acts as a built-in check-and-balance mechanism, and promotes continual adjustment, which in turn results in a more effective system of governance. Actors from different sectors may have opposite views with respect to a public policy issue; however, perhaps without even being aware of it, something as simple as this opposition contributes to the larger system of governance, with the actions of one actor serving as a check-and-balance on the behavior of another. Moreover, this type of rivalry may lead to an increase in dialogue between actors holding opposing views, which may result in collaboration in the form of multistakeholder governance initiatives. With respect to the Great Lakes, this rivalrous friction may take several different shapes. For example, 
private prosecutions, such as Lynda Lukasik's prosecution of the City of Hamilton (discussed in Chapter 3), or petitions to the Office of the Auditor General are rivalrous check and balance mechanisms put in place by government to help ensure the fulfillment of public policy goals. Alternatively, check and balance processes may be initiated and carried out entirely by nonstate actors, such as the CIAC's requirement that chemical industry members report of emission of toxic substances under Responsible Care, or the Blue Flag program's independent assessment of beach water quality and environmental health.

7. In a fully evolved sustainable governance system, public, private, and civil society sector initiatives work together in a systematic way to achieve a common public policy goal.

According to Webb (2005), although numerous innovative numerous rule instruments, processes, and institutions exist in Canada; they are often random and ad hoc. This systematic aspect of sustainable governance approaches involves "concerted efforts to draw on the full range of options available," in a "coordinated and coherent" fashion (Webb, 2005). In terms of the Great Lakes remediation, this would entail the full knowledge and use of relevant actors, processes, rule instruments, and institutions. 
CHAPTER 5: EXAMINING THE RAP APPROACH THROUGH THE LENS OF SUSTAINABLE GOVERNANCE 
This chapter will build upon the findings of the previous one, which explored the changing governance paradigm, and reviewed three prominent governance frameworks to determine which most closely aligned with the Great Lakes Remedial Action Plan approach. In Chapter 4, it was concluded that sustainable governance best depicts the innovative governance mechanisms and interactions that are involved in the Great Lakes remediation approach. This chapter will endeavor to shed light on the RAP approach using insights gathered from interviews with key informants from the public, private and civil society sectors, in addition to representatives from multi-actor initiatives. Sustainable governance describes a system in which the public, private, and civil society sector actors are all involved in the responsibilities, costs, and learning associated with governance (Webb, 2005). Although sustainable governance does incorporate the use of conventional regulatory methods, its primary emphasis lies in making use of the hitherto unexploited potential of the private and voluntary sectors, and of individual citizens, "to assist in governing in the public interest" (Webb, 2005). This is accomplished through the use of a combination of both governmental and nonstate institutions, processes, and rule instruments (“initiatives”) (Webb, 2005).

A variety of public, private, and civil society sector-initiated standards designed to improve Great Lakes environmental quality can be categorized as rule instruments based on Webb's (2005) definition: "stipulations of objective criteria that are designed to influence or control behavior and that allow for evaluation of whether an entity or activity is or is not in compliance with the criteria." Similarly, a large number of processes have been put in place to foster public and industry participation in various aspects of the RAP approach. According to Webb (2005), processes are methods used to enhance the ability of actors to make meaningful and informed contributions to decisions they have a stake in. Process innovations either take the 
form of programs that increase access to information (thereby improving an entity's ability to protect itself), or approaches that enhance the decision making capacity of parties with respect to issues that concern them (Webb, 2005). Finally, each sector also contributes a range of institutions to the RAP approach, which contribute to governing Great Lakes issues.

This section will make the important distinction between direct and indirect, and conventional and innovative initiatives. Direct initiatives refer to those that are explicitly defined by or incorporated into the RAP approach. Because the RAP approach has a legal basis, the public sector agencies play a major role. Thus, the roles of various levels of governments in the approach are, for the most part, considered direct. The theory of sustainable governance does not require that all actors knowingly contribute to a particular public policy goal; it may in fact be the case that some actors are largely unaware of the contributions they have made to a given public policy issue. In other words, the actor's mandate may not explicitly address the issue itself, but may address a related issue, thus advancing the interests of the policy. It is enough that actors have shared interests, and as such may inadvertently forward the goals of a government program. In these cases, actors are considered indirect contributors to the system of governance.

State-centered command-and-control measures, such as laws and regulations, are the conventional regulatory approach, used to structure the behaviour of citizens and industry members. While these mechanisms remain centrally important and continue to be a foundational technique of governance, one of the hallmarks of sustainable governance is that it recognizes that nonstate actors have the capacity to develop their own governance innovations, independent of government. For example, nonstate rule instrument innovations relevant to the remediation of the Great Lakes include the chemical industry's Responsible Care program, and the international 
Blue Flag beach certification. Both of these governance mechanisms were established without government involvement or consultation.

What follows is a discussion of civil society, private sector, and governmental actors, rule instruments, processes, and institutions that constitute and contribute to achieving the goals of the Great Lakes RAP system of governance. As discussed in Chapter 2, it was decided that focusing primarily on actors and initiatives that were observed to make significant contributions to RAP goals and objectives (rather than simply compiling an exhaustive list), would better serve the investigation. It was thought that this analytical approach of selected actors and initiatives would reveal the more relevant and insightful results than a comprehensive listing approach. It is important to note that this also applies to the selection of conventional government ruleinstruments discussed in this thesis; though numerous federal, provincial, and municipal laws and regulations could apply, those few selected for discussion in this thesis (based on a literature review and interviews) are playing a direct role in governing the RAP approach, or serve as examples of innovative uses of these rule-instruments. A more complete list of possibly applicable rule instruments, processes, institutions, and actors can be found in Appendix B.

\subsection{Public Sector Rule Instruments, Processes, Institutions, and Actors}

\subsection{Federal Public Sector Rule Instruments, Processes, Institutions, and Actors}

The International Joint Commission

As described in Chapter 3, the International Joint Commission (IJC) is the chief governing body charged with overseeing the RAP approach under the GLWQA. An interview 
with an IJC representative cemented the distinct identity of the institution responsible for overseeing AOC progress, as the commission has made frequent, non-binding suggestions to Canadian and U.S. governments on this matter since the advent of the RAP approach (Respondent A1, interview with the author, April 11, 2013). The very idea that the IJC is the primary overseer of the remediation of the Great Lakes calls to mind Webb's (2005) observation that checks and balances on government are an integral part of the sustainable governance framework. The IJC is arguably one of the most deeply rooted institutions involved in the RAP approached; hence, by closely following the progress of AOCs, and by making what have sometimes been harsh criticisms of the sites' progress, both countries have been compelled to take action. Respondent A observes that in spite of bearing no risk of legal repercussions in the face of non-compliance with GLWQA obligations, the federal government is attentive to IJC recommendations: "There's no question that there's people working at Environment Canada spending good parts of their days or weeks or months concerning themselves about what the IJC might say, how they might manage an IJC report that's critical of something. I don't think that's necessarily interference, it's necessary for the governance of the Great Lakes" (Respondent A1, interview with the author, April 11, 2013). The inference is that while the IJC does not have legal authority to compel action; the commission is nonetheless viewed as having "legitimacy" (Respondent A1, interview with the author, April $11^{\text {th }}, 2013$ ). Also implicit in this statement is the suggestion that without the oversight of an external, bi-national institution, the remediation of the Great Lakes could not be expected to succeed. Certainly, it is worth questioning whether the lakes could be restored as effectively if Canada and the U.S. had undertaken separate endeavors, avoiding the scrutiny of an inter-jurisdictional entity, and the inevitable comparison of each country's approaches and successes. Although this scenario differs slightly from the context in 
which Webb (2005) describes the usefulness of healthy rivalry between actors in a sustainable governance framework, fears of lagging behind the U.S. have no doubt played a role in ensuring the continued investment of the Canadian government in the RAP approach. The IJC can be viewed as fueling this rivalry by drawing attention to each country's shortcomings, thereby compelling them to action.

\section{Environment Canada}

An interview with Environment Canada senior RAP program coordinator, Respondent A2, provided a "behind the scenes" portrait of the history of Canada's RAP program, and the fundamental differences between the Hamilton Harbour and Toronto and Region RAPs. Respondent A2 also provided some interesting insights with respect to the differing levels of resilience of the Hamilton Harbour and Toronto and Region RAPs to withdrawal of government supports. Under the Mike Harris Ontario government in the 1990s, RAP support from the province all but evaporated, and Environment Canada (which holds joint responsibility for the Toronto RAP under the Canada-Ontario Agreement) was forced to step in to ensure the country's RAPs remained on target (Respondent A2, interview with the author, February 26, 2013). During this time, Environment Canada briefed M.P.s and cabinet ministers on RAP issues. According to Respondent A2, these efforts played a key role in keeping RAPs afloat in Canada (interview with the author, February 26, 2013).

According to Respondent A2, the Hamilton RAP "model" proved to be more resilient than the Toronto and Region RAP to this withdrawal of provincial government support in the 1990s (Respondent A2, interview with the author, February 26, 2013). During these "dark years", the MOE withdrew funding and the Toronto RAP team lost their coordinator, and Environment 
Canada looked to the Hamilton Harbour RAP set-up, attempting to replicate the Hamilton model (Respondent A2, interview with the author, February 26, 2013). Since the RAP mandate aligned closely with those of a provincial government institution, the Toronto and Region Conservation Authority, and with those of a local civil society organization, Toronto Waterfront Trust, the organizations agreed to assume joint leadership of the RAP throughout the implementation phase (Respondent A2, interview with the author, February 26, 2013). Upon agreeing to take on the duties and responsibilities of the RAP in addition to those assigned to them under the Conservation Authorities Act, TRCA extended the AOC's boundaries were extended far beyond the Toronto harbor to include the connecting watersheds, so that the RAP encompassed the watersheds falling within TRCA jurisdiction (Respondent A2, interview with the author, February 26, 2013). When the Trust lost provincial funding, becoming a not-for-profit, the organization stepped aside, and TRCA became the sole RAP lead (Respondent A2, interview with the author, February 26, 2013).

\section{The Canada-Ontario Agreement Respecting the Great Lakes Basin Ecosystem}

The Canada-Ontario Agreement Respecting the Great Lakes Basin Ecosystem (COA) helps Canada to fulfill its obligations under the GLWQA by facilitating dialogue with provincial ministries (Ministry of the Environment, 2013). The agreement can be considered a conventional governmental rule instrument as it delineates the roles and obligations of Canadian and Ontario governments with respect to restoring the Great Lakes ecosystem. COA was first signed in 1971, and has since been renewed periodically, which can be viewed as an indication of the abiding commitment of the federal government to delisting each of the 14 remaining AOCs falling in the country's jurisdiction (Ministry of the Environment, 2013). As the parties responsible for delivering environmental services, Environment Canada and the U.S. Environmental Protection 
Agency can be viewed as the federal agencies with the primary duty to ensure the fulfillment of each country's commitments under the GLWQA. Under the Canada-Ontario Agreement Respecting the Great Lakes Basin Ecosystem (COA), federal signatories include Environment Canada, Fisheries and Oceans Canada, Health Canada, Natural Resources Canada, Transport Canada, and Agriculture and Agri-food Canada, which establishes each actor's responsibility for aspects of the GLWQA obligations that fall within their jurisdiction (Ministry of the Environment, 2013).

State laws, such as the Fisheries Act (discussed below), used to structure industry behaviour, are an example of a longstanding conventional rule instrument. As detailed in Chapter 3, the RAP approach has its foundation in bi-national legislation: the Boundary Waters Treaty (BWT) and Great Lakes Water Quality Agreement (GLWQA). These documents served as a legal basis for the approach, around which the remediation of the Great Lakes is centered. Although provisions for the approach itself are embedded in the BWT, GLWQA and related policies, numerous other pieces of federal and provincial environmental legislation enforce similar goals, thereby advancing the interests of approach, although they are not explicitly a part of it.

The Fisheries Act

Numerous federal laws apply (to varying degrees) when addressing environmental issues in the Great Lakes. For example, provisions for fish habitat degradation and water quality - two areas in which the Lakes have experienced significant environmental degradation- are demarcated in the federal Fisheries Act, which was enacted in 1868 (Department of Fisheries and Oceans, n.d.). The relevance of the Fisheries Act to the RAP approach is twofold, as it includes 
provisions for both fish habitat protection and water quality, disruptions to both of which have led to BUIs. Protection provisions are outlined in Section 35, which includes the prohibition of harmful alteration, disruption, or destruction of fish habitat. Section 36 forbids the deposit of harmful substances "in any type of water frequented by fish or in any place under any conditions where the deleterious substance or any other deleterious substance that results from the deposit of the deleterious substance may enter any such water." The Act also contains provisions to ensure the reparation of habitat damage (Greenbaum and Wellington, 2010). This piece of federal legislation has direct and tangible applications to the RAPs. As indicated in Chapter 3, included among the beneficial use impairments (BUIs) (the presence of which qualifies a site for categorization as an Area of Concern) are restrictions on fish and wildlife consumption, tainting of fish and wildlife flavor, degradation of fish and wildlife population, fish tumors or other deformities, restrictions on drinking water consumption, and loss of fish and wildlife habitat. The relevance of the Act to the GLWQA objectives is acknowledged in the Toronto and Area RAP sedimentation report, which recommends the use of the Fisheries Act for improving industrial compliance with erosion control measures (Metro Toronto and Region Conservation Authority, 1993).

\section{Canadian Environmental Protection Act}

The Canadian Environmental Protection Act (CEPA) is also applicable to the fulfillment of GLWQA objectives. CEPA, which was first passed in 1992, emphasizes sustainable development and pollution prevention practices, both of which are underlying themes in the RAP approach. The Act establishes a system for identifying, assessing, and regulating toxic substances. Under CEPA, citizens "may participate in decisions on environmental matters, may compel the Minister to investigate an alleged contravention of the Act, and may bring a civil 
action when the federal government is not enforcing the law" (Environment Canada, 2012). This can be considered an opportunity for citizens concerned about non-compliance with environmental standards to voice their concerns, and seek legal recourse if necessary. Drawing on the insights of Webb (2005), the public participation aspect of the Act can be considered a government process innovation, because it allows stakeholders to have a stake in decisions that concern them. Additionally, by thus empowering citizens, the Government of Canada holds itself doubly accountable for governing the release of harmful substances to the environment. It can therefore also be considered a check-and-balance mechanism on federal environmental governance, as it provides civil society sector members with an opportunity to monitor government and private sector compliance with the law.

Great Lakes Sustainability Fund

Another important government process innovation that emerged out of necessity from the inter-jurisdictional nature of the RAP approach, and the ensuing need to transfer federal resources to other actors is funding mechanisms. The federal government transfers funding to RAP programs directly using the Great Lakes Sustainability Fund, in addition to funding associated with COA. According to the Environment Canada website, the Great Lakes Sustainability Fund (GLSF)

was established to work in partnership with other agencies and local community stakeholders to advance Remedial Action Plans (RAP) that have been developed for each of Canada's remaining Areas of Concerns located within the Great Lakes Basin. GLSF provides technical and financial support to projects (up to one-third of the total cost) that implement remedial actions to complete the clean up and restoration in three key priority areas: fish and wildlife habitat rehabilitation and stewardship; contaminated sediment assessment and remediation; and innovative approaches to improve municipal wastewater effluent quality. Emphasis is placed on meeting the goals under the CanadaOntario Agreement Respecting the Great Lakes Ecosystem (Environment Canada, 2013). 
Collaborating agencies (including other federal departments provincial ministries, municipalities, conservation authorities, local RAP implementation committees, and project managers) are eligible to apply for a portion of GLSF funding (Environment Canada, 2013). Though vast majority of these collaborating agencies are governmental, RAP teams and implementation committees are often composed of actors from a variety of different sectors (many of whom are involved in decision making with an important influence on the RAP outcome); therefore the process extends beyond simple shuffling across government departments, or even between various levels of government (Environment Canada, 2013). In this manner, the fund is an example of another instance in which the state can be seen to embrace both the local dimension of the RAP approach, and the participation of nonstate actors in potentially significant decision making. Because of the large amount of variation in the severity of environmental degradation and progress of RAPs, funding is allocated based on perceived need, rather than distributed equally among the country's 14 RAPs. Prior to being approved for funding, the target projects of potential recipients must also meet the criteria imposed by the Canadian Environmental Assessment Act (CEAA). The CEAA requirement is, of course, another example of a government rule instrument that supports the RAP approach, albeit indirectly.

Federal government Watchdog Institutions

The federal government has also developed innovative institutions via the establishment of state-based "watchdogs" such as the Office of the Auditor General, and the Commissioner of the Environment and Sustainable Development. The 1977 Auditor General Act established the duties and responsibilities of the Auditor General, which include auditing federal government departments and agencies (Office of the Auditor General Canada, 2011). An amendment made to the Act in 1995 created the federal Commissioner of the Environment and Sustainable 
Development, which performs a similar function in ensuring government meets its sustainable development objectives (Office of the Auditor General Canada, 2013). In a sustainable governance approach, these state institutions are considered deliberate, state-based check-andbalance mechanisms, and are seen to promote rivalrous friction among actors. This type of statebased check and balance process will discussed in further detail below in Section 5.12.

\subsection{Provincial Public Sector Rule Instruments, Processes, Institutions, and Actors}

Ministry of the Environment

Respondent A3, a Ministry of the Environment (MOE) representative specializing in $\mathrm{COA}$ and the Great Lakes summarized the role of the province in the RAP approach as contributions in the form of science and technical support, project level funding, management, and infrastructure funding. The COA representative attributes the low delisting success to high cost of remedial solutions, and the complexity of environmental problems, which were initially underestimated by RAP actors. Echoing the sentiments of Respondent A2, Respondent A3 observes that the AOC classification based on BUIs, and the associated 3-step RAP process appear to be straightforward; however, decades after the approach was established, very few AOCs have managed to meet the criteria for delisting (Respondent A3, interview with the author, December $\left.20^{\text {th }}, 2012\right)$. The RAP approach does not celebrate or reward incremental progress, which has perhaps skewed the public's perception of the advancements that have in fact resulted in vast improvements to the health of the lakes.

Respondent A4 noted that Great Lakes Guardian Community (GLGCF) fund is a vehicle used by the MOE to fund projects related to Great Lakes (some RAP projects, but not necessarily RAP projects) (interview with the author, February $13^{\text {th }}, 2013$ ). The ministry also makes 
commitments under the Canada-Ontario Agreement (COA), in which funds are jointly provided with the federal government. GLGCF tends to fund local, community-based environmental projects, whereas COA funding tends to go towards science-based, and technical skill-based program delivery. The respondent also suggested that through these funding vehicles, the federal and provincial governments have distanced themselves from the implementation of RAP goals: "You receive the money and its your project, the MOE doesn't own it. So we are enabling people to develop their own projects, fund them, and hopefully come up with some benefits for the Great Lakes and AOCs specifically, because the project design has to meet the commitments under COA" (Respondent A4, interview with the author, February $13^{\text {th }}, 2013$ ).

Respondent A5, the MOE lead for the Hamilton Harbour RAP, raises the question of what will happen to restoration and protection initiatives, and state-funded RAP organizations once sites have been delisted:

The real test of sustainable governance is moving beyond the RAP. When Hamilton Harbour has been delisted, environmental management has to continue. What happens after the RAP banner comes down; how does the community move forward and sustain the broad interest in the Harbour? There is a need; other management issues in the Harbour, for some sort of multi-stakeholder process for the harbor. Who knows what kind of other issues will come up in the future? There would have to be some sort of ongoing monitoring. From the outset, the Hamilton Harbor RAP has identified issues it wants to tackle; some are outside of the scope of the RAP (e.g. public access to the harbor front), but are important to the community. The Hamilton Harbor RAP goes over and above what is required for delisting (interview with the author, December 21, 2012).

This is an important consideration, as the environmental health as a resource as precious as the Great Lakes should not be viewed simply as an item to crossed off a list when GLWQA stipulations have been satisfied. Fortunately, the high degree of involvement of nonstate actors in the Hamilton Harbour RAP suggests that these commitments would persist in the event that the state-led RAP approach was terminated. As noted in previous chapters, the RAP's Bay Area 
Restoration Council stemmed from an existing civil society initiative; this suggests that the level of commitment and enthusiasm in the community transcends government decisions with respect to the approach. The above excerpt indicates that in the past, community members have pushed the boundaries of the RAP to tackle environmental issues they deemed important. Thus, it is likely that these individuals and organizations would continue to do so if the state-led RAP approach was dissolved.

Ontario Environmental Bill of Rights/Environmental Registry

The Hamilton Harbour RAP Stage 1 report notes that although the site continued to show evidence of severe environmental degradation, in 1990 major industries discharging to the harbour were in fact meeting Ontario Ministry of the Environment standards, which speaks to the important role of provincial rule instruments in restricting industrial point source pollution, and stabilizing pcbs and heavy metal contaminant concentrations (Ontario Ministry of the Environment et al., 1992). There a number of significant pieces of provincial legislation that can be said to further the goals of the RAP approach as they address environmental goals and objectives. The Ontario Environmental Bill of Rights, for instance, appears to be highly relevant to the remediation of the Great Lakes. Although the Bill (enacted in 1993) takes the shape of a conventional state rule instrument, it can be considered a somewhat innovative one, because embedded in it is a process for enabling public participation. The EBR rule instrument and its promotion of public access to information and upholding constitutes a government process innovation, as it increases the ability of the public to be involved in environmental issues. By establishing the Environmental Registry, the Bill improves access to "environmentally significant" policies and legislation being considered, and reaffirms the rights of citizens to participate in government decisions concerning environmental matters, to hold government 
accountable for these decisions (Environmental Commissioner of Ontario (ECO), 2012).

Additionally the EBR awards Ontario residents the right to appeal ministry decisions regarding environmental licenses, and permits granted to projects or entities (ECO, 2012). Finally, the EBR provides citizens with the right to sue in the event that a public resource sustains environmental damages.

Environmental Commissioner of Ontario

Another important function of the EBR has been its establishment of the Environmental Commissioner of Ontario (ECO), a quasi-independent "environmental watchdog” of the Legislative Assembly charged with assessing government compliance with the EBR. Similar to the federal and provincial Offices of the Auditor General and the federal Commissioner of the Environment and Sustainable Development, ECO can be considered an example of an innovative government institution, because it creates a check and balance on regulatory enforcement, outside of the courts. Although appeals to ECO may be considered reactive mode of public participation (as the public is not included in decision making from the outset), they allow for the halting of projects that may potentially constitute harmful environmental behaviour. Referring to the Ontario Commissioner of the Environment and the ability for citizens to request investigations in cases of suspected non-compliant environmental behaviour, Webb (2005) remarks: "Arguably, the existence of such a check-and-balance institution, and the associated process for citizen petitions, can act as a form of 'distant early warning' device that may decrease the likelihood of environmental disasters such as that of Walkerton happening in the future." 


\subsection{Municipal Public Sector Governance Rule Instruments, Processes, Institutions, and Actors}

A number of bylaws (conventional rule instruments) have the power to either reinforce or disrupt RAP goals; for instance, if sewer use bylaws in Hamilton and Toronto are not enforced, water quality (and associated BUIs) may be affected. Toronto Water is a division of the municipality, charged with the delivery of safe drinking water, collection and treatment of wastewater, and stormwater management (City of Toronto, 2003). Toronto Water's Wet Weather Flow Master Plan is a municipal rule instrument that contains provisions for the management of combined sewer overflows (CSOs) and stormwater, both of which can be said to be impeding the site's progress towards delisting (City of Toronto, 2003).

City councils are considered conventional state institutions. Bearing responsibility for management of the city's infrastructure, these institutions have a large potential to influence RAP outcomes, particularly for issues such as water quality. The Hamilton City Council has had a significant influence on RAP decision making, as they have been lobbied for funding for the completion of several important remediation goals, such as the Randle Reef sediment remediation project, and upgrading of the Woodward Ave Treatment Plant. The Toronto City Council appears to be further removed from RAP projects. The validity of this apparent discrepancy will be explored further in Chapter 6.

\section{Toronto City Council}

Discussion with municipal entities revealed a sharp contrast between the respective involvements of the Hamilton and Toronto city councils in their RAPs. Toronto City Council's involvement in the RAP is incidental, as sewage and stormwater outflow are a part of every city's mandate (Respondent A6, interview with the author, April 24, 2013). The city has several 
rule instruments in place that have the potential to indirectly contribute to RAP goals, such as the innovative, green development standard for new buildings, which is partially voluntary (Respondent A6, interview with the author, April 24, 2013). Respondent A6 observes that city resources for stormwater management be strained by future environmental issues:

As we see all over the world, climate change is going to mean that there's more frequent violent storm events, that will only put more stress on our system. We're doing our best—we're building these huge tunnels at the waterfront to store the overflows and stormwater so they can we treated properly, but they're large capital expenditures and for the most part, we're bearing them on our own (interview with the author, April 24, 2013).

In a large city, issues that garner public attention (e.g. expanding the city's subway) may take priority over less visible and hence seemingly less important (and capital intensive) issues such as those associated with the Toronto RAP goals (e.g, upgrading and modernizing the sewer system). Thus, the progress of the RAP may suffer as a result of the prioritization of other urban issues over those related to the remediation of the city's watersheds.

\section{Toronto Water}

Respondents A7 and A8, representatives from Toronto Water, detailed a "signature project" addressing the combined sewer overflow (CSO) issue that is required for delisting. The project will involve management discharge from 50 outfalls that receive CSOs located on the Don River and inner harbor of Toronto. This will be accomplished using a series of underground tunnels and storage tanks. There will be a high-rate treatment facility to treat the CSOs that have been captured, constructed within a water lot south of the Ashbridges Bay treatment plant. The goal is to clean up lower Don River (which carries the stigma of being one of the most polluted rivers in country), the inner harbor, and Taylor Massey Creek. Toronto Water representatives indicate the presence of "philosophical differences" between Toronto Water and NGO partners 
with respect to the nature of this particular remedial action. NGOs favour the use of "green solutions", emphasizing pollution prevention (i.e. preemptive measures) rather than relying on end-of-pipe remedies (e.g. stormwater ponds as opposed to underground tunnels). The position of Toronto Water, however, is that end-of-pipe treatment is necessary in this case, as prevention measures would be insufficient to address the large volume of CSOs (Respondents A7 \& A8, interview with the author, July 2, 2013). This lack of consensus between Toronto Water and NGO partners can be viewed as an example of rivalrous friction between actors. Pollution prevention is a growing trend in environmental management, and certainly merits a place in discussions surrounding issues like CSOs. However, if the issue can indeed not be remedied effectively using preventative measures, it is likely that the only way to meeting the objectives required for delisting is to use end-of-pipe treatment. Although in this case, it was not practical for Toronto Water to heed the advice of NGOs, this scenario indicates the extent of civil society vigilance with respect to RAP issues, which may prove useful as a check-and-balance on future decisions made by the organization.

Toronto and Region Conservation Authority

Similar to the way Environment Canada and the Ministry of the Environment delegate RAP projects to various actors (both state and nonstate), upon the Toronto and Region RAP's appointment as TRCA as project lead, a smaller scale entrustment of RAP projects to private and civil society sector actors has taken place:

.... Often folks don't know that they're stewards, and yet they're acting as stewards. So what are the strengths and weaknesses? I think that having the TRCA as a RAP steward to some degree, and the alignment of our policies very closely with the RAP objectives, on a day-by-day, hour-by-hour basis - as the TRCA jurisdiction has developed over the last 25 years - the public has someone at the table all the time, thinking about the importance of natural areas, the importance of cover, the 
importance of fisheries. I would say that in the last years, there have been changes within the provincial and federal financing and their abilities to be as involved in smaller, local situations, but the conservation authority is generally there, all the time. I think this is a general benefit to the RAP. We rarely pull up the RAP logo.... But when we're writing a policy document we will remind people that the RAP is important (Respondent A9, interview with the author, April 25, 2013).

A number of interesting points are raised in the above interview excerpt. First, the dual commitment of TRCA to the remediation of the Toronto RAP under both the Conservation Authorities Act and with its formal assumption of Toronto RAP duties appears to have resulted in a more dependable system than was in place prior to this change in leadership. TRCA's mandate as a conservation authority already aligned very closely with the objectives and values entrenched in the GLWQA (Respondent A2, interview with the author, February 26, 2013). The TRCA's responsibility to protect and remediate the Toronto watersheds (delineated in the Ontario Conservation Authorities Act) extends further than the duties and responsibilities they agreed to take on when they assumed the lead role of the Toronto RAP. In the event that the RAP approach was to be dissolved, TRCA would continue to carry out many of the same duties, as they are mandated to do so under the Conservation Authorities Act. In a sustainable governance system, often when one actor or initiative fails, another emerges to take its pace. The role of TRCA as RAP lead appears to exemplify this sustainable governance characteristic. Thus, it might be said that the Toronto and Region RAP approach was ultimately made more "robust" as a result of this change in governance. Finally, the above excerpt suggests that often, Toronto RAP projects are so far removed from state RAP administration that nonstate partners collaborating in their implementation are wholly unaware of the policy foundation of these projects. These insights raise the question of whether it is necessary for these nonstate stewards to be aware of the larger picture of governance they are contributing to. Based on the advances 
that have been made with respect to many BUIs in the Toronto AOC (i.e. wetland restoration, improved beach water quality, fishing), perhaps not.

\section{Hamilton City Council}

In contrast with the Toronto RAP, the Hamilton City Council appears to be far more involved in the RAP process. According to city council member Respondent A10, sewer-use bylaws to have been instrumental in limiting the quantity of wastewater that enters treatment plants, which helps to address BUIs related to water quality (interview with the author, December 18, 2012). Additionally, the Over-strength and Sewage Discharge Agreement requiring industries to pay for emissions in excess of admissible levels has led to the establishment of on-site treatment at U.S. Steel and Arcelormittal Dofasco (Respondent A10, interview with the author, December 18, 2012). In the context of sustainable governance, this shifting of some of the financial burden associated with the RAP from the municipality to industry stakeholders, can be viewed the harnessing of nonstate energies to forward a public policy objective. In this case, private sector members are sharing in the responsibilities and costs associated with meeting RAP targets. The respondent also views Bay Area Restoration Council, the RAP's public outreach arm, as helpful for eliminating the "us versus them" mentality (Respondent A10, interview with the author, December 18, 2012). While the public tends to push for a faster timeline than government and industry members, if everyone is sitting around the same table, there is a better understanding of the barriers, and why the project is prevented from progressing as quickly as was originally anticipated (Respondent A10, interview with the author, December 18, 2012). 
It is also worth noting a Hamilton city Councilor's observation that although governments typically have short attention span with respect to public policy projects, this has not been the case with the RAP approach: "The reason they are not bailing is that there is a long history, a clear commitment that must be followed up on. A constituency has been built; we fully expect stakeholders to follow though" (Respondent A10, interview with the author, December 18, 2012). This observation supports the hypothesis that the RAP approach aligns with the sustainable governance framework, as the involvement of private and civil society members diminishes the influence of Webb's (2005) "realities of governing in the twenty-first century" (i.e. variable political willpower, difficulty holding public interest in a particular issue for an extended length of time) on the policy outcome.

\subsection{Local (RAP-level) Public Sector Rule Instruments, Processes, Institutions, and Actors}

Hamilton Harbour RAP

As described in Chapter 3, the Hamilton Harbour RAP is comprised of three multistakeholder institutions: BAIT, BARC, and the Stakeholder Forum. Each involves public, private, and civil society sector actors. These will be discussed in greater detail in Section 5.41, under "Multistakeholder Initiatives". These institutions and their relation to participating actors and initiatives are depicted in Figure 2.1.

Toronto and Region RAP (Toronto and Region Conservation Authority)

The Toronto RAP is primarily operated by the Toronto and Region Conservation Authority (TRCA). TRCA is considered a government institution, as it was established by the Ontario Conservation Authorities Act in 1946 (Conservation Ontario, 2009). The Ministry of 
Natural Resources (MNR) administers the Act and associated conservation authority programs (Ontario Ministry of Natural Resources, 2013). Under the Act, conservation authorities are "mandated to ensure the conservation, restoration and responsible management of Ontario's water, land and natural habitats through programs that balance human, environmental and economic needs" (Toronto and Region Conservation Authority, 2013). Among other environmental objectives, TRCA aims to ensure the protection, management, and restoration of the rivers, lakes, and streams within their jurisdiction (Toronto and Region Conservation Authority, 2013). Because this mandate encompasses the goals of the Toronto RAP, TRCA was an excellent candidate for replacing the MOE in the role of RAP lead, when the province opted to decrease its involvement in the RAP approach under the Ontario Harris government in the 1990s. The Toronto RAP team also includes representatives from Environment Canada, Ontario Ministry of the Environment, and the Ontario Ministry of Natural Resources. These institutions and their relation to other actors and initiatives contributing to the Toronto RAP approach are depicted in Figure 2.2.

\subsection{Civil Society Rule Instruments, Processes, Institutions, and Actors}

Countless civil society groups have emerged to address pressing Great Lakes issues, with diverse mandates and objectives. The following section will highlight select civil society actors, processes, institutions, and rule instruments that have contributed, or demonstrate potential to contribute to the RAP approach objectives.

\subsection{National/International Civil Society Rule Instruments, Processes, Institutions, and Actors}


The Blue Flag Beach Standard and Certification

One international civil society rule instrument that has played a part in achieving RAP goals is the Blue Flag Program. The Blue Flag beach award is a voluntary eco-label program operated by a European non-profit, nonstate organization known as the Foundation for Environmental Education (FEE). The Program originated in France in 1985, when French coastal municipalities were presented with the Blue Flag for their observance of sewage treatment and water quality stipulations (FEE, 2006). In 1987, the FEE approached the European Commission with a request to expand the program to a cross-continental initiative. The Blue Flag has since become an international symbol of sustainable coastal tourism, awarded to beaches and marinas based on a standard set of criteria. Today, 3849 beaches and marinas in 46 countries currently hold Blue Flag status (FEE, n.d.). In Canada, responsibility for the program has been delegated to Environmental Defence Canada, a non-partisan NGO that challenges the public and private sectors, in addition to community members, to improve their behaviour with respect to the environment (Environmental Defence, 2012). The group can be considered a learning organization, as its mandate includes research and identification of environmental threats. The organization also has a public outreach component, which makes it an ideal overseer of the Blue Flag Program, the success of which is greatly benefitted by public awareness of the award.

The primary objectives of the Blue Flag Program overlap considerably with those adopted by many RAP teams: to educate the public on the subject of coastal environments, and to encourage the consideration of environmental issues in decisions made by local communities and their partners (FEE, 2006). Beaches are awarded the Blue Flag for demonstrating compliance with a set of 32 criteria, divided among the following four categories: environmental education and information, water quality, environmental management, and safety and services. 
If beach quality regresses from one season to the next and no longer meets mandatory criteria, the FEE reserves the right to rescind awards, providing local jurisdictions with an incentive for the continued compliance with the award stipulations (FEE, 2006).

The application of this particular voluntary initiative to water quality control in the Great Lakes is obvious, given the beach award's stringent water quality stipulations. What is perhaps less obvious, is the label's role as a check-and-balance for government water quality regulations. As with other areas legislated by government, many industrial and municipal violations of wastewater regulation escape without detection, or for whatever reason, fail to result in penalties for the parties at fault. Beaches that have been awarded a Blue Flag will be subject to periodic audits in addition to regular inspection by government officials. In addition, Great Lakes AOCs that house Blue Flag-certified beaches must not only comply with government regulations and policies, they are also under public pressure to retain their award. It might therefore be said that they are doubly accountable for ensuring a particular water quality standard is met. It is important to emphasize that while the Blue Flag program role in the Toronto RAP approach is certainly collaborative in the sense that its contributions to the goals and objectives of the RAP are welcomed by the RAP team, on another level it might be considered confrontational, since by establishing and operating an independent water quality rule-instrument, the posting of daily results showing that a particular beach was not open for swimming implicitly raises the question that government regulations and/or implementation of same are inadequate.

According to the Toronto and Region AOC's 2010 Status of Beneficial Use Impairments report, the pursuit of Blue Flag status was listed as a key action that addressed the AOC's beach closing BUI, which was issued due to the presence of bacteria in quantities that exceeded safe levels for swimming at several of the site's beaches. Eight of the city's eleven beaches are in 
possession of a Blue Flag award, and the certification of remaining beaches is currently in progress (City of Toronto, 2009). Securing the beach award is a goal of the City of Toronto Beaches Plan, which aims to implement related aspects of the site's RAP (City of Toronto, 2009). Although it is unclear whether pursuit of the Blue Flag was incorporated into the site's RAP goals to increase the accountability of the AOC team, or simply to increase public confidence in the remediation efforts using an internationally recognized symbol of water quality, the end result remains the same: beach water quality is monitored by an external third party, which acts as a supplement to government monitoring.

According to Respondent $\mathrm{C} 8$, aside from bringing international recognition to the city, the pursuit of certification encourages partnerships between municipalities, community groups, local NGOs, while increasing tourism and support for local industries (interview with the author, March 26, 2013). Strong multi-actor relationships founded upon civil society rule instrument like Blue Flag increase the resilience of the RAP approach, rendering it less vulnerable to changes in local government and the variable interest of municipalities. In other words, is not likely that an elected official would opt out of the Blue Flag program, given the multitude benefits conferred by possessing the beach award. Although meeting the program's stringent criteria already serves to forward the Toronto and Region RAP goals, there is some talk of incorporating new criteria, such as biodiversity, which would cause the initiatives' mandates to overlap further (Respondent C8, interview with the author, March 26, 2013).

The Canadian Water Network

While the Blue Flag program concentrates on measuring compliance with a predetermined set of water quality standards, recommendations made by the Canadian Water 
Network (CWN) are more dynamic, as it is a research-oriented civil society organization. The CWN can be considered an innovative process, as it is a mechanism for "bringing together key decision-makers to determine shared water management needs across municipalities, industry and governments from local to national" (Canadian Water Network, 2013). The network then proceeds to link decision makers with research partners (Canadian Water Network, 2013). An organization such as this is a useful tool at any stage in the RAP, depending on the nature of research needs.

\title{
5.22 Regional Civil Society Rule Instruments, Processes, Institutions, and Actors
}

\author{
Lake Ontario Waterkeeper
}

Lake Ontario Waterkeeper is a registered charity founded in response to growing fears of the safety of drinking water following the Walkerton tragedy in Southwestern Ontario, where seven individuals were killed after drinking tap water infected with E. coli ( Lake Ontario Waterkeeper, n.d.). It is part of a larger movement of Waterkeeper programs, which began in 1966 on the Hudson River in New York (Tully and Mattson, 2004). The Ontario program's founding members, Krystyn Tully and Mark Mattson, have commented on the frequent failure of traditional government rule instruments to ensure environmental protection and citizen health:

Canada's environmental laws - on paper - are strong and farsighted enough to relieve health officials of this burden. With proper enforcement and monitoring programs in place, no one should be at risk from contamination, no ecosystem would be threatened and no health official should need to make such tough choices. Unfortunately, these laws are not always enforced, and their laudable goals not always met. Proof is found in contaminated fish, which are protected by the Fisheries Act; contaminated birds, which are protected by the Migratory Birds Convention Act; and polluted waterways, which are protected by a whole host of 
provincial statutes. And each time these laws are not used to prevent polluters from abusing our resources, public health pays the price (2004).

The Waterkeeper mandate addresses this perceived gap in governmental capability to uphold what are ostensibly thorough environmental laws and regulations. The program conducts their own academic and field researching, using this and existing legislation to support appeals and legal action, both processes that are considered to be characteristic of sustainable governance.

Lake Ontario Waterkeeper is an excellent example of an actor that has contributes as a check-and-balance mechanism in a sustainable governance system. The organization does not purport to act in the place of government, but rather acts to correct and prevent governmental failures in what is inevitably an imperfect system of governance. It might therefore be said that the efforts of groups like Lake Ontario Waterkeeper serve to bolster existing state governance mechanisms. Many of the group's initiatives have a direct influence on the RAP approach. For example, Waterkeeper carries out independent beach water quality testing, and reports the results using a free cell phone application called "Swim Guide," which alerts the public of poor beach water quality (Lake Ontario Waterkeeper, n.d.). Through this process and others, the organization acts as a watchdog on government adherence to their own regulations and policies, in addition to monitoring state regulation of potentially harmful industrial activities affecting regional environmental issues.

The organization considers governmental failures to enforce environmental laws and regulations as a dereliction of the state responsibly to uphold the legislation it enacts (Respondent C7, interview with the author, April 17, 2013). Respondent C7 conveys these sentiments in the following statement: 
...You can get into a lot of different discussions about the regulatory spectrum, I understand that, but in terms of outcomes, that was a loss for us in Ontario. And it's one that has never been built back up since those cuts were made, we've just seen further and further cuts. So a lot of the tools that we were using in the past and found effective, are losing their efficacy. So the whole principle behind Ontario Waterkeeper was that there's really good environmental laws on the books, and all we need to do is enforce them. If the laws that existed were enforced and followed all the time, the lake would be safe for swimming, drinking, fishing.... As laws start to become problematic, because they're being enforced, then you see industry push back and government gives into industry, and those laws slowly erode and become more and more voluntary or optional, and organizations like ours have fewer and fewer options to participate and enforce laws at all (interview with the author, April 17, 2013).

Lake Ontario Waterkeeper has identified what many Canadians view as an alarming trend with respect to environment legislation. One particularly disturbing example of this is the recent amendment to the Fisheries Act via omnibus budget legislation. The amendment removes the fish habitat protection provisions from the $A c t$, focusing instead on the fostering of economically viable fisheries (Paris, 2012). It is quite likely that this will (and has already begun to) interfere with the organization's ability to carry out its mandate. In the larger picture of sustainable governance, however, the failure of "one approach does not necessarily mean an overall implementation failure but rather that another actor, instrument, institution, or process is in a position to 'pick up the slack' or otherwise act as a check and balance concerning a particular behaviour" (Webb, 2005). This can be taken to mean, perhaps, that the erosion of environmental legislation is creating a gap in the governance of the Great Lakes, which might be filled, for example, with innovative rule instruments in the form of voluntary codes, similar to the Responsible Care and the Blue Flag program. Alternatively, it may mean that organizations like Lake Ontario Waterkeeper must shift their mandates slightly to ensure continued relevance in the $21^{\text {st }}$ century.

Interestingly, Respondent C7 from Lake Ontario Waterkeeper was the only respondent who expressed skepticism regarding the theoretical basis of sustainable governance, considering 
it "...code for get rid of regulation, get rid of government and download to the private sector, at which point, everything becomes voluntary" (interview with the author, April $17^{\text {th }}, 2013$ ). This comment reflects a misunderstanding of the sustainable governance framework, which should in no way be viewed as a call for the state to surrender its legitimate responsibility to govern, leaving it in the hands of nonstate entities with inferior capabilities. Instead, it can be seen as nonstate actors sharing in the responsibilities and costs of governance in a "coordinated, accountable way that supplements the governance of state activities of the state" (Webb, 2005).

\section{Great Lakes Commons Map}

The Great Lakes Commons Map is a uniquely innovative civil society process that taps into the "crowdsourcing" trend. That is, the map allows collaborators to submit reports to a range of categories (including one for Areas of Concern), permitting participants to highlight Great Lakes issues for others to see (Great Lakes Commons Map, n.d.). The map, which was developed by the Great Lakes Commons Initiative (GLCI) grassroots organization, is conceptually premised on the perceived need to reclaim the lakes as a commons. The GLCI website describes a commons as "something shared by many and belonging to none. A true commons lives in the understandings, relationships, actions, and laws recognized by the public. A commons needs commoners who are empowered to act as stewards and protectors" (n.d.). This process has a clear application to the RAP approach, and might be used, for example, to inform community members of an approaching stakeholder meeting (e.g. in the case of the Hamilton Harbour RAP, a BARC meeting), or to attract attention to or inspire activism around a particular AOC project (e.g. Randle Reef in the Hamilton Harbour). 


\subsection{Local Civil Society Rule Instruments, Processes, Institutions, and Actors}

Hamilton Harbour RAP Civil Society Participants

One example of the use of federal rule instruments to ensure adherence to the goals of a RAP occurred in Hamilton, ON, where a local environmentalist named Lynda Lukasik succeeded in the private prosecution of the City of Hamilton for violating the terms of the act (Environmental Bureau of Investigation, 2000). Local citizens, McMaster University, and the Environmental Bureau of Investigation (EBI) monitored water quality in the Redhill Creek (a part of the Hamilton Harbour watershed), and found that leachate from a city-run landfill containing PCBs and ammonia had been discharging into the creek (Environmental Bureau of Investigation, 2000). The city pleaded guilty and was fined $\$ 300000$ (Environmental Bureau of Investigation, 2000). Regulations under the Fisheries Act allow for fine-splitting, wherefore a private informant receives one half of the proceeds of a private prosecution; accordingly, \$150 000 was awarded to Lukasik. Lukasik used part of the sum to found Environment Hamilton, a not-for-profit group that aims to educate citizens about environmental issues in the city, empowering them to protect and enhance the local environment (Environment Hamilton, 2013). A separate conviction was also made under the Ontario Water Resources Act, resulting in an additional $\$ 150000$ fine.

According to Webb (2005) private prosecutions and citizen triggered investigations are categorized as sustainable governance process innovations, as they facilitate the participation of nonstate stakeholders in decisions that would otherwise be controlled exclusively by government. Based on the success of this prosecution, it appears that the Fisheries Act is a useful tool for enabling public participation in environmental decision making. The prosecution can be 
considered both an example of the successful use of a federal government rule instrument and also of a civil society process (these will be discussed at length in Section 5.3). This particular case is interesting because it involved the harnessing of the century-old Fisheries Act for use as part of an innovative process (characteristic of sustainable governance system), in such a way that indirectly promotes the fulfillment of Canada's objectives under the GLWQA. This marriage of traditional and innovative, and direct and indirect mechanisms is at the heart of the sustainable governance framework, which allows for a distribution of the responsibilities and costs associated with governance away from the state and onto the shoulders of the private sector and civil society (e.g. community activists such as Lynda Lukasik). It is not unreasonable to envisage the future use of private prosecutions in other cases of non-compliance. It is, however, important to note recent changes made by the federal government to the Fisheries Act and other environmental legislation, which may have weakened their power for future use in cases of noncompliance.

Although the prosecution of the city of Hamilton in September 2000 for violations under both the federal Fisheries Act and the Ontario Water Resources Act was effective in bringing about a change in behaviour, Respondent $\mathrm{C} 3$ notes that a successful prosecution is not necessary to bring about tangible change:

...Even if you don't succeed [with a prosecution], you raise concerns and that can have an impact. I mean I think about the Rennie [landfill] case, and it was a very tangible outcome because the site was remediated, and that also was a domino effect, because as soon as the city realized that it was vulnerable on this front they actually went in and looked at every different closed landfill in the municipality, they knew: 'Ok, they know how to do this, and look at what happened. They caught us off guard.' And they didn't want it to happen again, partially because it would be costly and embarrassing for them. So that's one example where I can see very tangible impacts (interview with the author, February 15, 2013). 
The above excerpt demonstrates the self-awareness of this particular civil society actor's role in the larger picture of sustainable governance, which extends beyond exercising citizen power to bring about environmental justice in one simple case of non-compliance. Rather, by exercising this right, community activists are making known their identity as watchdogs on state enforcement of environmental legislation. The Respondent C3 understands that the effects of a private civil action are further reaching than the outcome of the trial, and are likely to compel state entities (like the city of Hamilton) to tread carefully in the future, removing what might have been a significant impediment to the AOC's delisting.

Petition to the Office of the Auditor General

Although discussions of the role of civil society in environmental governance are often limited to NGOs, individual activists and community groups also have the potential to make important contributions to the RAP approach. This is apparent, for example, in the use of a petition to the Office of the Auditor General by community activists as a tool to bring attention to the stagnant progress of the contaminated sediment remediation at the site. In October 2002, Lynda Lukasik, executive director of local ENGO Environment Hamilton, and her colleague Dr. Mark Sproule-Jones, vice president on the board of directors of Environment Hamilton, petitioned the Office of the Auditor General with their concerns regarding the progress of a particular aspect of the site's RAP. The petitioners felt that site's primary environmental concern, a 55500 cubic meter coal tar deposit containing hazardous concentrations of polycyclic aromatic hydrocarbons (PAHs), was being neglected during the implementation phase of the Hamilton Harbour RAP (Lukasik and Sproule-Jones, 2002). This pile of carcinogenic, persistent, and bioaccumulative sediments, nicknamed "Randle Reef", accumulated in the Hamilton Harbour as a waste product of past industrial activities. The petitioners objected to the proposed solution, 
which involves the construction of a dry cap dyked containment facility approximately 9.5 ha (hectare) in size, intended to contain the sediments and diminish the environmental effects associated with high concentrations of PAHs (Lukasik and Sproule-Jones, 2002).

In their petition, Ms. Lukasik and Dr. Sproule-Jones invoked the commitment of the federal government to restoring the Great Lakes under the Canada Ontario Agreement Respecting the Great Lakes Basin Ecosystem (2002). The petitioners noted that the CanadaOntario Agreement has demarcated PAHs as Tier 1 substances, a category reserved for contaminants thought to require immediate attention and rapid elimination from the Great Lakes. Consequently, the 1995 Hamilton Harbour RAP identified Randle Reef as a primary remediation objective, and recommended that the polluted sediments be physically removed from the Harbour. However, in 2002, the federal government propositioned that the sediment pile instead be contained through in-filling (Lukasik and Sproule-Jones, 2002). Among other things, the petitioners asked that Minister of the Environment justify this deviation from the original plan of removing the sediments, and commit to a timeline for the start and finish of the remediation of Randle Reef. In their response, Environment Canada countered that the federal government was under "no legal obligation to clean up the Randle Reef sediments or to provide the funding to clean up these sediments," and proceeded to list the funding contributed to the Randle Reef project by the department from the RAP's advent to the time of the petition (Environment Canada, 2002). It was also stated that the project was anticipated to begin by late fall 2003 (Lukasik and Sproule-Jones, 2002).

Although the project has finally received commitments from responsible parties to contribute the total required for containing the sediments, the project has yet to begin as of September 2013 (Churchill, 2013). This of course calls to question the success of the petition by 
Lukasik and Sproule-Jones, and also of the general usefulness of petitions to watchdog bodies like the Auditor General as processes working within a system of sustainable governance. In the context of sustainable governance, this petitioning process can be considered an example of what Webb (2005) refers to as "rivalrous friction" between actors. Here, community activists have taken initiative and called for action from government on an issue that was at the time (and for the most part, continues to be today) at a standstill. By bringing forth this petition, Lukasik and Sproule-Jones made known their dissatisfaction with the efforts of Environment Canada and the Department of Fisheries and Oceans to meet the needs of the community. Although no perceptible changes appear to have been brought about by this petition (as the containment solution remains the favoured solution, and the project has yet to be implemented in 2013), it can be viewed as an indication that community activists are keeping a close watch on government departments responsible for RAP progress. Thus, within a larger system of sustainable governance, community activists making use of innovative government processes (i.e. petitions to the Auditor General) can be viewed as having a check-and-balance function on government commitments under the GLWQA.

Hamilton Harbour RAP Civil Society Initiatives

The previously discussed legislative foundation of the RAP approach and related policy documents have noted the important role of public participation at the macro (binational/national), meso (provincial/regional), and micro (local/RAP) scales. Just as the RAP approach as a whole stemmed from a civil society NGO (Great Lakes United) report criticizing the binational approach to remediating the Great Lakes, one of the primary arms of the Hamilton Harbour RAP, the Bay Area Restoration Council (BARC) was built upon an existing community 
group (“Save Our Bay”). Civil society participation has been woven directly into the Hamilton Harbour RAP from the early days via BARC, which fulfills the site's public interest obligation.

Respondent $\mathrm{C} 2$, an academic expert with extensive experience with community involvement in RAPs, comments that the strength of the RAP process comes when citizens have the authority to come to the table and negotiate in their own interest (interview with the author, December 12, 2012). The respondent notes that the process fails in situations where government believes their role is to tell community what their plan is, "imposing" decisions on the community rather than empowering them to make their own decisions (interview with the author, December 12, 2012). It is worth considering whether the Randle Reef project can be considered an instance in which government imposed a decision upon the community, rather than allowing them to make their own decisions. One member of the BARC board of directors suggested that the involvement of nonstate actors in the Hamilton RAP was, to some degree, a façade, calling to question the belief that the decision making process is democratic (Respondent $\mathrm{C} 4$, interview with the author, February 14, 2013). The respondent observes: “it's still a few knowledgeable individuals deciding what is politically expedient in terms of money" (Respondent $\mathrm{C} 4$, interview with the author, February 14, 2013). Yet, interviews conducted with other civil society BARC board of director members reflected different perspectives; Respondent C5, for example, considers the council's decision making approach to be consensus-based (interview with the author, February 8, 2013). Respondent C6 considers BARC to be highly adaptable, and not susceptible to state interference during decision making: "We don't have a large government bureaucracy shackling our decisions or behaviours. We can literally, in the space of minutes, turn 180 degrees, implement a whole new strategy, allocated funds completely differently; whereas, 
Environment Canada or the MOE wouldn't be able to do that" (interview with the author, March $15,2013)$.

Regardless of whether Respondent C4's allegation of one-sided decision making is simply conjecture, or if it is founded on fact, when considered from a solely public policy perspective, coming to a (loose) consensus on the remediation method and assembling the funding required to carry out the Randle Reef remediation project can in itself be seen as a monumental success. Once the project is implemented, what is arguably the largest barrier to delisting will have been removed. The variable responses received with respect to this project may simply be a case, as Webb (2005) puts it, in which an attitudinal shift is needed when operating within a sustainable governance system "accepting less-than-perfect operating conditions as a given; accepting the need for a sharing of power with diverse, less-than-perfect governance partners; and accepting that governance in the public interest is more like managing a complex multivariate ecosystem full of unknowns and surprises than it is like operating a mechanical device with clear inputs and outputs."

Toronto RAP Local Civil Society Initiatives

Based on the insights and information provided by informants, it appears that Toronto civil society is less aware and engaged in the RAP, and consequently, community involvement is less extensive. In contrast with the Hamilton Harbour RAP, there are fewer civil society members in the official Toronto RAP organizational structure; it is composed primarily of collaboration between various government entities. Direct public involvement is limited to TRCA volunteer programs, and participation in the Etobicoke-Mimico, Humber, and Don watershed councils. 
Don Watershed Council

According to Respondent C8, the Toronto and Region RAP project manager, community involvement is built into the structure of TRCA, as each watershed comprising the AOC has its own watershed specialist, and each specialist has a watershed council consisting of members of the public (interview with the author, February 1, 2013). The Don Watershed Council, for example, works closely with the RAP approach (Respondent C9, interview with the author, June $4,2013)$. Much of the council's remediation work is tied to stormwater control, which is the biggest polluter and greatest danger to the health of the river. Unlike BARC, government employees can be members, although individuals must apply and be appointed as members of the council. Similar to BARC, however, the councils have a strong advocacy role, promoting government spending on environmental protection (Respondent C9, interview with the author, June 4, 2013). The community groups comment on all social, economic, and environmental policy documents that affect their watersheds. When policy reports differ from or express stronger views than those of TRCA, the council includes a disclaimer at the bottom of reports (Respondent C9, interview with the author, June 4, 2013). The watershed councils are "arms" of TRCA; in other words, they do not have funding of their own, and are limited to making recommendations (Respondent C9, interview with the author, June 4, 2013). Hence, the watershed councils are community groups with a clear watchdog role on the Toronto RAP. 


\subsection{Private Sector Rule Instruments, Processes, Institutions, and Actors}

\subsection{National/Bi-National Private Sector Rule Instruments, Processes, Institutions, and Actors}

Chemical Industry's Responsible Care Standard

The Chemical Industry Association of Canada (CIAC) introduced Responsible Care in 1985, and chemical industry associations in more than fifty countries worldwide have since adopted the initiative (CIAC, 2009). It might be argued that due to being a non-profit organization, the CIAC should be considered a civil society actor, and the Responsible Care program should then be categorized as a civil society governance mechanism. However, because the CIAC (by virtue of being an industry association) acts as a vehicle for industry member involvement in the RAP approach, it will be considered as a private sector initiative for the purposes of this thesis.

The devastating outcomes of severe chemical spills such as those that took place in Seveso, Italy (1976), and Bhopal, India (1984) shook public faith in the chemical industry considerably. The sector's rapid descent from being hailed a "miracle provider" of chemical products to being "commonly regarded as "greedy, rapacious, and irresponsible" can also be attributed to its release of exorbitant quantities of pollutant emissions (Gunningham, 1995). Hence, the Responsible Care voluntary initiative was borne out of a desire to ameliorate the sector's public image, reassure the public of the chemical industry's integrity, and to assuage demands for increased stringency in government regulation (Gunningham, 1995).

The basis for Responsible Care is a statement called "Ethic and Principles for Sustainability," which CIAC members must pledge their commitment to annually. The most recent version of the statement was formed with input from diverse civil society stakeholders, 
with the intention of taking into account the sustainability expectations and concerns of Canadian citizens (CIAC, 2009). The second level in the organizational structure of the program consists of codes of practice, which include criteria for each stage of a chemical's life cycle, from its initial creation to its large-scale manufacture, transportation, use, and disposal. This component can be considered a rule instrument, because establishes behavioural criteria for participating industry members. Companies participating in Responsible Care are also required to establish a management system for continual improvement through its use of the "plan-do-check-act" process throughout the implementation of the codes of practice. The CIAC provides members with support and encouragement in various forms, including minimum standards, checklists and guidelines, and networks of experts (CIAC, 2009). The program is monitored by an institution known as the CIAC National Advisory Panel, which is composed of $12-16$ activists, advocates, and academics, charged with advising the association on matters related to environment, public health, labour issues, transportation safety, consumer products and social responsibility (CIAC, 2009). Verification, the process by which the CIAC confirms that the Responsible Care ethic is being followed, is carried out by a team of advocates, experts, and community members who visit participating firms every three years (CIAC, 2009). In their $9^{\text {th }}$ Biennial Report, the International Joint Commission mentions Responsible Care as an example of a private sector voluntary contribution to the Great Lakes restoration effort (IJC, 1998). Being a nonstate rule instrument verified by a third party, Responsible Care can be considered a valuable supplement to government pollution standards.

The Chemical Industry Association of Canada's (CIAC) requires members to comply with Responsible Care standards of behaviour. This innovative rule instrument has no doubt played an inadvertent role in forwarding the objectives of the RAP by ensuring the Canadian 
chemical industry members curb environmentally harmful behaviours. Respondent B1, a representative from Responsible Care, notes that the federal National Pollutant Release Inventory includes 350 substances, and only requires reporting of quantities greater than a ton. In contrast, Responsible Care's members are required to report on the release of over 850 substances, irrespective of quantities released. The program has been immensely successful in that respect, having brought about a reduction in industry discharge across Canada from 206000 tons in 1992 to 30000 tons in 2011 (Respondent B1, interview with the author, January 25, 2013). According to the respondent, Responsible Care participants have made direct, local contributions to the St. Clair River, St. Lawrence River, and Niagara River RAPs (Respondent B1, interview with the author, January 25, 2013). In fact, Dow Chemical Canada can be credited with completing a major cleanup of contaminated sediments in the St. Clair River ("Open houses on contaminated sediment in the St. Clair”, 2013). Hence, by raising the standard for environmental performance above and beyond what is required by law, and holding its members to stringent behavioural criteria, Responsible Care can be seen to contribute to the RAP approach on both the macro and micro scales. The program can be considered an extraordinarily valuable sustainable governance tool, supplementary to the regulatory and enforcement activities of government, while improving the industry's public image and the health of the Great Lakes.

\subsection{Local Private Sector Rule Instruments, Processes, Institutions, and Actors}

Hamilton RAP Private Sector Initiatives

Private sector involvement has been a recurrent theme in the Hamilton Harbour AOC. There are a number of industry members and organizations with direct involvement in the RAP's 
components (i.e. BARC, BAIT, the Stakeholder Forum), including steel industry members U.S. Steel (formerly Stelco) and Arcelormittal Dofasco (formerly Dofasco), whose pollution legacies in the Hamilton Harbour can be considered partially responsible for several of the AOC's BUIs. Additionally, the Hamilton RAP team has recognized two local industry associations as important partners in the remediation process: the Hamilton Industry Environmental Association (HIEA) and Hamilton Halton Homebuilders Association (HHHA). The role of HIEA in the remediation of the site is easily discernable upon reviewing the organization's mandate, which expresses aspirations to improve the local environment through "joint and individual activities, and by partnering with the community to enhance future understanding of environmental issues and help establish priorities for action" (Hamilton Industry Environmental Association (HIEA), 2013). HIEA compiles and releases annual pollution surveys, making the environmental performance data of participating industry members available to the public (HIEA, 2013). This sustainable governance process adds another layer to industry accountability, while aiding participating companies in complying with internal standards, in addition to environmental legislation (thereby acting as a check-and-balance). Although the correlation between HHHA (an association specializing in residential development) and the city's RAP is perhaps unclear at first glance, insights obtained from interviews conducted during this investigation indicate the presence of an ongoing dialogue between the association and the site's RAP team, and revealed contributions made by HHHA to Hamilton Harbour remediation goals.

Respondent A noted that private sector engagement in the RAP approach has been inconsistent, particularly at the level of individual AOCs (interview with the author, April 11, 2013). If this is in fact the case, the Hamilton Harbour RAP appears to be an exception to this rule, as both industry associations and private sector members have been written into the RAP's 
organizational structure, through their participation in the Bay Area Restoration Council (BARC). Interview requests were sent to all BARC board members, since the council is comprised of civil society and private sector members, and it was thought that this would inject a variety of perspectives into this investigation of local governance of the Hamilton Harbour RAP.

In Chapter 5, the continued involvement of local steel industry members Arcelormittal Dofasco and U.S. Steel, and local industry associations (Hamilton-Halton Homebuilders Association (HHHA) and Hamilton Industry Environmental Association (HIEA)) was noted. Representatives from Arcelormittal Dofasco and U.S. Steel sit on both the RAP's technical Bay Area Implementation Team (BAIT) and BARC, and are primarily involved via that route. Beyond this, U.S. Steel participates in independent initiatives to lessen their impact on the harbor, such as ISO 14001 certification, and HIEA membership (Respondent B2, interview with the author, March $\left.6^{\text {th }}, 2013\right)$.

Hamilton Industry Environmental Association

Respondent B3 underscored the importance of HIEA's public outreach mandate, which allows laypersons to bring forth their concerns, questions, and suggestions regarding the environmental status of member organizations (interview with the author, April $17^{\text {th }}, 2013$ ). HIEA appears to serve as a check-and-balance on the industry member compliance with government regulations and individual companies' environmental policies, as the association compiles the National Pollutant Release Inventory emission data of participating industry members, which provides the public with an additional layer of accountability. HIEA can be viewed as an innovative institutional middleman for industry and community members, as it facilitates and mediates dialogue concerning environmental solutions. Many community 
members have ideas for environmental improvements, but they may not be feasible for technical or financial reasons; HIEA is able to provide a framework for discussion in these cases (Respondent B3, interview with the author, April 17 $7^{\text {th }}, 2013$ ). Additionally, members of the public The insights provided by the HIEA representative echo those of Respondent A1, who (citing the example of Randle Reef sediment remediation in Hamilton Harbour) observed that because sustainable governance approaches encourage and facilitate community involvement, "well intentioned but ill-informed lay people" may cause projects to run off course (interview with the author, April 11, 2013). This is certainly an important consideration; resistance from concerned citizens and community groups has the power to cause significant delay in remediation projects, as was seen in case of the Randle Reef containment project. Bridging organizations like HIEA fill what would otherwise be a large gap in the RAP approach's community involvement aspect. Although it is not a perfect solution (i.e. HIEA did not succeed in expediting the Randle Reef project), some fine-tuning may yield an organization that more effectively assuages public concerns surrounding the more contentious RAP projects. For example, perhaps an increase in awareness of the organization, or education efforts would help to increase public understanding of the technical aspects of remediation projects.

Hamilton-Halton Homebuiler's Association

The Hamilton-Halton Homebuiler's Association (HHHA), on the other hand, was involved in the RAP presumably out of necessity, as several of the RAP's BUIs are exacerbated by development (i.e. loss of wildlife habitat). HHHA is a member of BAIT, and has played a large role in the team's urbanization and land management program, making contributions to the RAP via public education (i.e. handing out information pamphlets detailing environmental status of areas targeted for development) (Respondent B4, interview with the author, April 10 $0^{\text {th }}, 2013$ ). 
Additionally, the association has established an award for environmental excellence, to be presented to one member organization each year (Respondent B4, interview with the author, April 10 $\left.0^{\text {th }}, 2013\right)$.

Toronto RAP Private Sector Initiatives

Industry involvement is also visible in the Toronto AOC, although private sector involvement in the RAP itself is more indirect than that of U.S. Steel and Arcelormittal Dofasco. Industry members have not been explicitly "written in" to the RAP per se as in the case of the Hamilton Harbour RAP; however, the Toronto and Region Conservation Authority engages in partnerships with industry members to help meet RAP objectives. In June 2013, Coca Cola Canada pledged $\$ 500000$ towards a wetland restoration project at Tommy Thompson Park (Water Canada, 2013). The project aims to reduce contamination in 1.4 million cubic metres of water, in addition to creating new habitat (Water Canada, 2013). The proposed wetland restoration will address several of the site's BUIs, including loss of fish and wildlife habitat, and degradation of fish and wildlife populations.

\subsection{Multistakeholder Rule Instruments, Processes, Institutions, and Actors}

5.41 National/Binational Multistakeholder Rule Instruments, Processes, Institutions, and Actors

The Great Lakes RAP Approach

The RAP approach is clearly a multi-actor initiative (both at the macro and micro scales), but it is also itself composed of an intricate web of single and multi-actor mechanisms. Many multi-actor initiatives can be considered inherently innovative, because they traverse the 
traditional divides between the public, private, and civil society sectors. This section will explore a number of multi-actor initiatives that contribute in a variety of ways to the accomplishment of GLWQA goals.

The GLWQA's open-endedness with respect to the governance mechanisms employed to fulfill each country's obligations (beyond its requirement of the three-step plan), and the necessary site-specific nature of individual RAPs lends itself to innovation with respect to the processes, rule instruments, and institutions that are established at each site. Because RAPs are, by definition, ad hoc solutions, and the resources, environmental issues, and local politics vary substantially between AOCs, RAP officials are restricted to working with actors that are readily available. The Toronto and Hamilton AOCs appear to have benefitted greatly from being located in large urban centres, with an abundance of resources, and virtually countless civil society and private sector actors with which to form joint initiatives targeting RAP goals. In fact, multi-actor initiatives have been built directly into the Hamilton Harbour RAP organizational structure, with industry and civil society representation in both the public outreach institution (BARC) and the implementation arm (BAIT).

ISO 14001

A multistakeholder rule instrument that holds a high potential application for making indirect contributions to forwarding the goals of the RAP approach is International Standards Organization (ISO) 14001 standard for environmental management systems. ISO is a multistakeholder NGO, and the largest developer of international standards around the globe (International Standards Organization (ISO), n.d.). ISO standards are developed by working groups, with participation by government, industry, and civil society. First published in 1996, 
ISO 14001 is the "corner stone" standard of the International Standards Organization (ISO) 14000 series (U.S. EPA, 2013b). According to Potoski and Prakash (2005), it is "perhaps the most important and visible voluntary environmental program," consisting of over 36000 registered facilities worldwide. It is the only standard in the series under which certification by a third party certification authority is permitted. The standard does not demand outright adherence to a particular set of environmental performance criteria; it rather delineates requirements for the implementation, maintenance, and improvement of an environmental management system (EMS) (U.S. EPA, 2013b). Similar to the Responsible Care Program, ISO 14001 employs what is known as a "plan-do-check" framework to guide EMS requirements (U.S. EPA, 2013b).

As applied by businesses, the standard is relevant to virtually every aspect of the remediation of the Great Lakes, including water quality control. There are a number of ways in which ISO 14001 can be used to improve water quality; for instance, through the certification of government departments, or alternatively, through governmental promotion of private sector certification for industries affecting water quality. The latter option has in fact been suggested by the IJC, who have recommended that the implementation of an ISO 14001-approved environmental management system be considered as a potential tool for improving the environmental performance of wastewater treatment plants (IJC, 2009). The U.S. Environmental Protection Agency (EPA) Office of Water has already laid the foundation for implementing this suggestion, through its designation of 11 U.S. organizations as "EMS Local Resource Centers," which exist to guide local governments through the process of implementing EMS (IJC, 2009). The commission suggests the EPA take this a step further, that this begin with the identification of gaps in existing policies and procedures in comparison with those stipulated by the ISO 14001 standard (IJC, 2009). 


\section{Government-Responsible Care MOU}

Although the program was initially developed in the absence of government instruction or input, both the federal government and Ontario provincial governments have since entered into memoranda of understanding (MOU) with the Chemical Industry Association of Canada regarding the Responsible Care program, which is an example of the transformation of "an industry association from a lobbying organization into a rule-making and self-policing body concerned with the behaviour of its members" (Webb, 2005). When examined within the context of the sustainable governance framework, this public-private contract can be considered a joint public-private sector rule instrument. The willingness of governments to enter into these MOUs is significant, not only because it can be viewed as an indication of government approval of the Responsible Care program, but also because of its implication that public sector departments and the chemical industry have shared goals concerning the health of the environment. This publicprivate agreement gives credence to the self-regulatory initiative, and can be considered an example of government breaking out of its conventional role as a legal authority through participation in an innovative partnership that emphasizes voluntary, non-regulatory actions.

\section{Great Lakes St. Lawrence Cities Initiative}

The Great Lakes and St. Lawrence Cities Initiative (GLSLCI) is an NGO that works in collaboration with municipalities in the Great Lakes region. The initiative is a "binational coalition of mayors and other local officials that works actively with federal, state, and provincial governments to advance the protection and restoration of the Great Lakes and the St. Lawrence River" (Great Lakes and St. Lawrence Cities Initiative, n.d.). The initiative has a clear potential to serve as a linking mechanism within the RAP approach, where disconnect between 
participating jurisdictions is perhaps an inevitable consequence of establishing a bi-national solution to address what are primarily regional and local environmental issues. One example of a GLSLCI collaboration that forwards the objectives of the GLWQA, is through a memorandum of cooperation (MOC) with the province of Ontario that aims to support the Canada-Ontario Agreement (Ministry of the Environment, 2013). The MOU, first signed in 2008, occasioned a number of joint projects between the GLSLCI and the province, resulting in improvements in the following areas: the preservation of beach health, the improvement of stormwater and wastewater practices, and encouraging investment in the Great Lakes by the private sector (Ministry of the Environment, 2013).

Built into the initiatives is a rule instrument known as the Water Conservation Network, which is a voluntary program member cities are asked to abide by (Respondent D2, interview with the author, June 11, 2013). Additionally, the group has contributed sustainable governance processes in the form of public hearings on Great Lakes issues (i.e. Asian Carp invasive species) (Respondent D2, interview with the author, June 11, 2013). According to the respondent, the group views themselves as playing a "catalyzing" role at the local level, in addition to being able to cut through "red tape" at higher levels of government (i.e. through the MOC) (interview with the author, June 11, 2013). The respondent considers the large number of Great Lakes actors to be problematic at times, as organizations overlap and step on each other's toes. The efforts of these groups might be better served if the collaboration route was taken, as opposed to various organizations "trying to re-invent the wheel" (Respondent D2, interview with the author, June 11, 2013). While can be useful to have organizations with similar mandates in some cases (as they reinforce each other as check-and-balances on government initiatives), beyond a certain point, new organizations become redundant unless they fill a gap that is not otherwise being addressed. 


\section{Council of Great Lakes Region}

One civil society group with potential to address variable state interest and resources, and erosion of protective legislation is the Council of Great Lakes Region (GGLR). The council emerged from a 2011 summit hosted by the Mowat Centre and Brookings Institution, which shed light on the "unrealized potential" of the Great Lakes Region with respect to cross-sectorial collaboration (Respondent D1, interview with the author, June $5^{\text {th }}, 2013$ ). GGLR is intended to act as a portal between environmental initiatives and economic transformation initiatives. In order to avoid overlap with existing agencies (e.g. Great Lakes Commission, IJC), decided to focus on economic transformation side rather than environmental remediation and protection side. Though the environmental state and economic status are connected in theory, in practice, there appeared to be a gap in collaboration between the two sectors. Respondent D1 observes that although the remediation accomplished depends (to some extent) on economic prosperity, the sectors operate independently, often with separate or opposing agendas. The respondent also identified what is indisputably a caveat associated with governance approaches like the RAP approach that have a legislative foundation: When these (environmental) projects are costly, the balance is skewed towards government (interview with the author, June $5^{\text {th }}, 2013$ ). In other words, the success of the approach is disproportionately dependent on government investment, even when taking contributions of nonstate actors into consideration. 


\subsection{Local Multistakeholder Rule Instruments, Processes, Institutions, and Actors}

Hamilton Harbour RAP Multistakeholder Initiatives

The Hamilton Harbour RAP is comprised of three multistakeholder initiatives. The Bay Area Restoration Council, introduced in Chapter 3, is an institution charged with public outreach and decision making with respect to remedial actions. The origin of BARC, which began as a community organization called "Save Our Bay", can be viewed as evidence of the important role of nonstate actors in the RAP approach. The council consists of civil society and private sector representatives, and provincial government institutions (e.g. Hamilton Port Authority, Hamilton Conservation Authority) (BARC, 2011). Civil society members include local environmental NGOs, such as Green Venture, and private sector members range from local members of the steel industry (e.g. U.S. Steel, Arcelormittal Dofasco), to local educational bodies (e.g. McMaster University) (BARC, 2011).

The Bay Area Implementation Team (BAIT) is the Hamilton Harbour RAP's implementation arm, and consists of public, private, and civil society sector stakeholders. Public sector participants in BAIT include Environment Canada, Fisheries and Oceans Canada, Ontario Ministry of the Environment, Ontario Ministry of Natural Resources, the Hamilton Conservation Authority, and the city of Hamilton (BARC, 2012). Private sector members include U.S. Steel, Arcelormittal Dofasco, and the Hamilton-Halton Homebuilders Association (BARC, 2012). Civil society sector members include the Hamilton Waterfront Trust, and the Royal Botanical Gardens (BARC, 2012).

The Hamilton Harbour RAP Stakeholder Forum is a process that is carried out periodically, on an as-needed basis. Because of this participating actors have varied throughout 
the history of the RAP. The Forum is reconvened intermittently to review the progress of the RAP's objectives (BARC, 2012). Public sector members of the 2012 Stakeholder Forum include Environment Canada, Fisheries and Oceans Canada, Ontario Ministry of the Environment, Ontario Ministry of Natural Resources, and the Hamilton Conservation Authority (BARC, 2012). Private sector members include Arcelormittal Dofasco, U.S. Steel, and Hamilton Industry Environmental Association (BARC, 2012). Civil society sector members include Lake Ontario Waterkeeper, and Environment Hamilton (BARC, 2012). It is important to note that many actors participate in more than one of the above Hamilton RAP multistakeholder initiatives. This can be viewed as an indication of the high level of direct involvement of nonstate actors in the governance of the Hamilton Harbour RAP. The above initiatives and their relation to participating stakeholders are depicted in Figure 2.2.

Although community opposition to RAP team decisions has been said to hinder progress (Respondent A1, interview with the author, April 11, 2013), when examined through the lens of sustainable governance, this type of "head butting" can be seen to serve an important function. In essence, community involvement can be viewed as a compromise, in which efficiency is sacrificed to some degree to achieve what is likely a more effective result. For example, as discussed in Chapter 3, the proposed Randle Reef containment solution was met with much resistance from the public. The outcome of the sediment containment solution remains to be seen, as implementation of the project has yet to begin; however, if this — or any — chosen remedial were in fact problematic, citizen activism would serve as a barrier to a potentially ineffective or harmful remedial action. It should also not be assumed (as Respondent A1 suggests) that concerned citizens are necessarily ignorant of the technical aspects of remediation. Lynda Lukasik and Mark Sproule-Jones (discussed in Chapter 3 and 5), who petitioned the Office of the 
Auditor General to request (among other things) that the containment proposal be reexamined, are both highly educated individuals and have demonstrated an extensive knowledge of both the scientific and legal aspects of the RAP approach (Lukasik and Sproule-Jones, 2002).

Respondent C1, a member of the BARC Board of Directors, notes the presence of some friction between BARC and the Hamilton Harbour RAP office (interview with the author, March $5,2013)$. However, "pushes and prods" from the RAP office should be viewed as an asset of the AOC's structural organization, rather than being antagonistic (Respondent $\mathrm{C} 1$, interview with the author, March $5^{\text {th }}$, 2013). Respondent A12, the RAP coordinator, considers the relationship between the various Hamilton Harbour RAP entities (BAIT, BARC, Stakeholder Forum) to be an example of collaborative governance (interview with the author, April 4, 2013). This appears to be an accurate description of these groups, as Respondent $\mathrm{C} 2$ notes they operate on the basis of consensus ("gentleman's agreements"), which is one of the definitive characteristics of collaborative governance (interview with the author, December $12^{\text {th }}, 2012$ ). The presence of rivalrous friction in other aspects of the Hamilton RAP (and the RAP approach as a whole) fails to coincide with the definition of collaborative governance as a consensus-based approach, thereby disqualifying them from fitting into this particular framework. However, it is certainly possible that instances of collaborative and/or participatory governance are present within the larger picture of governance, as Respondent A12's observation would suggest.

Respondent A12 considers not being employed directly by government to be highly advantageous, as it removes constraint from interactions with senior staff of stakeholder agencies or politicians, and facilitates dialogue with MPs, remarking: "I can put the RAP absolutely first; somebody else working for their own agency would have to remember the policies and procedures and the approach that their agency would take" (interview with the author, April $4^{\text {th }}$, 
2013). The ban of ministerial government employees from participating in BARC carries similar advantages, allowing the council to act as an impartial overseer of BAIT, which is co-chaired by the provincial and federal governments (Respondent C2, interview with the author, December 12, 2012). The following statement by Respondent $\mathrm{C} 2$ encapsulates the advantages of $\mathrm{BARC}$ as a watchdog institution: "The creation of the Bay Area Restoration Council to do their own thing, as well as being a watchdog on the BAIT, is a valuable governance mechanism. The institution is well ensconced in the community, a wide range of participants with a range of skills sets, will continue to work regardless of the position of government" (interview with the author, December $12,2012)$.

Respondent A12 has also observed that two competing tensions exist within the RAP approach: the concept of "eternal vigilance" and the need for constant improvement to meet community desires, and a concern that the ensuing "scope creep" (the extension and modification of RAP goals and objectives) will affect the timing of the AOC's delisting (interview with the author, April 4, 2013). These competing interests might be described as civil society demands versus state capabilities; while it is in the interest of government to meet the criteria for delisting as quickly and efficiently as possible, civil society members tend to hold out for the best possible result. One prominent example of this (and possibly the foundation for the respondent's remark) is the Randle Reef remediation project.

Civil society members opposed to the Randle Reef contaminated sediments solution invoke the sustainable development principle in their criticisms of the capping solution, which calls for the sustainable use of the natural environment in such a way that the needs of the present are met without "compromising the need of future generations to meet their own needs" (United Nations, 1987). It is difficult to argue that the containment and infilling of contaminated 
sediments — instead of removing and treating — does anything but that; the encasement is projected to have a lifespan of around 200 years, after which the issue will have to be revisited (Craggs, 2012). As evidenced by the amount of time taken to assemble funding for the project, however, each level of government involved is working with limited resources, and juggling a plethora of issues that are seen to take fiscal priority over this one in the eyes of the public. For these reasons, a more permanent solution may simply exceed the capabilities of government at this point in time. Additionally, removing the sediments would give rise to other important environmental considerations, such as whether the PCB-laden sediments could be removed and disposed of safely and effectively.

As discussed in Chapter 3, the Randle Reef contaminated sediment remediation is arguably the most contentious issue that must be resolved in order for the Hamilton Harbour AOC to be delisted. In addition to controversy surrounding the choice of remediation method discussed above, responsibility for the capping project's $\$ 138.9$ million price tag was also a point of conflict between the RAP team and community members. The proximity of sediments to U.S. Steel's outflow pipe has caused stakeholders to advocate for the company to contribute a significant proportion of the costs, as they are suspected to be party responsible for the environmental catastrophe (Respondent C3, interview with the author, February 15, 2013). The steel company has signed on to contribute the steel required for the containment facility, in addition to \$2 million cash (Respondent B2, interview with the author, March 6, 2013). Respondent C3 remarked that there appeared to be an "abuse of the spirit of the RAP" where the Randle Reef project was concerned, in which stakeholders, though ostensibly invited to the table, were not given the opportunity to make significant contributions to the decision making process that lead to the selection of the capping solution, and the virtual absolution of U.S. Steel of the 
company's past transgressions (interview with the author, February $15^{\text {th }}, 2013$ ). Respondent C3

remarks:

I don't think that's an unreasonable expectation for a community, because what's happened, we talk about industry and private sector plays externalizing costs, and here's a prime example. The spirit of the RAP is coming around the table, but I think that's probably part of what contributed to this taking as long and being as challenging a process as it was. I think maybe sometimes - I don't mean "let's duke it out", but I think sometimes when the issues are really challenging ones, maybe it's better to have open and frank dialogue around the table, rather than being so polite about it (interview with the author, February $15^{\text {th }}, 2013$ ).

This observation raises questions of the degree of responsibility of industry members for decades-old environmental transgressions. Respondent A2, an Environment Canada representative remarked that government collaboration with Stelco's U.S. Steel regarding the Randle Reef sediments in the past 20 - 30 years may give the company grounds to use the defence of officially induced error were they to be charged for violating federal law (interview with the author, February 26, 2013). The defence can be used in cases where the defendant received erroneous legal advice regarding the transgression from an official responsible for administering or enforcing the law in question.

Partners in Project Green

The Toronto RAP lead, Toronto and Region Conservation Authority, has formed a public-private partnership called Partners in Project Green (PPG) with the Greater Toronto Airports Authority, the body responsible for managing, operating, and maintaining Toronto Pearson International Airport (Partners in Project Green (PPG), n.d.). This partnership is significant because PPG's programs and services are driven by collaboration with the business community surrounding the airport, together with the Region of Peel, City of Toronto, City of Mississauga, and the City of Brampton (PPG, n.d.). In what appears to be an exceptional 
example of a multi-actor initiative contributing to the sustainable governance framework, PPG is said to "[harness] the creative capital of private and public sector leaders to create unique collaboration opportunities resulting in unprecedented individual and collective benefits" (PPG, n.d.). Industry members participating in PPG include Coca Cola, Molsen Coors, Woodbine Entertainment Group, Supremex, Canadian Tire, and Keilhauer (Respondent D1, interview with the author, May 2, 2013).

Multistakeholder initiatives are useful tools for filling gaps in system of governance, and for linking RAP participants that would otherwise operate separately. Industry-government partnerships in particular increase the involvement of the private sector, which several respondents have observed to be lacking. Industry contributions to the Toronto and Region RAP are largely indirect; however, Partners in Project Green (PPG) connects industry members with a desire to be environmental stewards to RAP officials at Toronto and Region Conservation Authority (TRCA). Respondent D3, a PPG representative, observes that this type of partnership pushes the boundaries of industry behaviour beyond what regulation demands of them:

I think regulation in general can raise the bottom denominator, sort of raise the minimum level, but by working with businesses proactively and on a voluntary basis, you can push far beyond the bottom level, that it gives you a chance to lead regulations rather than follow them. It also provides a lot of learning and knowledge as regulations change over time. I think the work of businesses we're leading can certainly inform how we can effectively raise that bottom line. But really, for us, the big benefit is really that ability to push the bar forward, and have shining examples that others can emulate, and want to emulate. And that's the approach PPG takes; it's a very peer-based approach (interview with the author, May 2, 2013).

This excerpt suggests that this type of industry-government partnership is a highly effective way of both engaging industry members, and more importantly, of keeping them engaged, which has been observed to be an issue (Respondent A1, interview with the author, April 11, 2013). 


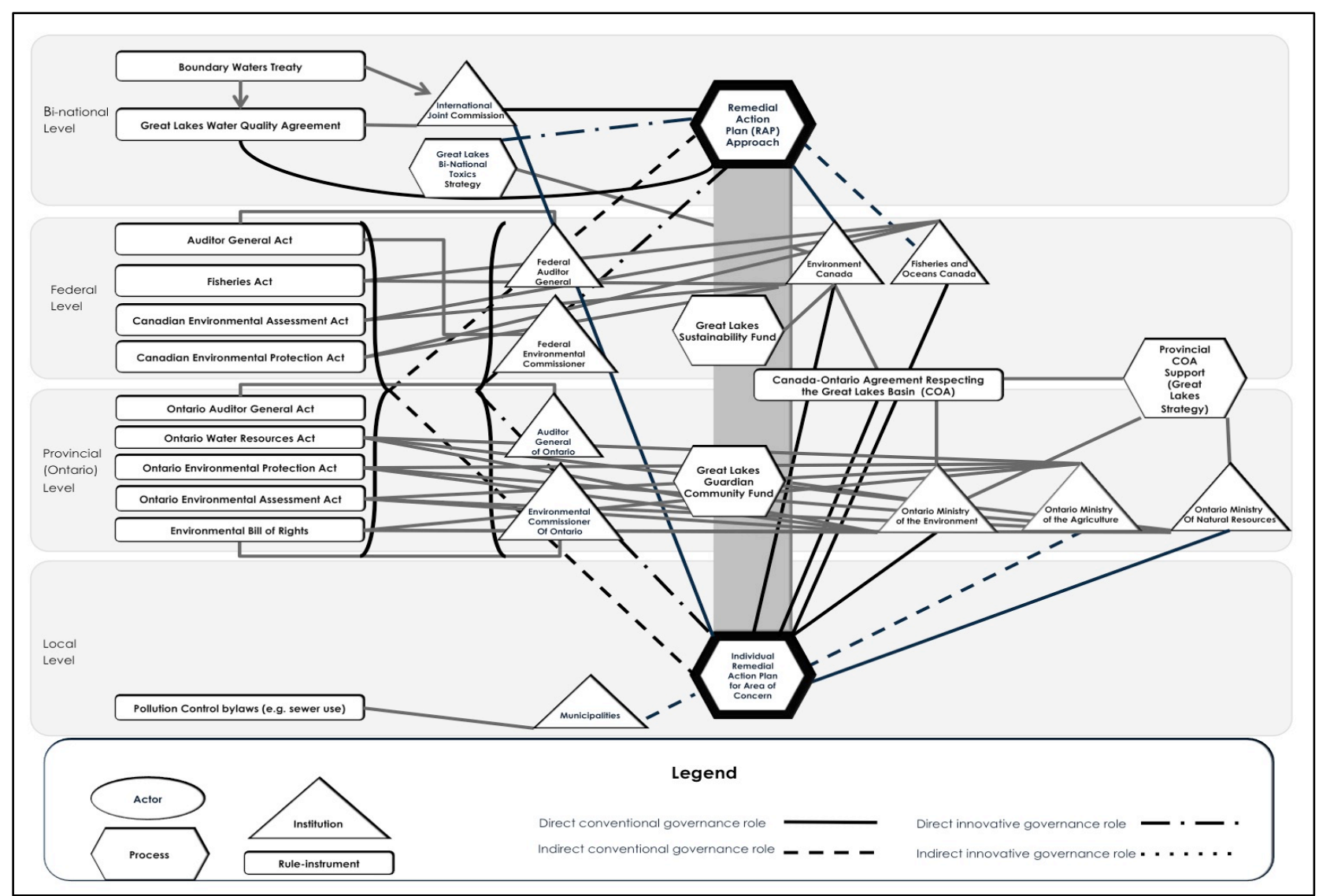

Figure 1.1 Governance institutions, processes, rule instruments, and actors applying to Canadian RAPs. Layer 1: Public Sector Dimension. This figure depicts the first layer of a mapping exercise of the RAP approach and initiatives and actors making direct or indirect contributions to it, highlighting both the underlying and innovative public sector initiatives. In addition to including the institutions and legislation from which the approach stemmed, this layer also includes innovative government watchdog institutions (federal, provincial Environmental Commissioners, Offices of the Auditor General). The complexity of this system of public sector actors involved in the RAP approach (from the bi-national scale to the federal, provincial, and local levels) demonstrates the importance of dialogue and collaboration across public sector jurisdictions. 


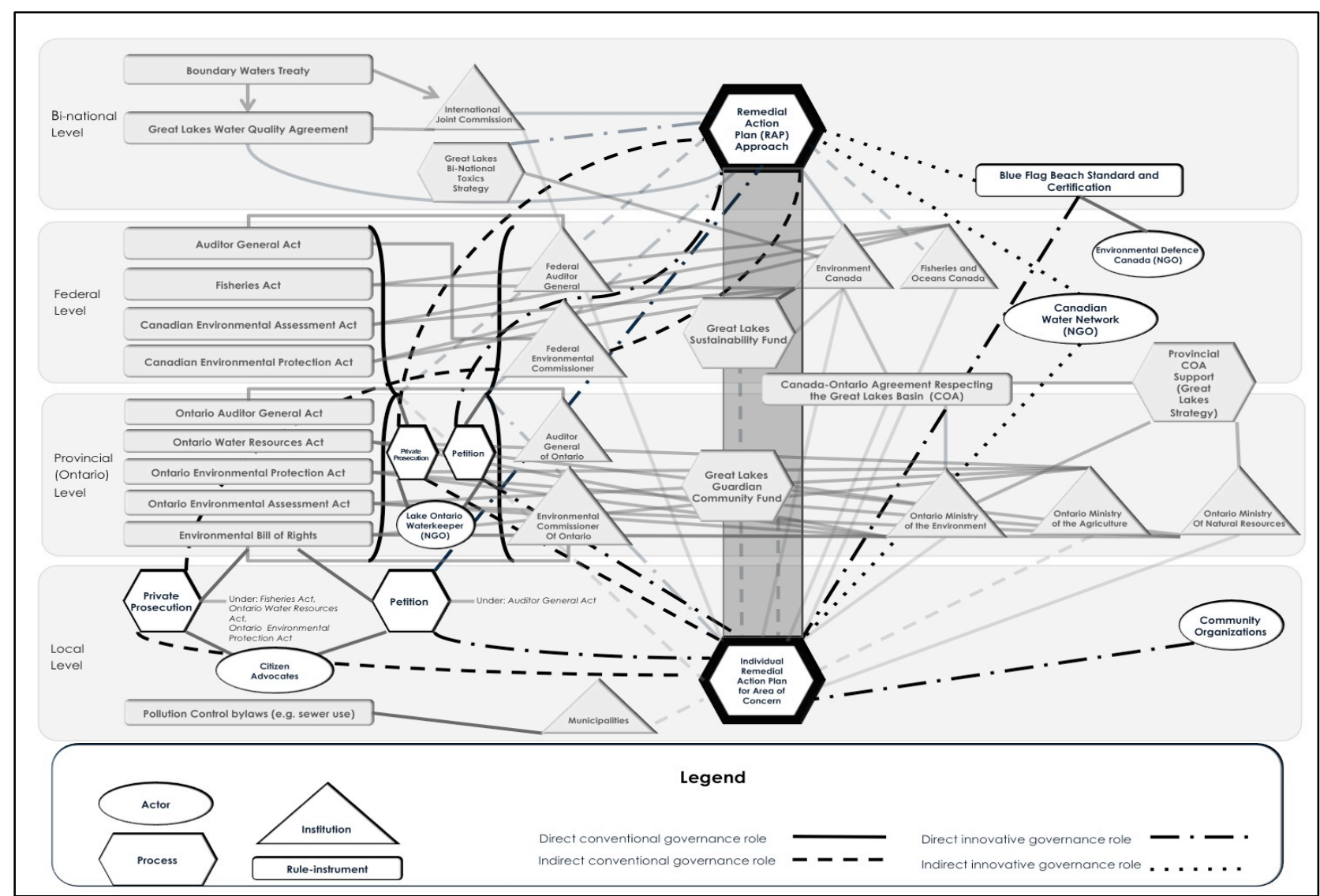

Figure 1.2. Governance institutions, processes, rule instruments, and actors applying to Canadian RAPs. Layer 2: Public + civil society sector dimension. This figure depicts the second layer of a mapping exercise of the RAP approach and initiatives and actors making direct or indirect contributions to it, highlighting the contributions of the civil society sector. As illustrated, civil society members contribute to the fulfillment of RAP objectives through the use of state processes: conventional private prosecutions (e.g. under the Fisheries Act, or the Ontario Water Resources Act), or petitions to innovative watchdog institutions (federal, provincial Environmental Commissioners, Offices of the Auditor General). Lake Ontario Waterkeeper is an example of a civil society actor that employs these methods, which may indirectly serve to advance RAP goals. Similar to the state-initiated petitioning and prosecution processes, the NGO-led Blue Flag rule instrument contributes to the RAP in a confrontational, rivalrous manner. Community organizations often make direct, innovation contributions at the level of individual RAPs, illustrated in Figures 2.1 and 2.2. 


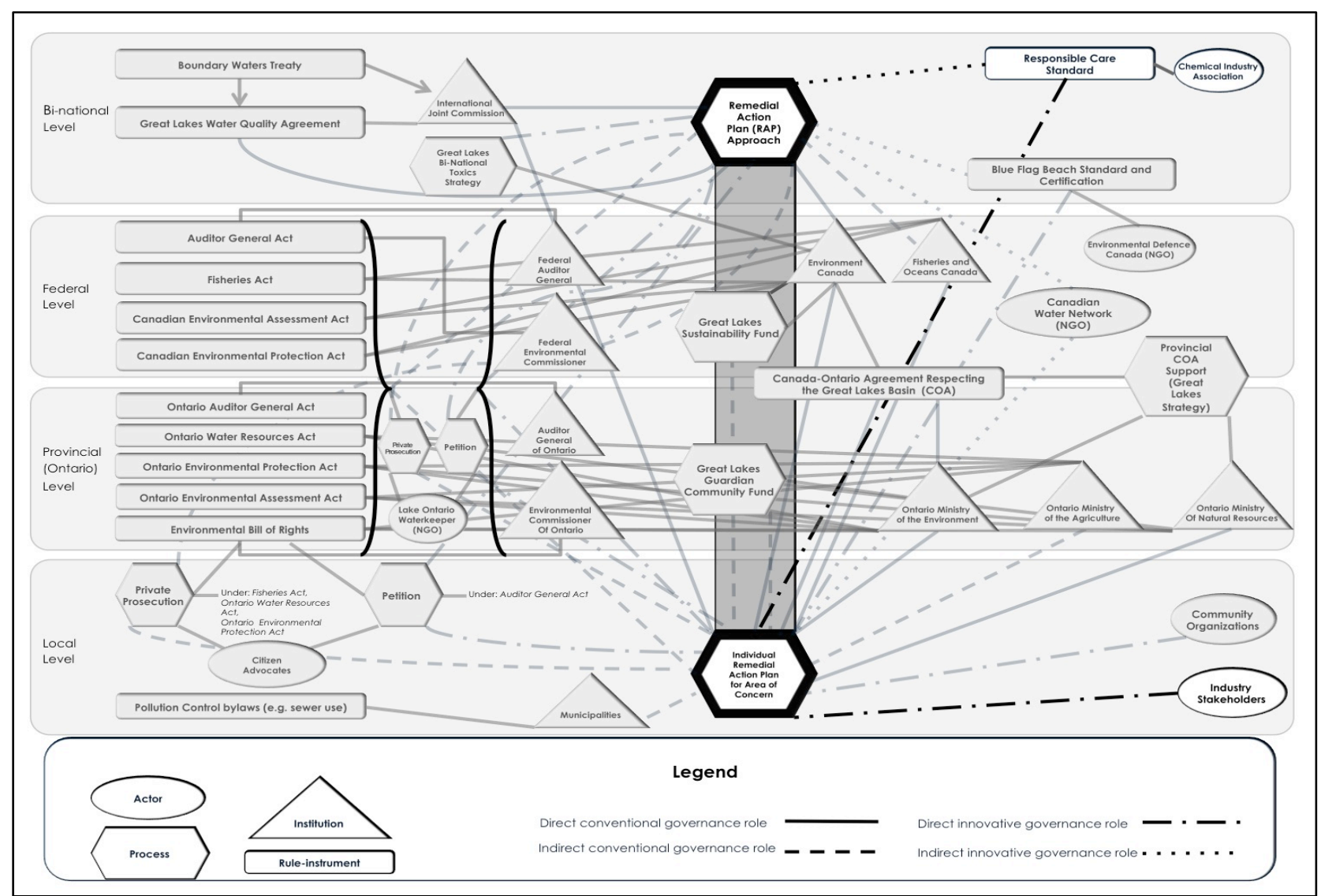

Figure 1.3. Governance institutions, processes, rule instruments, and actors applying to Canadian RAPs. Layer 3: Public + civil society + private sector dimension. This figure depicts the third layer of a mapping exercise of the RAP approach and initiatives and actors making direct or indirect contributions to it, highlighting the contributions of private sector members. The Responsible Care standard is considered an important bi-national private sector rule instrument innovation that forwards the goals of individual RAPs directly, and of the overarching RAP approach indirectly. It appears that private sector involvement is greater at the level of individual RAPs, as indicated in the above figure. Figures 2.1 and 2.2 illustrate the important contributions of industry members at the local level, to the Hamilton Harbour and Toronto and Region RAPs. 


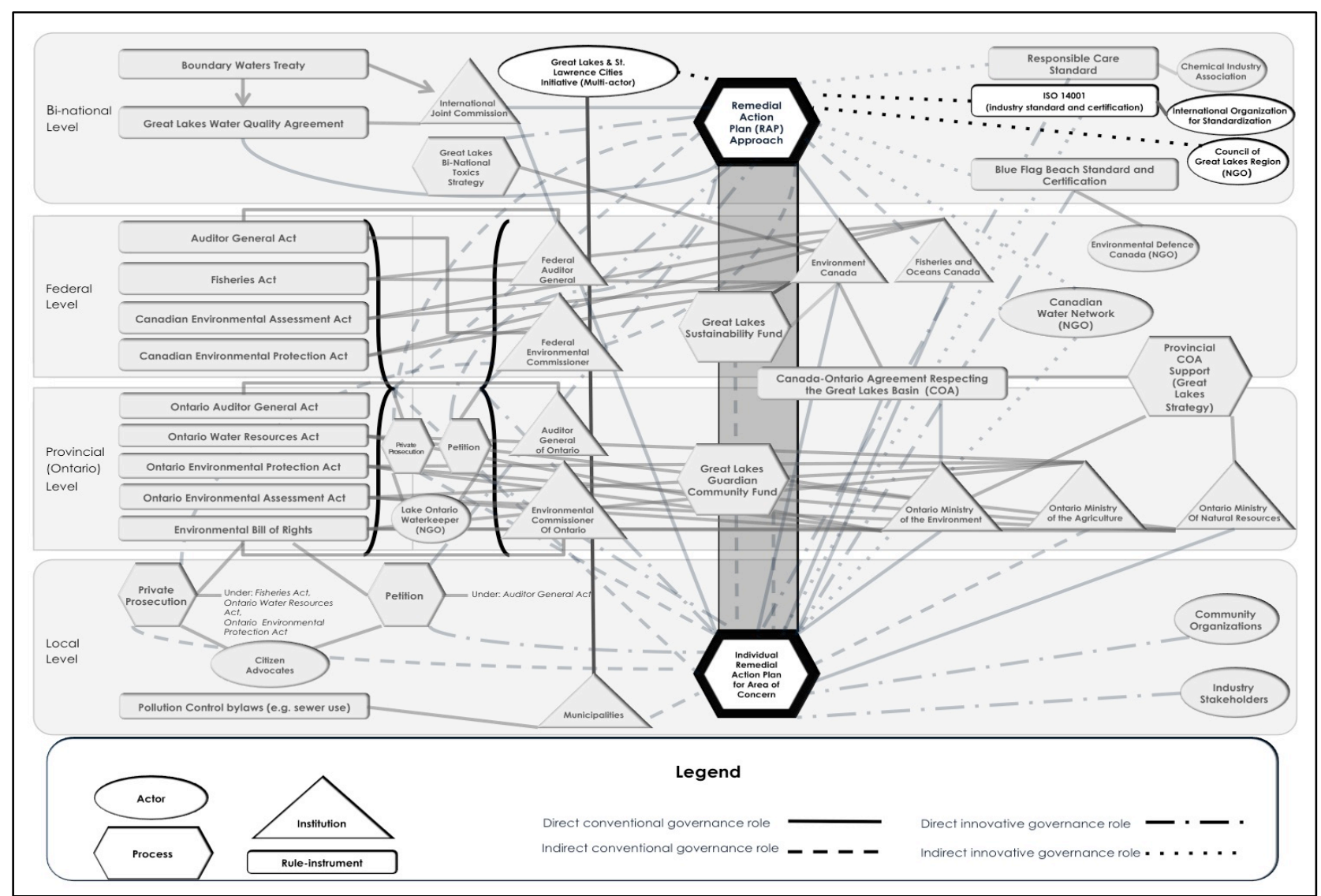

Figure 1.4. Governance institutions, processes, rule instruments, and actors applying to Canadian RAPs. Layer 4: Public + civil society + private sector + multistakeholder dimension. This figure depicts the fourth and final layer of a mapping exercise of the RAP approach and initiatives and actors making direct or indirect contributions to it, highlighting the multistakeholder actors (the RAP approach, individual RAPs, the Great Lakes St. Lawrence Cities Initiative, the Council of Great Lakes Region, and the International Organization for Standardization's ISO 14001 EMS standard and certification). Although it by no means depicts all actors and initiatives relevant to the remediation of Great Lakes, it should be noted that the portrait painted in the above figure is much more complete than that of Figure 1.1. This observation provides evidence of the complexity of the RAP system of governance, and of its extension far beyond the public sector rule instruments and institutions that established it. 


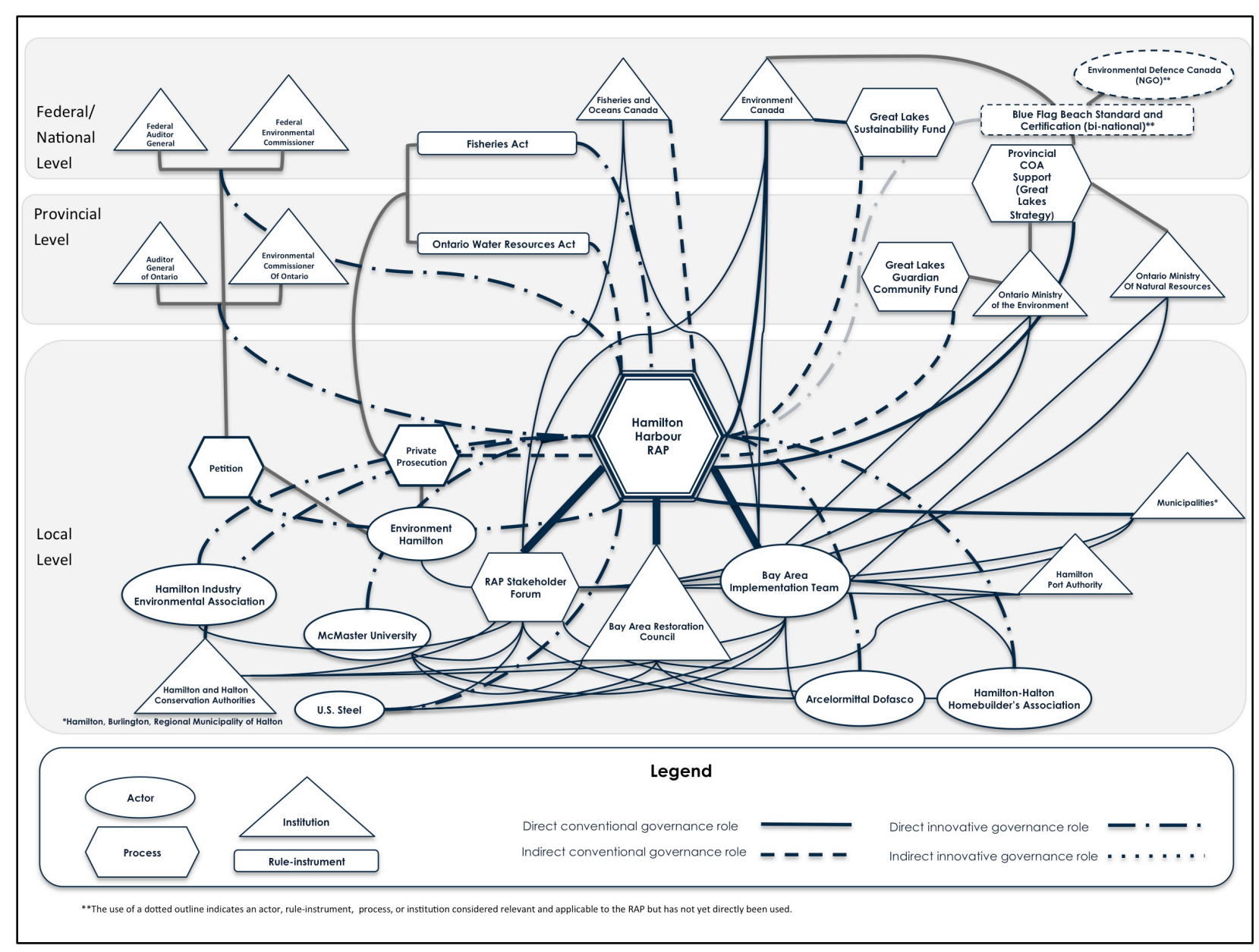

Figure 2.1. The Hamilton Harbour RAP: A sustainable governance perspective. The figure emphasizes the central roles of the Hamilton Harbour RAP's multistakeholder initiatives (Bay Area Restoration Council, Bay Area Implementation Team, Stakeholder Forum), through which the involvement of numerous private, civil society, and public sector entities is facilitated. Similar to the Toronto and Region RAP, provincial and federal government ministries (Environment Canada, Fisheries and Oceans Canada, the Ontario Ministry of the Environment, and the Ontario Ministry of Natural Resources) make direct, conventional contributions to the Hamilton RAP goals. It is important to note the harnessing of the innovative, rivalrous state processes (petitions to federal, provincial Environmental Commissioners, Offices of the Auditor General; private prosecution under the Fisheries Act and the Ontario Water Resources Act) by civil society sector members. The Blue Flag standard and certification, has yet to be applied to the Hamilton Harbour RAP (as none of the AOC's beaches are currently certified). This is indicated using dotted lines to outline this particular rule instrument and the overseeing actor. 


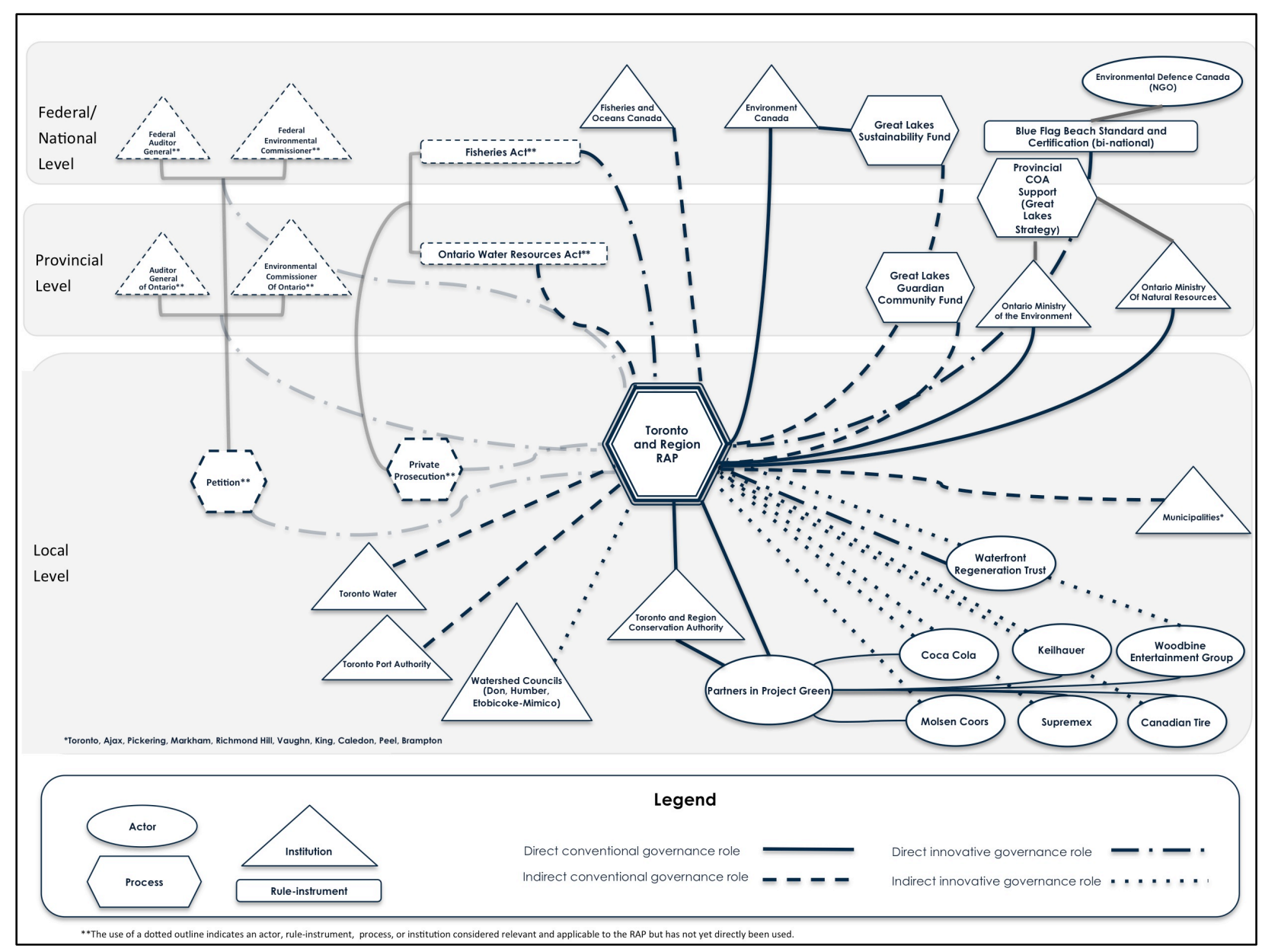

Figure 2.2. The Toronto and Region RAP: A sustainable governance perspective. The figure illustrates the important role of the Toronto and Region Conservation Authority, which serves as the RAP lead, and acts as an avenue for indirect private sector contributions to the goals of the RAP (e.g. Coca Cola, Molsen Coors, Canadian Tire, etc.). Similar to the Hamilton Harbour RAP, provincial and federal government ministries (Environment Canada, Fisheries and Oceans Canada, the Ontario Ministry of the Environment, and the Ontario Ministry of Natural Resources) make direct, conventional contributions to the Toronto RAP goals. Unlike the Hamilton RAP, there has been no harnessing of the innovative, rivalrous state processes by civil society sector members in the Toronto and Region RAP. The dotted lines outlining these processes, rule instruments, and institutions indicate the initiatives' potential applicability to the Toronto RAP. It is also important to note the direct, innovative contributions of the Blue Flag binational civil society rule instrument, as its criteria (e.g. for water quality) act as a check and balance on government monitoring. 


\section{CHAPTER 6: DISCUSSION}




\subsection{Revisiting the Tenets of Sustainable Governance}

In Chapter 4, the key principles of Webb's sustainable governance theory were identified as the "tenets of sustainable governance." This chapter aims to test the alignment of RAP approach with each of the delineated tenets, in order to pinpoint gaps between the existing system and the idea portrait of sustainable governance framework outlined by Webb (2005).

1. In a sustainable governance system, the responsibilities, costs, and learning associated with governance involve the public sector, private sector, and civil society organizations.

In the context of this tenet, responsibilities refer to the planning, development, implementation, enforcement (where applicable), maintenance and improvement of rule instruments, processes, and institutions under the authority or management of a given actor (Webb, personal communication, November 27, 2013). The key informant interview and literature review components of this investigation revealed a considerable number of the responsibilities associated with governing the Great Lakes remediation that have been entrusted to nonstate actors. In addition to this deliberate delegation of duties to the private and civil society sectors, some nonstate actors have taken on independent check-and-balance or watchdog roles, effectively ensuring the public sector's completion of its self-prescribed duties. This nonstate initiative increases the system's resilience to variability in state commitment (e.g. due to a change in government, etc.). Nonstate actors have in many cases placed themselves in a position to pick up the slack in the event that government departments fail to carry out their mandates. This is evident, for example, with the reporting criteria imposed on members of the chemical industry by the Responsible Care standard, which (according to Respondent B1) are 
markedly more rigorous than standards imposed by the National Pollutant Release Inventory (interview with the author, January 25, 2013). As demonstrated in Figure 1.2, this trend of sharing traditionally governmental responsibilities with nonstate actors is especially prevalent in the civil society sector.

According to interview respondents, in spite of the continued involvement of nonstate actors, the burden of financial cost (of projects aimed directly at the RAP approach) is chiefly borne by the provincial and federal ministries (Respondent A1, interview with the author, April 11, 2013). There are some exceptions, such as the $\$ 2$ million contribution made by U.S. Steel to the Hamilton Harbour RAP Randle Reef project. This lack of industry involvement in the cost aspect may well be considered a limitation of the system; being financially dependent on government certainly increases the risk of policy failure. It is also worth noting that expenditures can take forms other than financial costs (Webb, personal communication, November 27, 2013); this investigation revealed a number of non-financial resources contributed by industry and civil society members. For example, the Hamilton Harbour RAP's Bay Area Restoration Council board of directors consists of civil society and private sector representatives of stakeholder companies or organization that volunteer their employees' time and expertise.

Due to their interjurisdictional nature, RAPs may need to draw on financial resources of more than one level of government, and more than one government ministry. The advantages of this are evident, for example, with the appointment of Toronto and Region Conservation Authority as the Toronto and Region RAP lead. Respondent A2, a representative from Environment Canada involved in governing the approach since its advent, detailed the political events that resulted in a reduction in support for the Great Lakes remediation from the Ontario government under Premier Mike Harris in the 1990s (interview with the author, February 25, 
2013). In a strictly conventional system of governance relying on a single government institution or level of government, it is conceivable that this string of events (reduction of the provincial RAP budget, and removal of Ministry of the Environment representative as Toronto RAP coordinator) would have hindered the progress of RAPs in Ontario. As discussed in Chapter 6, the conservation authority's mandate (delineated in the Conservation Authorities Act) aligns very closely with the group's responsibilities under the RAP. Hence, by transferring some of the duties and costs associated with governing the Toronto RAP to TRCA, the project was able to overcome the withdrawal of provincial support.

With regard to the above tenet, "learning" is taken as referring to the concept of organizational learning, which describes the ability of an organization to develop, collect, and transfer knowledge, while adjusting their behaviour in accordance with these discoveries (Webb, personal communication, November 27, 2013). By this definition, all government agencies are, of course, considered learning organizations. This investigation also revealed a vast number of private sector and civil society learning organizations with varying levels of involvement in the RAP approach. In this case, a civil society learning organization may look like, for example the Blue Flag beach standard setting out criteria for participating jurisdictions, compiling the required environmental data from certified beaches, and potentially adjusting their stipulations in response to the data collected. Activist groups like Environment Hamilton and Lake Ontario Waterkeeper are also examples of civil society learning organizations; both entities carry out testing of environmental variables independent of government, and if the data is substandard, may file a petition or perhaps initiate a private prosecution. The Responsible Care standard is considered a private sector learning organization involved in the RAP approach, as it presents chemical industry members with a code of behavioural criteria that must be abided by, compiles 
the emission data reported by members, and has the power to adjust certification proceedings if needed.

It should be emphasized that in a sustainable governance system, there is in total a greater amount of resources being devoted to the issue with the involvement of nonstate actors and initiatives. This is evident, for example, with the chemical industry's Responsible Care program, and Environmental Defence's Blue Flag standard, which contribute to the pool of resources used to forward Great Lakes remediation objectives (in addition to government resources being used to address these issues), though they function independently from government, and are not incorporated into the RAP budget. From a coordination standpoint, this may pose a challenge, because it makes it more difficult to keep an inventory of all available resources, and adds another layer of complexity to what is at times a convoluted system. However, this is simply the nature of the sustainable governance beast; efficiency is sacrificed to some degree in order to achieve what is overall a more effective, robust system of governance.

2. The energies of these public sector, private sector, and civil society actors are harnessed via the rule instruments, processes, and institutions ("initiatives") they contribute to the resolution of a particular public policy issue.

Chapters 5 and 6 (in addition to the 'Annex' section of the Appendix) list some of the notable rule instruments, processes, institutions and corresponding actors contributing (or with some potential to contribute) to the Great Lakes RAP approach. As previously mentioned, one of the largest limitations of this investigation with respect to all of these actors and their initiatives is that there are simply too great a number to keep track of - this speaks volumes with respect to the above tenet. Countless civil society and private sector members have been involved in the remediation of the Great Lakes, directly or indirectly contributing to RAP goals, resulting in the 
evolution of a public sector initiative into an intricate, multi-actor network comprised of almost as many private and civil society initiatives as state initiatives. This is illustrated in Figures 1.1, 1.2, 1.3, and 1.4, which display a selection of notable actors, processes, rule instruments, and institutions making either direct or indirect contributions to the fulfillment of Canada's obligations under the GLWQA.

3. Private sector and civil society initiatives complement, rather than detract from conventional state rule instruments, processes, and institutions.

The alignment of the Great Lakes RAP approach with this particular tenet was explored by asking interview subjects whether their initiative "supports, improves, or interferes with any other initiative currently in place to address the remediation of AOCs" (Seep Appendix X ). Interviews with key informants overwhelmingly provided evidence of the complementarity of private and civil society sector initiatives with conventional rule instruments, processes, and institutions. The vast majority of respondents did not consider their initiative to interfere with any other; however instances of "head butting" between public sector and nonstate members working together on collaborative initiatives were frequently cited (i.e. contentious sediment remediation project in the Hamilton Harbour RAP). This should not be interpreted as the pitting of initiatives from different sectors against each other; in a sustainable governance system this type of disagreement and debate is seen as an asset that allows sectors to act as checks-andbalances on each others' contributions to the approach. This type interaction ("rivalrous friction") will be discussed in greater detail below. 
4. In a sustainable governance system, the value of multiple centres of authority is recognized.

The RAP approach substantiates Webb's (2005) claim that relying exclusively on conventional government mechanisms fails to meet the demands of twenty-first century governance. Since the advent of the RAP approach, a number of setbacks have occurred in the federal and provincial governments, which threatened the achievement of delisting of Canada's AOCs. The effective withdrawal of support for the RAP approach from the provincial government under Premier Mike Harris in the 1990s is an example of a public sector decision that resulted in considerable setbacks for the approach, a political move that Respondent A2 estimates cost Ontario RAPs $5-8$ years (interview with the author, February 26, 2013). The more recent federal amendments to environmental legislation may further diminish their capacity to protect the Great Lakes. Although it is too soon to discern the effects these changes will have on the progress of Canada's RAPs, it is conceivable that they will result in similar delays. Fortunately, as evidenced by the system's ultimate resilience in the face of provincial funding cuts, centres of authority outside of government have allowed the RAPs to progress despite setbacks in the public sector realm. Bodies administering international/bi-national certifications and standards (e.g. chemical industry's Responsible Care, International Organization for Standardization's ISO 14001, Environmental Defence's Blue Flag beach award), for example, act as an supplementary centre of authority governing the behaviour of their participants. As discussed in Chapters 5 and 6, these nonstate centres of authority are valuable checks-andbalances on public sector decision making. Alternate centres of authority also take the shape of government innovations; the provincial and federal Environmental Commissioners and Auditor Generals, for instance, act as internal checks-and-balances on government decision making. 
While it cannot be disputed that conventional (state) and innovative (private and civil society sector) centres of authority coexist in the RAP approach to governing the remediation and protection of the Great Lakes, there is some question as to the extent to which this has been recognized by primary governing bodies (i.e. government ministries). For example, when questioned about the applicability of the Responsible Care code of behaviour imposed on chemical industry members to the approach, one longstanding RAP expert indicated that she had never considered this potential application (Respondent C2, interview with the author, December 12, 2012). Furthermore, with the exception of the Blue Flag certification (which is listed as a Toronto and Region RAP goal), there appears to be little collaboration with or awareness of the contributions of these nonstate centres of authority in forwarding the GLWQA objectives. The reverse may also be true as well: These centres of authority may be largely unaware of their role in the approach. This lack of awareness (both of the initiatives of nonstate actors by public sector members, and of the extent to which the initiatives of nonstate actor contribute to RAP objectives) surfaced as a common theme in this investigation, and will be discussed in greater detail in sections 6.3 and 6.4 .

5. The value of multi-actor collaborations is recognized.

As discussed above, the RAP approach, while rooted in legislation, has in practice become a complex, multi-actor initiative. Since being established by the GLWQA, the approach has morphed into a complex, tangled web of public, private, and civil society sector initiatives, many of which constitute smaller-scale multi-actor initiatives. Figures 1.4 depicts some noteworthy multi-actor initiatives at the bi-national level contributing (or with the potential to 
contribute) to the RAP approach. The Great Lakes and St. Lawrence Cities Initiative, for instance, is a multi-actor initiative consisting of an NGO that works in partnership with municipalities in the Great Lakes region. Based on the key informant interviews and review of relevant policy documents, it might be fair to say that the benefits of multi-actor collaborations have been recognized on the local scale (at the level of individual RAPs), but receive much less recognition at the level of larger-scale initiatives, particularly when they are not geared directly towards the Great Lakes (e.g. Responsible Care's primary objective is to ensure accountability of chemical industry to public).

6. A potential for healthy rivalry between actors exists.

Chapters 5 and 6 indicated that healthy rivalry between actors is a common theme in the RAP approach. Oftentimes large-scale environmental projects like the remediation of the Great Lakes pit sectors against each other; this trend is particularly salient where civil society and private sector members are concerned. Historically, the two sectors have held opposing views with respect to environmental issues, as each has viewed the other's mandate as directly conflicting with their own. In this investigation, indications of healthy rivalry were observed on numerous occasions. For example, as described in Chapter 6, Lake Ontario Waterkeeper frequently lobbies against the behaviours of industry members (and, in turn, government authorization of said behaviours) in cases where it is seen to threaten the health of Lake Ontario. While a representative from the group expressed their disapproval of multi-stakeholder approaches such as the RAP approach, which considers industry members as allies rather than enemies, the friction created by this civil society group plays an important role in ensuring the GLWQA objectives are met. As mentioned in Chapters 5 and 6, ingrained in Lake Ontario 
Waterkeeper's mandate are several mechanisms that serve to bolster public sector remediation efforts. For instance, the civil society organization carries out water testing, independent of government, thereby acting as a check-and-balance on regulated monitoring. Additionally, the group also uses existing legislation to back appeals (e.g. of certificates of approval awarded under CEAA) and prosecutions. While from the organization's perspective, they may appear to be fighting a losing battle, the vigilance of this and other watchdog organizations alerts public sector agencies of the check-and-balance on their enforcement of environmental regulations.

As groups such as Waterkeeper make frequent (and often costly) demands on government ministries, and express relatively harsh criticisms of public and private sector behaviours, they might be said to constitute one "extreme" on the governance spectrum. However, their activism is necessary to offset demands made by so-called "rival" forces at the opposite end of the spectrum. These rival forces may take the shape of, for instance, industry members pushing for deregulation and reduced accountability to the public, or governments responding to these demands with bills that erode the efficacy of environmental legislation (e.g. Harper government's Bill C-38 that included material changes to the Fisheries Act and the Canadian Environmental Assessment Act, among others). Groups such as Ecojustice, the Canadian Environmental Law Association, and Environment Hamilton can also be placed in the same "category" as Lake Ontario Waterkeeper, as they frequently challenge industry behaviour using conventional rule instruments. In summary, although civil society activist groups may consider many of their failed petitions and prosecutions to be futile, it is these efforts that create the rivalrous friction that functions in tempering activism occurring at the other end of the governance spectrum. 
7. In a sustainable governance system, public, private, and civil society sector initiatives working together in a systematic way to achieve a common public policy goal. This is not the case for numerous rule instrument, process, and institutional innovations existing in Canada, which are, in contrast, random and ad hoc.

The RAP approach is not considered ad hoc in this sense, as the innovative (and conventional) initiatives discussed in this thesis have been seen to work together systematically (e.g. see Figures $1.1-1.4 ; 2.1,2.2)$. An inevitable challenge that accompanies the "systematicness" of sustainable governance approaches is the difficulty of coordinating a wide range of actors, processes, rule instruments and institutions across the public, private and civil society sectors. McLaughlin and Krantzberg (2012) observe that coordination difficulties have caused significant delays in the RAP approach, as no overarching plan has been established to coordinate the multitude of actors and initiatives involved. In order to improve the alignment of the RAP approach with this tenet, it is necessary to make a "concerted effort to draw on the full range of options available" (Webb, 2005). This might be accomplished by performing an appraisal of contributing initiatives, identifying gaps and redundancies, and adjusting the system accordingly. One limitation of this aspect of sustainable governance is the substantial investment of time and resources that systematic coordination requires (Webb, 2005).

The proposed Ontario Great Lakes Protection Act may contribute to increasing the systematicness of the RAP approach as a whole. The proposed Act would "promote collaboration and coordination amongst the Great Lakes community, including First Nations and Métis communities, Ontario ministries and other orders of government, environmental groups, scientists, farmers, industry, recreation and tourism sectors in order to share information, discuss priorities and develop initiatives. The act would help Ontario and our partners take action at the lake, coastal and watershed scale, as well as basin-wide" (Ministry of the Environment, 2013b). 
Additionally, the Act would establish an institution referred to as the Great Lakes Guardian Council, which would serve as a platform for coordination and collaboration among Great Lakes partners (Ministry of the Environment, 2013b).

\subsection{Learning from the Hamilton Harbour and Toronto and Region RAPs}

The differences in structural organization, and actors, processes, rule instruments, and institutions contributing to the Hamilton Harbour and Toronto and Region RAP approach are highlighted in Figures 2.1 and 2.2.

\section{The Bay Area Restoration Council's explicit championing of the Hamilton Harbour AOC's environmental issues, and publicizing of solutions has resulted in widespread awareness of the RAP among private and civil society sector stakeholders. This publicity can be credited with maximizing stakeholder involvement and securing the funding support required to meet RAP goals.}

Chapter 6 related the comments of Respondent A9 (a TRCA representative), which suggest that Toronto RAP goals are not often explicitly addressed, but are rather accomplished indirectly, as a byproduct of TRCA's distinct but similar watershed goals. In contrast with the Toronto RAP, the Hamilton Harbour RAP is the chief policy avenue through which the harbor's environmental issues are currently being governed. Hamilton community, industries, and local governments (if not participating directly) appear to be familiar with RAP issues, particularly those that are contentious (i.e. Randle Reef, water treatment plant upgrades). These issues are frequently discussed in local media, and the RAP's progress is reported on periodically. 
Furthermore, members of the BARC Board of Directors have spoken in front of Hamilton city council to advocate RAP issues, and have ongoing community and industry engagement efforts (Respondent C6, interview with the author, March 15, 2013). In contrast, Toronto City council is largely unaware of RAP goals and commitments (Respondent A6, interview with the author, April 24, 2013). Although TRCA has a number of public outreach enterprises (e.g. the conservation authority's annual Paddle the Don event), they do not appear to promote the concept of the RAP, although they are relevant to environmental issues being addressed by the TRCA that overlap with RAP goals. In summary, the Hamilton Harbour's use of RAP policies to govern the remediation of the Hamilton AOC appears to be more direct and explicit than the Toronto RAP approach, in which RAP recommendations are rerouted through existing TRCA projects and programs. This strength of the Hamilton Harbour RAP, the direct involvement and awareness of nonstate actors, is a characteristic common to each of the three governance approaches examined, and can be viewed as an indication of the RAP approach's alignment with each.

2. The Hamilton Harbour RAP's direct involvement of private and civil society sector representatives with respect to both public outreach and implementation can in many respects be considered a more complete embodiment of the collaborative, participatory, and sustainable governance frameworks than is exhibited by the Toronto and Region RAP.

It is remarkable to see the vastly different governance systems (depicted in Figures 2.1 and 2.2) that blossomed from the same fundamental policy approach embedded in the GLWQA. In spite of similarities between the geographies and urban issues faced by the cities of Hamilton and Toronto, the Remedial Action Plan models employed for each AOC are structurally quite divergent. Respondent A4, MOE representative for Toronto RAP, characterizes the differences 
between the Hamilton Harbour and Toronto and Region approaches to carrying out the duties

and responsibilities associated with their respective RAPs as follows:

We don't have a restoration council set up similar to Hamilton. It comes down to the fact that there was not a lot of interest, despite that fact that it was the biggest, and probably the most expensive solution here in Toronto, to having a multitiered layer of administrative issues here in Toronto. Specifically, we haven't really had much interest or drivers beyond the municipal governments, and their participation (despite the fact that they are always welcome at our RAP meetings), they don't routinely come unless there's an issue where we need the city of Toronto there.... If you go to most industries, they won't have a clue what a Toronto RAP is. It's somebody on the street corner that's singing to try and get money (interview with the author, February 13, 2013).

In Hamilton, the Bay Area Restoration Council (BARC) in its earliest form predated the RAP (Save Our Bay community organization), but became the RAP's official stakeholder group following Annex 1 of the GLWQA. Members "leave their hats at the door," a philosophy that is intended to provide all stakeholders with an equal, unbiased voice (Respondent C2, interview with the author, December 12, 2012). Respondent C6, a BARC Board of Directors member, commented on the role of BARC in the Randle Reef decision-making process (interview with the author, March 15, 2013). His commentary speaks to the extensive stakeholder dialogue (both internal and external to BARC) that took place during the decision-making surrounding Randle Reef, the presence of which aligns with all three of the governance frameworks examined.

BARC became an impartial reviewer of proposals for suggestions for remediation. There were different interest groups in the community advocating different things. BARC very much took a public role in terms of trying to be clear about the information, trying to overwhelm subjective info with objective info, trying to replace rhetoric with facts. Then it became a matter of government advocacy, lobbying, trying to align the original funding. It became a more public-facing issue in terms of providing info of what the project would look like, timelines. When it became clear that more money was required, BARC tried to inform the public and politicians. More recently, there was a completely different approach, where key funders were discussing among themselves, trying to align the funding to get the project done (interview with the author, March 15, 2013). 
Prior to the introduction of Annex 1 of the Great Lakes Water Quality Agreement, Hamilton community members were aware of the lack of state policy measures in place to address the severely degraded Hamilton Harbour, and responded by forming a community group called "Save our Bay." The site's official RAP team was built around this pre-existing community group, and was the basis for the Bay Area Restoration Council that exists today. One of the tenets listed in Section 7.1, and a distinguishable characteristic of sustainable governance, is the harnessing of citizen, industry, community, and NGO potentials to address a public policy problem. The choice to use an existing community group as a jumping off point for the Hamilton RAP indicates a governmental desire to promote innovative, multistakeholder collaborations, rather than relying entirely on conventional regulatory approaches.

\section{The Blue Flag certification of eight of Toronto's beaches supplements government regulatory approaches and is a confrontational check and balance mechanism that makes important, yet indirect contributions to Toronto and Region RAP goals, suggesting that the RAP approach goes beyond the typical new governance consensus-based, collaborative methods of involving nonstate actors.}

As evident from Figure 2.2, the Toronto RAP lags behind the Hamilton Harbour RAP considerably in the embodiment of many of the distinctive sustainable government precepts. This observation is particularly salient when looking at the first and second tenets described in 7.1. While the direct involvement of nonstate actors has certainly benefitted the Hamilton Harbour RAP, this is not to say that indirect initiatives are unable to make significant contributions as well. It is important to note, for example, the indirect role of the Blue Flag Program in forwarding the water quality goals of the Toronto and Region RAP. While eight of Toronto's beaches have received a Blue Flag beach award, none of the Hamilton AOC's beaches are in possession of the certification. Considering the status of the water quality BUI of the Hamilton 
Harbour RAP, and the status of contaminated sediments in the harbour, it is unlikely that the beaches would meet the beach award's stringent environmental criteria. The absence of the Blue Flag award from the Hamilton Harbour RAP governance structure is indicated in Figure 5.1, with the use of a dotted to border the rule-instrument rectangle.

This water quality certification is considered confrontational, because it has the potential to bring state failures to light (i.e. in the event that a beach is denied Blue Flag status, or a previously certified beach is unable to renew its certification due to a decline in water quality from one year to the next). It is this type of innovative, check and balance mechanism that distinguishes the RAP approach as a sustainable governance approach, rather than simply being a participatory or collaborative governance approach.

4. TRCA's assumption of the Toronto and Region RAP lead role increased its resilience to variability in government commitment, as it provided RAP goals and objectives with added protection under the Conservation Authorities Act. Following the example of the Hamilton Harbour RAP and writing stakeholders into the RAP's organizational structure would further cement the project's autonomy, increasing its resilience in the face of government failure.

TRCA agreed to take on the duties of the RAP primarily because its mandate aligned so closely with RAP goals that little actual adjustment appears to have been required on their end. It was rather the scope of the Toronto and Region RAP that required some tweaking improve its alignment with TRCA goals and responsibilities. (Respondent A2, interview with the author, February 26, 2013). According to Respondent A2, Environment Canada lamented some of the effects of charging TRCA with Toronto RAP duties, such as the geographical expansion to the RAP to include all of the watersheds falling under the conservation authority's jurisdiction (interview with the author, February 26, 2013). Certainly, this expanded Toronto RAP will run a greater cost than the original would have; however, this adjustment of RAP duties and 
responsibilities to align more closely with their mandate strengthens. By doing so, they rendered the many of the RAP's goals and objectives similar to those entrenched in the Conservation Authorities Act. This political move inadvertently created a "safety net", as it suggests that TRCA would continue to work towards Toronto RAP goals indirectly, simply by carrying out their mandate as a conservation authority.

5. While the ability to petition watchdog institutions (e.g. the Office of the Auditor General, Environmental Commissioner) is a government initiative, these process innovations are a source of the rivalrous friction between actors that is a distinguishing trait of a sustainable governance system. The use of this process by civil society individuals in the Hamilton Harbour RAP offers additional evidence of the approach's alignment with the tenets of sustainable governance.

These processes are depicted in Figure 2.1, which depicts the Hamilton Harbour RAP from a sustainable governance perspective. Chapters 5 and 6 detailed the use of a petition to the Office of the Auditor General, in addition to the use of a private prosecution (which is considered a conventional, but also a rivalrous process) as attempts by community activists to remove perceived impediments to the achievement of RAP goals. These processes were also included in Figure 2.2, which illustrates the Toronto and Region RAP; however, the shapes representing relevant institutions, rule instruments and processes are depicted using dotted lines. This indicates that these initiatives have yet to be employed by stakeholders, but remain a potential avenue for citizens or community organizations concerned about the progress of the Toronto RAP. 


\section{CHAPTER 7: CONCLUDING REMARKS AND RECOMMENDATIONS}




\subsection{Concluding Remarks}

The sustainable governance model was found to best describe the system of governance employed to achieve the Great Lakes remediation goals. The insights and information collected throughout this investigation revealed characteristics of participatory, collaborative, and sustainable governance embedded in the RAP approach. The foundation for each of these three frameworks is the involvement of nonstate actors in what is conventionally considered to be largely a government responsibility. Sustainable governance encompasses important aspects of participatory and collaborative governance (e.g. extending democratic participation throughout the policy cycle, consensus-based decision making involving multiple stakeholders) but also acknowledges the value of distinct independent nonstate actors, instruments, institutions and processes, sometimes engaging in rivalrous, and confrontational activities that challenge and point out weaknesses of existing state-based governance approaches in addition to complementing existing state-based governance approaches.. It was this marriage of collaborative and confrontational methods in the RAP approach that suggests the presence of a sustainable governance system that is not acknowledged or considered in participatory and collaborative approaches.

As discussed in Chapter 3, arguably one of the most common criticisms of the RAP approach is the slow progress of sites towards delisting. As numerous respondents discussed or alluded to, this appears to be an innate consequence of multi-stakeholder governance structures, particularly in the case of multi-actor discussions surrounding contentious projects. This may also indicate, however, a need to redefine expectations of RAP timelines. According to Respondent A1, in 1987, there was an "underestimation" of the complexity of remediating the 
AOCs. It is perhaps for this reason that the focus of the IJC has shifted from viewing the RAP as a "catch-all" solution to tackling beneficial use impairments one-by-one (Respondent A1, interview with the author, April 11, 2013). Each AOC has a different combination of environmental issues (BUIs), often requiring different resources and solutions. Additionally, capacity for community involvement varies greatly across AOCs, resulting in community-based solutions that are unique and consequently difficult to document. It is for this reason that comparing different AOCs has been equated with comparing "apples to oranges" (Respondent A4, interview with the author, February 13, 2013). Because of this, the remedial actions, organizational structures, and actors, processes, rule instruments, and institutions of individual RAPs must always be ad hoc to some degree. This is not to say that governance mechanisms employed at one RAP cannot be useful to another; on the contrary, the rate of achievement of RAP goals would likely be increased if each site drew upon the successes and failures of others. For example, the information and insights gathered in this thesis suggest that it appears to be the consensus among the government actors that the Hamilton RAP model, in which (industry and community) stakeholder involvement is maximized, is ideal (Respondent A2, Respondent C2). Thus, applying similar governance principles (e.g. the deliberate and explicit involvement of nonstate actors in planning, decision making, implementation, and monitoring) at other AOCs would likely bring about similar successes.

The comments of Respondent C2 capture this shift in the mindset of RAP officials away from attributing the failure of sites to delist to fundamental policy deficiencies to recognizing and celebrating modest environmental successes: "If you judge the success of a RPA by the number of AOCs that have been delisted, RAPs are a failure" (interview with the author, December 12, 2012). If success of RAPs is gauged instead by measuring incremental progress, the Hamilton 
Harbour RAP can be considered shining example for other RAPs (Respondent C2, interview with the author, December 12, 2012). This view of the approach (i.e. breaking down RAP goals into manageable chunks that can be tackled by a range of actors) is better suited to evaluating the RAP's system of governance, which is better characterized as a "complex multivariate ecosystem full of surprises" than a "mechanical device with clear inputs and outputs" (Webb, 2005).

\subsection{Recommendations}

In addition to the above lessons gathered from the Toronto and Region and Hamilton Harbour RAP systems of governance, a number of recommendations can be made with respect to the RAP approach in general:

1. Increase the "systematicness" of the RAP approach as whole, and of individual RAPs. At the local scale, systematically assemble Toronto and Region RAP stakeholders so that the governance structure more closely resembles that of the Hamilton Harbour RAP.

One recurrent theme in the insights collected via key informant interviews is ignorance of the larger picture of governance outside of the scope of their sector's (or, in some cases, organization's) mandates and contributions; that is, representatives from entities contributing directly to the RAP approach fail to see indirect contributions made by other actors to the overarching system of governance. What is perhaps even more remarkable is that actors making indirect contributions were themselves largely unaware of their role in the approach. This trend appears to be particularly visible in the Toronto and Region RAP, where industry stakeholders are considered "RAP stewards" with minimal or no awareness of the RAP (Respondent A9, 
interview with the author, April 25, 2013). This likely stems, at least in part, from the statecentric nature of the RAP, where nonstate actors have been relegated to making recommendations (e.g. as members of Watershed Councils), with little other capacity to influence decision making. The Hamilton Harbour RAP was constructed around an existing stakeholder institution; as a result, actors are more cognizant of their contributions than is often the case with other RAPs. Government officials fully endorse the collaborative Hamilton Harbour model, and consider it the "poster child" for RAPs (Respondent A2, interview with the author, February 26, 2013).

This stark contrast in both the stakeholder involvement and perceptions/evaluations of the two RAPs reflects the projects' differing alignments with the sustainable governance framework. The direct stakeholder participation model employed by Hamilton Harbour RAP's creates a more systematic, and robust system of governance, in which there is a deliberate acknowledgment of the responsibilities and contributions of both state and nonstate actors. By systematically identifying common goals and assembling stakeholders around the table for open discussion, the Hamilton Harbour RAP model increases avenue for industry involvement, which has been observed to be lacking in comparison with that of the public and civil society sectors in many RAPs. The Toronto and Region RAP would likely benefit from performing a similar type of appraisal of useful actors and initiatives and writing them in to the RAP, such as in the Hamilton Harbour multistakeholder initiatives. Of course, there is also the question of variable stakeholder engagement and willingness to participate. The point source pollution responsible for some of the Hamilton AOC's most serious environmental problems (e.g. Randle Reef contaminated sediments) makes identification of industry culprits a no-brainer, and can be used as leverage for prompting private sector participation. Pollution entering the Toronto and Region AOC, in 
contrast, is largely non-point source, so it is virtually impossible to assign blame. In spite of this, industry stakeholders of the Toronto and Region RAP appear to be receptive to the idea of environmental stewardship (e.g. given their willingness to participate in Partners in Project Green); perhaps this enthusiasm can be further harnessed to futher RAP goals in a more direct manner.

2. Conduct an appraisal of actors and initiatives involved in the RAP approach and individual RAPs, identifying gaps. Address government failures and limitations with respect to the RAP approach with multistakeholder institutions.

Appendix B provides a more extensive list of actors and their initiatives than were included in Chapters 5 and 6. This list is by no means considered to be comprehensive; it rather lists actors, rule instruments, processes, and institutions that "surfaced" from the literature and policy documents reviewed, and the insights gathered during key informant interviews. However, as a wide variety of key informant actors (representing the full range of sectors and jurisdictions involved in the RAP approach) were interviewed, it is likely that the majority of actors (and their initiatives) making significant, direct contributions to the approach have been included and discussed. Hence, the absence of entries in a particular category may indicate a gap in the system of governance.

One important issue that arose frequently during key informant interviews was the question of what will become of AOCs once they meet the criteria for delisting, in the event that the RAP approach deemed no longer necessary (Respondent A1, interview with the author, April 11, 2013; Respondent A4, interview with the author, February 13, 2013) With the exception of the renewed Canada-Ontario Agreement Respecting the Great Lakes Basin Ecosystem, which will include a commitment to long term monitoring, the future of multi-actor groups that have 
arisen from the RAP approach (e.g. BARC) remains uncertain (Respondent A4, interview with the author, February 13, 2013). In this case, groups that are not directly integrated into RAPs, or with a mandate that deals exclusively with RAPs are at an advantage; it is easy to conceive that these groups will continue doing as they have always done (i.e. monitoring and protection of the Great Lakes), paying little mind to public policy advances. While the direct involvement of nonstate actors is no doubt advantageous at this point in time, initiatives that currently make indirect contributions to the RAP approach or individual RAPs (operating largely from the sidelines), but that share exhibit priorities and values similar to those upon which the GLWQA was established will likely prove extremely useful with the inevitable dissolution of the approach. Civil society organizations such as the Great Lakes and St. Lawrence Cities Initiative, Lake Ontario Waterkeeper, Environmental Defence, and local community organizations will likely fill the gap left when official RAP teams are disbanded.

Respondents representing activist civil society groups (i.e. Lake Ontario Waterkeeper, Environment Hamilton) expressed concerns about the recent erosion of environmental legislation (e.g. Fisheries Act, Canadian Environmental Assessment Act) they consider to be vital to the remediation and continued protection of the Great Lakes Ecosystem. The loss of federal government support and diminished ability of the public to use this legislation to pursue private prosecutions (e.g. in cases where non-compliance threatens the goals of the GLWQA) is certainly deplorable; however, in scenarios such as these, having a wide array of nonstate actors, rule instruments, processes, and institutions to draw upon can be advantageous. In a truly "sustainable" system of governance, another rule instrument would emerge to fill this gap. It is possible this will occur through conventional methods. For instance, the proposed Ontario Great Lakes Protection Act may very well serve this function. Alternatively, and perhaps more 
interestingly, this gap can be viewed as an opportunity for the establishment of an innovative nonstate rule instrument. Looking at Appendix B, there appears to be a significant gap in the governance system in the area of multi-actor institutions, which have the ability to development rule-instruments independent of government (in a sustainable governance system).

3. Recognize the importance of confrontational, rivalrous methods, in addition to collaborative ones, at the level of individual RAPs.

Hamilton Harbour RAP stakeholders expressed dissatisfaction with the outcomes of decisions made by official RAP institutions, and with public sector adherence to RAP objectives. Community activists responded by invoking the use of private prosecution provisions under the Fisheries Act and Ontario Water Resources Act, as well as petitioning the Office of the Auditor General. The private prosecution was successful, and addressed problematic public sector behaviours that were hindering the progress of the RAP. While the petition was unsuccessful in the official sense, it serves more than one purpose in terms of the larger picture of governance: first, it alerted public sector actors of the commitment and enthusiasm of civil society members with respect to the remediation, making clear their intention to monitor government actions concerning the RAP; second, it increased awareness of the RAP approach, which may in turn lead to increased public and private sector engagement and participation.

In the Toronto and Region RAP, we do see some recognition of the value of innovative external check and balance mechanisms, such as the Blue Flag beach rule instrument, as evidenced by the addition of Blue Flag certification as an objective in official reports. Perhaps the success of the Toronto RAP could be improved through the use of the petition and private prosecution processes described above. Similarly, if the Hamilton Harbour were to openly pursue 
Blue Flag certification, this would constitute an increased recognition of the value of nonstate regulatory and confrontational approaches alongside conventional methods in a sustainable governance system.

4. Adopt a change of attitude that reflects recognition of the complexity and disorder that are part and parcel with the use of a sustainable governance approach.

Respondent D3 summarized the main challenge of applying the sustainable governance to the RAP approach in the following question: "How do we balance the energy and the vitality and the nimbleness that we get from all the nonstate organizations and activity with the kind of systematic outlook convening vision that usually comes from the government side?'(interview with the author, June 5,2013). Perhaps the answer to this question lies in the pursuit of some form of the "frank and open dialogue" called for Respondent C3 (interview with the author, February 15, 2013). The comparative success of the Hamilton Harbour RAP suggests that if public, private, civil society actors are systematically assembled, and invited to contribute to the RAP in a direct and meaningful way, environmental health of AOCs will be restored at a greater rate. This type of assembly would prove useful for the large-scale approach, in addition to individual RAPs. This large-scale assembly might take the shape of a conference, in which an inventory of each sector's actors, processes, rule instruments, and institutions might be conducted, and roles assigned accordingly. This method would also allow gaps in the system of governance to be identified and filled with relative ease; presumably (as typically occurs in sustainable governance systems) one or another of the numerous Great Lakes actors would come forward with an initiative that meets the perceived need. 
APPENDIX A: CONSENT AGREEMENT FORM 


\section{Ryerson University Consent Agreement}

The Great Lakes Regime: An Example of Sustainable Governance?

You are being asked to participate in a research study. Before you give your consent to be a volunteer, it is important that you read the following information and ask as many questions as necessary to be sure you understand what you will be asked to do.

Investigators: This investigation is being conducted by Madeleine Martin, an M.A.Sc. candidate in the Environmental Applied Science and Management Program at Ryerson University. She is working under the supervision of Dr. Kernaghan Webb, director of the Institute of the Study of Corporate Social Responsibility at Ryerson University.

Purpose of the Study: The purpose of this study is to determine whether the current policy approach aimed at remediating the Great Lakes ecosystem could be categorized as a "sustainable governance" approach. Sustainable governance describes an approach to environmental protection where a combination of governmental, nonstate organization, and industry governance initiatives work together in a systematic way to improve the environment. ${ }^{1}$ Due to its involvement of multiple actors, this sustainable governance approach is considered more flexible than traditional methods, since the successful delivery of services is not solely dependent on government. ${ }^{1}$ Although sustainable governance recognizes the important role of government and conventional regulatory methods such as laws and regulations, it also encourages the use of nonstate capabilities to achieve public policy goals. ${ }^{2}$

Description of the Study: After you give your consent to participate in this investigation, you will be interviewed on the topic of your group's involvement in the remediation of the Great Lakes. You are asked to express your own opinions, rather than speaking in an official capacity. You will be provided with a complete list of interview questions 2 weeks in advance of your scheduled interview date. The interview will take place in one sitting, at a private location agreed upon in advance by you and the investigator. It will last approximately one hour.

What is Experimental in this Study: None of the procedures used in this study are experimental in nature. The only experimental aspect of this study is the gathering of information for the purpose of analysis.

Risks or Discomforts: In order to minimize the possibility of experiencing discomfort during or after interviews, you will receive questions in advance, which will allow time for the preparation of responses that you feel do not disclose facts or opinions that you are not fully comfortable with. You will also be sent a draft summary of your responses following the scheduled interview,

\footnotetext{
${ }^{2}$ Webb, Kernaghan. (2005). Sustainable Governance in the Twentieth Century: Moving Beyond Instrument Choice. In Eliadis, P., Hill, M., \& Howlett, M. (Eds.), Designing Government: From Instruments to Governance (242 - 280$).$ Montreal \& Kingston: Mcgill-Queen's University Press.
} 
so that you may edit your responses if necessary. In addition, unless you consent to having your identifying information included in the thesis, steps will be taken to ensure that you remain anonymous. See 'Confidentiality' section for details. If you consent to the inclusion of your identifying information in the thesis project, paragraphs of the final thesis containing your name and/or job title in conjunction with excerpts of your interview responses (both direct quotes and summarized content) will be sent to you by email, so that you may approve the context in which your interview content is used prior to its submission to the university.

Benefits of the Study: You will not gain any direct benefits from participation. However, your participation in this interview will provide insights into the contributions of existing governmental and nonstate initiatives to the remediation of the Great Lakes. It is hoped that by gathering these insights, measures for improving upon existing initiatives might be recommended. Additionally, the investigation may expose a need for the creation of new, innovative initiatives, the adoption of which may allow the current system to operate with greater effectiveness.

Confidentiality: Unless otherwise specified, you will not be identified by name, nor will any other identifying information be included in either the thesis drafts or the final write-up. Your original interview transcripts will be linked with a code, and all identifying information will be excluded from them. Additional measures that will be taken to ensure your confidentiality is not breached include the encryption and password protection of computer files containing your original interview content, and the locking up of hard copies of your interview transcripts.

Documents or hard copies of interview transcripts will be destroyed one year from the original interview date for all participants (anonymous and otherwise).

Please indicate whether you consent to having your identifying information included in the thesis project, or whether you wish to remain anonymous, by checking one of the boxes below:

I consent to the use of my name and job title in conjunction with the insights I provide in responses to interview questions in all documents related to this investigation.

\section{I wish to remain anonymous.}

Incentives to Participate: This research is being conducted on a voluntary basis. You will not receive financial compensation for your participation.

Voluntary Nature of Participation: Participation in this study is voluntary. Your choice of whether or not to participate will not influence your future relations with Ryerson University. If you decide to participate, you are free to withdraw your consent and to stop your participation at any time without penalty or loss of benefits to which you are allowed.

At any point in the study, you may refuse to answer any particular question or stop participation altogether. If, following the interview, or after reviewing transcripts of your interview responses, you choose to withdraw your consent, please contact Madeleine Martin using the telephone number or email address provided below. Once you have indicated the withdrawal of your 
consent, all hard copies and electronic documents containing your interview content will be destroyed.

\section{Use of Recording Device}

The use of a recording device during the interview is recommended, as it allows for greater accuracy and precision in the transcription of your interview responses. However, you may optout of the use of the recording device and have your responses recorded manually (i.e. by hand) instead.

All auditory files or hard copies of recorded interviews will be destroyed within one year of the original interview date.

Please indicate whether you consent to the use of a recording device during your interview by checking one of the boxes below:

\section{I consent to the use of a recording device throughout the duration of my interview.}

\section{I wish to have my responses recorded by hand only.}

Questions about the Study: If you have any questions about the research now, please ask. If you have questions later about the research, you may contact:

\section{Madeleine Martin}

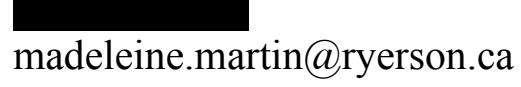

If you have questions regarding your rights as a human subject and participant in this study, you may contact the Ryerson University Research Ethics Board for information.

Research Ethics Board

c/o Office of the Vice President, Research and Innovation

Ryerson University

350 Victoria Street

Toronto, ON M5B 2K3

416-979-5042 


\section{Agreement:}

Your signature below indicates that you have read the information in this agreement and have had a chance to ask any questions you have about the study. Your signature also indicates that you agree to be in the study and have been told that you can change your mind and withdraw your consent to participate at any time. You have been given a copy of this agreement.

You have been told that by signing this consent agreement you are not giving up any of your legal rights.

Name of Participant (please print)

Signature of Participant

Date

Signature of Investigator

Date 
APPENDIX B: LIST OF ACTORS, PROCESSES, RULE INSTRUMENTS, INSTITUTIONS 
An entity may fall under more than one category (i.e. actor AND institution, etc). Multiple categorizations will be indicated with an asterix* .

$\underline{\text { Public Sector }}$

\begin{tabular}{|l|l|}
\hline & Bi-national \\
\hline Actors & $\begin{array}{l}\text { International Joint Commission (IJC)* } \\
\text { IJC Council of Great Lakes Research Managers } \\
\text { IJC Great Lakes Science Advisory Board } \\
\text { IJC Great Lakes Water Quality Board } \\
\text { IJC Great Lakes -St. Lawrence River Task team }\end{array}$ \\
\hline Processes & $\begin{array}{l}\text { The Great Lakes Remedial Action Plan Approach } \\
\text { Great Lakes Binational Toxic Strategy } \\
\text { IJC's Biennial Reports }\end{array}$ \\
\hline $\begin{array}{l}\text { Rule } \\
\text { instruments }\end{array}$ & $\begin{array}{l}\text { Boundary Waters Treaty (BWT) } \\
\text { Great Lakes Water Quality Agreement (GLWQA) }\end{array}$ \\
\hline Institutions & \begin{tabular}{l} 
International Joint Commission \& associated councils* \\
\hline
\end{tabular}
\end{tabular}

\begin{tabular}{|l|l|}
\hline & Federal \\
\hline Actors & $\begin{array}{l}\text { Environment Canada* } \\
\text { Fisheries and Oceans Canada* } \\
\text { Natural Resources Canada* } \\
\text { Office of the Auditor General* } \\
\text { Commissioner of the Environment and Sustainable Development* }\end{array}$ \\
\hline Processes & $\begin{array}{l}\text { Great Lakes Sustainability Fund } \\
\text { National Pollutant Release Inventory } \\
\text { Canada-Ontario Agreement Respecting the Great Lakes Basin } \\
\text { Ecosystem }\end{array}$ \\
\hline $\begin{array}{l}\text { Rule } \\
\text { instruments }\end{array}$ & $\begin{array}{l}\text { Auditor General Act } \\
\text { Canadian Environmental Assessment Act } \\
\text { Fisheries Act } \\
\text { Canada Water Act } \\
\text { Canadian Environmental Protection Act \& Environment Registry } \\
\text { Canadian Environmental Assessment Act }\end{array}$ \\
\hline
\end{tabular}




\begin{tabular}{|l|l|}
\hline & $\begin{array}{l}\text { Environmental Enforcement Act } \\
\text { Environmental Violations Administrative Monetary Penalties Act } \\
\text { Species at Risk Act }\end{array}$ \\
\hline Institutions & $\begin{array}{l}\text { Environment Canada* } \\
\text { Fisheries and Oceans Canada* } \\
\text { Natural Resources Canada* } \\
\text { Office of the Auditor General* } \\
\text { Commissioner of the Environment and Sustainable Development* }\end{array}$ \\
\hline
\end{tabular}

\begin{tabular}{|l|l|}
\hline & Provincial \\
\hline Actors & $\begin{array}{l}\text { Ontario Ministry of Natural Resources* } \\
\text { Ontario Ministry of the Environment* } \\
\text { Ontario Ministry of Agriculture and Food* } \\
\text { Office of the Auditor General* } \\
\text { Environmental Commissioner* } \\
\text { Environmental Review Tribunal* }\end{array}$ \\
\hline Processes & $\begin{array}{l}\text { Great Lakes Sustainability Fund } \\
\text { National Pollutant Release Inventory } \\
\text { Canada-Ontario Agreement Respecting the Great Lakes Basin } \\
\text { Ecosystem }\end{array}$ \\
\hline $\begin{array}{l}\text { Rule } \\
\text { instruments }\end{array}$ & $\begin{array}{l}\text { Auditor General Act } \\
\text { Environmental Bill of Rights } \\
\text { Ontario Water Resources Act } \\
\text { Clean Water Act } \\
\text { Ontario Environmental Protection Act } \\
\text { Ontario Environmental Assessment Act } \\
\text { Ontario Water Resources Act } \\
\text { Conservation Authorities Act } \\
\text { Great Lakes Protection Act } \text { (proposed) } \\
\text { Ontario Environmental Assessment Act } \\
\text { Ontario Environmental Protection Act } \\
\text { Ontario Water Resources Act }\end{array}$ \\
\hline Institutions & $\begin{array}{l}\text { Ontario Ministry of Natural Resources* } \\
\text { Ontario Ministry of the Environment* } \\
\text { Ontario Ministry of Agriculture and Food* } \\
\text { Office of the Auditor General* } \\
\text { Environmental Commissioner* } \\
\text { Environmental Review Tribunal* }\end{array}$ \\
\hline
\end{tabular}




\begin{tabular}{|l|l|}
\hline Actors & Municipal/Local \\
& $\begin{array}{l}\text { Toronto and Region AOC } \\
\text { City of Toronto } \\
\text { Town of Ajax } \\
\text { City of Pickering } \\
\text { City of Markham } \\
\text { Town of Richmond Hill } \\
\text { City of Vaughn } \\
\text { Town of Caledon } \\
\text { Peel Region } \\
\text { City of Brampton } \\
\text { Toronto Port Authority }\end{array}$ \\
\cline { 2 - 3 } & $\begin{array}{l}\text { Hamilton Harbour AOC } \\
\text { City of Hamilton } \\
\text { City of Burlington } \\
\text { Regional Municipality of Halton } \\
\text { Conservation Halton } \\
\text { Hamilton Conservation Authority } \\
\text { Hamilton Port Authority }\end{array}$ \\
\hline Processes & $\begin{array}{l}\text { The Great Lakes Remedial Action Plan Approach } \\
\text { Great Lakes Binational Toxic Strategy } \\
\text { IJC's Biennial Reports }\end{array}$ \\
\hline $\begin{array}{l}\text { Rule } \\
\text { instruments }\end{array}$ & $\begin{array}{l}\text { Boundary Waters Treaty (BWT) } \\
\text { Great Lakes Water Quality Agreement (GLWQA) }\end{array}$ \\
\hline
\end{tabular}

\section{Civil Society Sector}

\begin{tabular}{|l|l|}
\hline Actors & $\begin{array}{l}\text { Be-national } \\
\text { Great Lakes for Environmental Education } \\
\text { Great Lakes United }\end{array}$ \\
\hline Processes & Blue Flag Beach Standard and Certification \\
\hline $\begin{array}{l}\text { Rule } \\
\text { instruments }\end{array}$ & Great Lakes Commission \\
\hline Institutions & . \\
\hline
\end{tabular}




\begin{tabular}{|l|l|}
\hline & National \\
\hline Actors & $\begin{array}{l}\text { Canadian Environmental Law Association } \\
\text { Environmental Defence } \\
\text { Ecojustice } \\
\text { Canadian Water Network }\end{array}$ \\
\hline Processes & $\begin{array}{l}\text { Check and balance processes (e.g. independent water testing, petitions, } \\
\text { appeals, etc.) }\end{array}$ \\
\hline $\begin{array}{l}\text { Rule } \\
\text { instruments }\end{array}$ & Great Lakes Commission \\
\hline Institutions & \\
\hline
\end{tabular}

\begin{tabular}{|l|l|}
\hline Retors & Lake Ontario Waterkeeper \\
\hline Processes & $\begin{array}{l}\text { Check-and-balance processes (e.g. independent water testing, petitions, } \\
\text { appeals, etc.) }\end{array}$ \\
\hline $\begin{array}{l}\text { Rule } \\
\text { instruments }\end{array}$ & Great Lakes Commission \\
\hline Institutions & \\
\hline
\end{tabular}

\begin{tabular}{|l|l|}
\hline & Local \\
\hline Actors & $\begin{array}{l}\text { Hamilton Harbour RAP } \\
\text { Royal Botanical Gardens } \\
\text { Royal Hamilton Yacht Club } \\
\text { Green Venture } \\
\text { Burlington Sustainable Development Committee } \\
\text { Environment Hamilton } \\
\text { Hamilton Waterfront Trust } \\
\text { Hamilton-Wentworth Stewardship Council }\end{array}$ \\
& $\begin{array}{l}\text { Toronto and Region RAP } \\
\text { Waterfront Toronto } \\
\text { Waterfront Regeneration Trust } \\
\text { Watershed Councils (Don, Humber, Etobicoke-Mimico) }\end{array}$ \\
\hline Processes & $\begin{array}{l}\text { Independent testing of environmental variables (e.g. conducted by } \\
\text { Environment Hamilton) }\end{array}$ \\
\hline $\begin{array}{l}\text { Rule } \\
\text { instruments }\end{array}$ & \multicolumn{2}{|l|}{ Great Lakes Commission } \\
\hline Institutions & \\
\hline
\end{tabular}




\section{Private Sector}

\begin{tabular}{|l|l|}
\hline & Bi-national \\
\hline Actors & Toronto Pearson International Airport \\
\hline Processes & $\begin{array}{l}\text { Auditing (e.g. by CIAC, to ensure adherence to Responsible Care } \\
\text { criteria) }\end{array}$ \\
\hline $\begin{array}{l}\text { Rule } \\
\text { instruments }\end{array}$ & Responsible Care certification and standard \\
\hline Institutions & \\
\hline
\end{tabular}

\begin{tabular}{|l|l|}
\hline & National \\
\hline Actors & Toronto Pearson International Airport \\
\hline Processes & $\begin{array}{l}\text { Auditing (e.g. by CIAC, to ensure adherence to Responsible Care } \\
\text { criteria) }\end{array}$ \\
\hline $\begin{array}{l}\text { Rule } \\
\text { instruments }\end{array}$ & Responsible Care certification and standard \\
\hline Institutions & Chemical Industry Association of Canada National Advisory Panel \\
\hline
\end{tabular}

\begin{tabular}{|l|l|}
\hline & Regional \\
\hline Actors & Council of Great Lakes Industries (U.S.) \\
\hline Processes & \\
\hline $\begin{array}{l}\text { Rule } \\
\text { instruments }\end{array}$ & \\
\hline Institutions & \\
\hline
\end{tabular}

\begin{tabular}{|l|l|}
\hline Actors & Local \\
\hline & Toronto and Region RAP \\
& Ryerson University \\
University of Toronto \\
Unilever Canada (Partners in Project Green) \\
Coca Cola (Partners in Project Green) \\
Molsen Coors (Partners in Project Green) \\
Supremex (Partners in Project Green) \\
Canadian Tire (Partners in Project Green) \\
Keilhauer (Partners in Project Green) \\
Halton Legion (Royal Canadian Legion) (Partners in Project Green) \\
Woodbine Entertainment Group (Partners in Project Green) \\
& $\begin{array}{l}\text { Hamilton Harbour RAP } \\
\text { Arcelormittal Dofasco }\end{array}$ \\
\hline
\end{tabular}




\begin{tabular}{|c|c|}
\hline & $\begin{array}{l}\text { U.S. Steel } \\
\text { Hamilton-Halton Homebuilder's Association } \\
\text { Hamilton Industry Environmental Association } \\
\text { McMaster University }\end{array}$ \\
\hline \multicolumn{2}{|l|}{ Processes } \\
\hline $\begin{array}{l}\text { Rule } \\
\text { instruments }\end{array}$ & $\begin{array}{l}\text { Internal industry environmental policies (e.g. those of Arcelormittal } \\
\text { Dofasco, U.S. Steel) }\end{array}$ \\
\hline Institutions & \\
\hline
\end{tabular}

\section{Multi-Actor}

\begin{tabular}{|l|l|}
\hline & Bi-national \\
\hline Actors & $\begin{array}{l}\text { Great Lakes Commission } \\
\text { Great Lakes and St. Lawrence Cities Initiative } \\
\text { International Organization for Standardization } \\
\text { Council of Great Lakes Region }\end{array}$ \\
\hline Processes & Auditing for compliance with ISO 14001 stipulations \\
\hline $\begin{array}{l}\text { Rule } \\
\text { instruments }\end{array}$ & $\begin{array}{l}\text { ISO 14001 Environmental Management Systems standard and } \\
\text { certification }\end{array}$ \\
\hline Institutions & \\
\hline
\end{tabular}

\begin{tabular}{|l|l|}
\hline & National \\
\hline Actors & \\
\hline Processes & \\
\hline $\begin{array}{l}\text { Rule } \\
\text { instruments }\end{array}$ & \\
\hline Institutions & \\
\hline
\end{tabular}

\begin{tabular}{|l|l|}
\hline & Regional \\
\hline Actors & \\
\hline Processes & \\
\hline $\begin{array}{l}\text { Rule } \\
\text { instruments }\end{array}$ & \\
\hline Institutions & \\
\hline
\end{tabular}




\begin{tabular}{|l|l|}
\hline & Local \\
\hline Actors & \\
\hline Processes & $\begin{array}{l}\text { Toronto and Region RAP } \\
\text { RAP Progress Reports } \\
\text { Sustainable Manufacturing Partnership Consortium (PPG) } \\
\text { Properties and Office for Sustainable Innovation (PPG) } \\
\text { Logistics Leaders Executing Sustainable Solutions (PPG) } \\
\text { Hamilton Harbour RAP }\end{array}$ \\
\hline $\begin{array}{l}\text { Rule } \\
\text { instruments }\end{array}$ & Annual Towards Safe Harbours Report Card \\
\hline Institutions & \\
\hline
\end{tabular}




\section{Appendix C: Interview Respondent Key}

Group A-Public Sector

Respondent A1 - International Joint Commission Representative

Respondent A2 - Rimi Kalinauskas Senior Rap Coordinator, Environment Canada

Respondent A3 - Conrad deBarros, Ministry of the Environment (MOE), COA/Great Lakes Project Manager

Respondent A4 - Dan Joyce, MOE lead, Toronto RAP

Respondent A5 - MaryEllen Scanlon, MOE lead, Hamilton Harbour RAP

Respondent A6 - Councilor Mike Layton, City of Toronto

Respondent A7 - Toronto Water representative

Respondent A8 - Toronto Water representative

Respondent A9 - Toronto and Region Conservation Authority representative

Respondent A10 - Councilor Brain McHattie, City of Hamilton

Respondent A11 - Meg St. John, Toronto and Region RAP project manager

Respondent A12- John Hall, Hamilton Harbour RAP coordinator

Group B-Private Sector

Respondent B1 - Bob Masterson, Vice President, Responsible Care Canada

Respondent B2 - Andrew Sebestyen, U.S. Steel

Respondent B3 - Karen Logan, Hamilton Industry Environmental Association

Respondent B4 - Adi Irani, former president Hamilton-Halton Homebuilder's Association

Group C-Civil Society

Respondent C1 -BARC Board of Directors member

Respondent C2 - Gail Krantzberg, academic expert with frontline RAP experience

Respondent C3 - Lynda Lukasik, community activist and Environment Hamilton founder 
Respondent C4 - Pat Chow-Frazer, BARC Board of Directors member Respondent C5 - Martin Keller, BARC Board of Directors member Respondent C6 - Scott Koblyk, BARC Board of Directors member Respondent C7 - Lake Ontario Waterkeeper Representative Respondent C8 - Blue Flag Program (Environmental Defence) representative Respondent C9 - Don Watershed Council member

Group D - Multistakeholder initiatives

Respondent D1 - Reuven Scholzberg, Mowat Centre (Council of Great Lakes Region representative)

Respondent D2 - Melissa Soline, Great Lakes and St. Lawrence Cities Initiative

Respondent D3 - Dennis Braun, Partners in Project Green Representative 


\section{References}

Ansell, Chris, and Gash, Alison. (2007). Collaborative Governance in Theory and Practice. Journal of Public Administration Research and Theory, 18.

Aulich, Chris. (2009). From Citizen Participation to Participatory Governance in Australian Local Government. Commonwealth Journal of Local Governance, 2.

Bay Area Restoration Council (BARC). (2011). "Who We Are". Retrieved from http://www.hamiltonharbour.ca/about-who.htm

Bay Area Restoration Council (BARC). (2012a). "RAP Frequently Asked Questions". Retrieved from http://www.hamiltonharbour.ca/RAP/faq.htm

Bay Area Restoration Council (BARC). (2012b).“About the RAP”. Retrieved from http://www.hamiltonharbour.ca/RAP/about.htm

Bay Area Restoration Council (BARC). (2012c). 2012 Towards Safe Harbours Report Card. Retrieved from http://www.hamiltonharbour.ca/documents/BARC-2012-reportcardonline-draft_03.pdf

Bay Area Restoration Council (BARC). (2012d). “Accomplishments and Challenges”. Retrieved from http:/www.hamiltonharbour.ca/RAP/accomplishments.htm\#toxic

Bay Area Restoration Council (BARC). (2012e). "Hamilton Harbour Remedial Action Plan Stakeholder Forum 2012”. Retrieved from <http:/www.hamiltonharbour.ca /rap/hhrapforum.htm>

Bay Area Restoration Council (BARC). (2012f). "BAIT Stakeholders”. Retrieved from $<$ http://www.hamiltonharbour.ca/rap/stakeholders.htm>

Beierle, Thomas C.; and Konisky, David M. (1999). Public Participation in Environmental Planning in the Great Lakes Region (Discussion Paper 99-50). Retrieved from Resources for the Future website < http://rff.org/Publications/Pages/

PublicationDetails.aspx?PublicationID=17138>

Beierle, Thomas C.; and Konisky, David M. (2001). What are we gaining from stakeholder involvement? Observations from environmental planning in the Great Lakes. Environment and Planning C: Government and Policy, 19: 515 - 527.

Brinkerhoff, Jennifer M.(2002). Government non-profit partnership: A defining framework. Public Administration and Development (22): 19 - 30.

Botts, Lee; and Muldoon, Paul. (2005). Evolution of the Great Lakes Water Quality Agreement. East Lansing: Michigan State University Press.

Boyer,William. (1990). Political Science and the $21^{\text {st }}$ Century: From Government to Governance. Political Science and Politics, 23(1). 
Botts, Lee; and Muldoon, Paul. (2005). Evolution of the Great Lakes Water Quality Agreement.

East Lansing: Michigan State University Press.

Boyer,William. (1990). Political Science and the $21^{\text {st }}$ Century: From Government to Governance. Political Science and Politics, 23(1).

Canadian Boreal Forest Agreement (CBFA). (2010). "Canadian Forest Industry and Environmental Groups Sign World's Largest Conservation Agreement Applying to Area Twice the Size of Germany." <http://canadianborealforestagreement.com/ index.php/en/media/>

Canadian Environmental Law Association. (2012). “About CELA.” Retrieved from http://www.cela.ca/whoweare

Canadian Water Network (CWN). (2013). “Our Approach.” Retrieved from http://www.cwnrce.ca/our-approach/

Castells, Manuel. (2008). The New Public Sphere: Global Civil Society, Communication Networks, and Global Governance. The ANNALS of the American Academy of Political and Social Science, 616(1): 78 - 93.

Chemistry Industry Association of Canada (CIAC). (2009). "Responsible Care." Retrieved from www.canadianchemistry.ca/ResponsibleCareHome.aspx

Churchill, D. (2013, September 30). Deal in Place to Clean up Randle Reef. The Hamilton Spectator. Retrieved from http://www.thespec.com/news-story/4132216-deal-to-cleanup-randle-reef-in-place/

City of Toronto. (2003). "Wet Weather Flow Management Master Plan.” Retrieved from http://www.toronto.ca/involved/projects/archived/wwfmmp_archive/pdf/cso/complete_repo rt.pdf

City of Toronto. (2009). "Great City, Great Beaches: Toronto Beaches Plan.” Retrieved from http://www.toronto.ca/legdocs/mmis/2009/ex/.../backgroundfile-18573.pdf

City of Toronto. (2013a). "Toronto Beaches Water Quality.” Retrieved from http://app.toronto.ca/tpha/beaches.html

City of Toronto. (2013b). "Wet Weather Flow Management Master Plan: FAQ." Retrieved from http://www.toronto.ca/involved/projects/archived/wwfmmp_archive/faq.htm

Conley, A., and Moote, Margaret. (2003). Evaluating collaborative natural resource management. Society and Natural Resources, 16: 371 - 386.

Conservation Ontario. (2009). "Conservation Authorities Act—Section 28 Regulations". Retrieved from http://www.conservationontario.on.ca/planning_regulations/section28.html

Craggs, Samantha. (2012). Plan for Hamilton's Randle Reef cleanup: Put coal tar 'in a big steel box'. CBC Hamilton. Retrieved from 
http://www.cbc.ca/news/canada/hamilton/news/plan-for-hamilton-s-randle-reef-cleanupput-coal-tar-in-a-big-steel-box-1.1212560

Department of Fisheries and Oceans. (n.d.). "Fisheries Act." Retrieved from http://www.dfompo.gc.ca/habitat/role/141/1415/14151-eng.htm

Edwards, Meredith. (2011). Participatory governance into the future: Roles of Government and Community Sectors. Australian Journal of Public Administration, 60(3): 78 - 88.

Gamper-Rabindran, Shanti., and Finger, Stephen R.(2013). Does industry self-regulation reduce pollution? Responsible Care in the chemical industry. Journal of Regulatory Economics, 43: $1-30$.

Geissel, Brigitte. (2009). Participatory Governance: Hope or Danger for Democracy? A Case Study of Local Agenda 21. Local Government Studies 35(4): 401 - 414.

Gravelle, Matthew; Baird, Katherine; and Green, Ian. (2008). Collaborative Governance and Changing Federal Roles. Public Policy Forum.

Environment Canada. (2002). "Response of Environment Canada To Environmental Petition No. 57 By Dr. Lynda Lukasik and Dr. Mark Sproule-Jones under the Auditor General Act Contamination Near Randle Reef in Hamilton Harbour. Retrieved from http://www.oagbvg.gc.ca/internet/English/pet_057_e_28765.html\#response 1

Environment Canada.(2003). "Canada's RAP Progress Report 2003." <http://www.ec.gc.ca/rapspas/default.asp?lang $=$ En\&n=D91BD30F-1>

Environment Canada (2010b). "Delisted Areas of Concern." $<$ http://www.ec.gc.ca/rapspas/defaultasp?lang=En\&n=1EDC431A-1>

Environment Canada. (2012). "A guide to understanding the Canadian Environmental Protection Act, 1999." Retrieved from http://www.ec.gc.ca/lcpecepa/default.asp?lang=En\&n=E00B5BD8-1\&offset $=1 \&$ toc $=$ show

Environment Canada (EC). (2013a). Federal Policy and Legislation. Retrieved from http://www.ec.gc.ca/eau-water/default.asp?lang=En\&n=E05A7F81-1\#Section1

Environment Canada (EC). (2013c). "Hamilton Harbour Area of Concern". Retrieved from http://www.ec.gc.ca/raps-pas/default.asp?lang=En\&n=18AD73C1-1

Environment Canada (EC). (2013d). Toronto and Region Area of Concern. Retrieved from $<$ http://www.ec.gc.ca/raps-pas/default.asp?lang=En\&n=5098A4FF$1 \&$ offset $=1 \&$ toc $=$ show $>$

Environment Canada (EC). (2013e). "Great Lakes Sustainability Fund.” Retrieved from http://www.ec.gc.ca/raps-pas/default.asp?lang=En\&n=F328E319-1

Environment Canada and the Ontario Ministry of the Environment. (2007). Canada-Ontario Agreement Respecting the Great Lakes Basin Ecosystem. 
Environmental Defence, (2012). "How We Work." Retrieved from http://environmentaldefence.ca/how-we-work

Environment Hamilton. (2013). "Who We Are." Retrieved from http://www.environmenthamilton.org/view/page/about

Environmental Bureau of Investigation. (2000). "Hamilton Environmentalist Succeeds in Private Prosecution - City of Hamilton fined $\$ 450000$ for toxic waste dump". Retrieved from http://ebi.probeinternational.org/prosecutions/city-of-hamilton/

Foundation for Environmental Education (FEE). (2006). "Awards for improving the coastal environment: The example of the Blue Flag". Foundation for Environmental Education.

Foundation for Environmental Education (FEE) (.n.d.). "History." Retrieved from http://www.blueflag.org /Menu/History

George, T., and Boyd, D. (2007). Limitations on the development of quantitative monitoring plans to track the progress of beneficial use impairment restoration at Great Lakes Areas of Concern. Journal of Great Lakes Research, 33: 686 - 692.

Great Lakes Commons Initiative. (n.d.). "Why a Great Lakes commons?” Retrieved from http:/greatlakescommons.mphinternet.com/why-a-great-lakes-commons/

Great Lakes Commons Map. (n.d.). "Welcome to the Great Lakes Commons Map.” Retrieved from http://www.greatlakescommonsmap.org/page/index/2

Great Lakes and St. Lawrence Cities Initiative. (n.d.). "About GLSLCI.” Retrieved from http://www.glslcities.org/aboutus.cfm

Greenbaum, Allan, and Wellington, Alex. (2010). Environmental Law and Policy. Ontario: Captus Press.

Gunningham, Neil. (1995). Environment, self-regulation, and the chemical industry: Assessing Responsible Care. Law and Policy: 17(1).

Hamilton Harbour RAP Team. (1992). Stage 1 Report: Environmental Conditions and Problem Definition. Retrieved from http://www.hamiltonharbour.ca/rap/documents/reports/Stage1_Oct1992/Whole_Report_H H\%20RAP_Stage1_Oct1992.pdf

Handcock, Mark S., and Gile, Krista J. (2011). Comment: On the concept of snowball sampling. Sociological Methodology, 41(1).

Hartig, John H.; and Valentyne, John R. (1989). The Use of An Ecosystem Approach to Restore Degraded Areas of the Great Lakes. Ambio: 18(8), 423 - 428.

Heinelt, Hubert. (2010). Starting Points and Key Conceptual Issues. In Governing Modern Societies: Towards Participatory Governance $(7-48)$. New York: Routledge. 
Hogl, Karl; Kvarda, Eva; Nordbeck, Ralf; and Pregernig, Michael. (2012). Part I The Challenge of Participation. In Environmental Governance $(27$ - 108). Northampton, MA: Edward Elgar Publishing Inc.

Hooghe, Liesbet, and Marks, Gary. (2003). Unraveling the Central State, but how? Types of Multi-level Governance. American Political Science Review, 97(2), 233 - 243.

Howlett, Michael. (2009). Governance modes, policy regimes and operational plans: A multilevel nested model of policy instrument choice and policy design. Policy Sciences, 42: 73 89.

Innes, Judith, and Booher, David E. (2003). Collaborative policymaking: Governance through dialogue. In M.A. Hajer \& H. Wagenaar (Eds.) Deliberative Policy Analysis: Understanding governance in the network society (33 -59). Cambridge: Cambridge University Press.

International Joint Commission (IJC).(1991). "Commission Approves List/Delist Criteria for Great Lakes Areas of Concern.” Retrieved from http://www.ijc.org/rel/focus/listdelist/

International Joint Commission (IJC).(1998). Ninth Biennial Report on Great Lakes Water Quality. Retrieved from http://www.ijc.org/files/publications/C75.pdf

International Joint Commission (IJC). (2009). Fourteenth Biennial Report on Great Lakes Water Quality. Retrieved from http://www.ijc.org/php/publications/pdf/ID1631.pdf

International Joint Commission (IJC). (2013a). "Restoring Beneficial Uses in Areas of Concern". Retrieved from http://www.ijc.org/rel/boards/annex2/buis.htm

International Joint Commission (IJC). (2013b). "The RAP Process". Retrieved from http://www.ijc.org/rel/boards/annex2/rap_process.htm

International Joint Commission (IJC). (2013c). Sixteenth Biennial Report on Great Lakes Water Quality. Retrieved from http://www.ijc.org/files/publications/16thBE_internet\%2020130509.pdf

International Standards Organization (ISO). (n.d.). "ISO 14001-Environmental Management Systems." Retrieved from http://www.iso.org/iso/home/standards/managementstandards/iso $14000 . h t m$

Jackson, John. (2005) Citizens working across national borders: The experience in the North American Great Lakes. In Bruch, C., Jansky, L., Nakayama, M., \& Salewicz, K. (Eds.) Public Participation in the Governance of International Freshwater Resources (118 - 138). New York: United Nations University Press.

Johns, Carolyn, and Sproule-Jones, Mark. (2009). Water Pollution Policy in Canada: Cases from the Past and Lessons for the Future. In D.L. VanNijnatten \& R. Boardman (Eds.), Canadian Environment Policy and Politics $(216$ - 235). Don Mills, Ontario: Oxford University Press. 
Jordan, Andrew; Wurzel, Rudiger; Zito, Anthony. (2005). The Rise of 'New' Policy Instruments in Comparative Perspective: Has Governance Eclipsed Government? Political Studies, 53, 477-496

King, Andrew; and Lenox, Michael. (2000). Industry self-regulation without sanctions: The chemical industry's responsible care program. Academy of Management Journal, 43(4): $698-716$.

Krantzberg, Gail. (2003). Keeping Remedial Action Plans On Target: Lessons Learned from Collingwood Harbour. Journal of Great Lakes Research, 29(4), 641 - 651.

Krantzberg, Gail. (2012). Renegotiation of the 1987 Great Lakes Water Quality Agreement: From Confusion to Promise. Sustainability, 4, 1239 - 1255.

Lake Ontario Waterkeeper. (n.d.). "Who We Are". Retrieved from http://www.waterkeeper.ca/whoweare/

Lubelle, Mark.(2004). Collaborative Environmental Institutions: All talk and no action? Journal of Policy Analysis and Management, 23(3): 549 - 573.

Lemos, Maria Carmen, and Agrawal, Arun. (2006). Environmental governance. Annual Review of Environment and Resources, 31: $297-325$.

Lukasik, Lynda; and Sproule-Jones, Mark. (2002). "Environmental Petition to the Auditor General Re: Coal Tar Contamination near Randle Reef, Hamilton Harbour." $<$ http://www.oag-bvg.gc.ca/internet/English/pet_057_e_28765.html\#yet>

Marshall, M.N. (1996). The key informant technique. Family Practice: 13(1).

McLaughlin, C., and Krantzberg, G. (2012). An appraisal of policy implementation deficits in the Great Lakes. Journal of Great Lakes Research, 37: 390 - 396.

Metro Toronto Remedial Action Plan (MTRAP). (1989). Stage 1: Environmental Conditions and Problem Definition. Retrieved from http://www.torontorap.ca/dotAsset/64923.pdf

Metro Toronto and Region Conservation Authority. (1993). "Clean and clear: The erosion and sediment control practices study." Retrieved from http://www.torontorap.ca/dotAsset/65219.pdf

Metro Toronto Remedial Action Plan (MTRAP). (1994). “Clean Water, Clear Choices:

Recommendations for Action." Retrieved from

http://archive.org/details/cleanwatersclear00metruoft

Ministry of the Enivronment. (2013). "The Canada-Ontario Agreement Respecting the Great Lakes Basin Ecosystem (COA)." Retrieved from http://www.ene.gov.on.ca/environment/en/subject/great_lakes/STDPROD_096902.html

Ministry of the Environment. (2013b). "Where we are headed: Proposed Great Lakes Protection Act." Retrieved from http://www.ene.gov.on.ca/environment/en/subject/great_lakes/STDPROD_103248 
Newig, Jens, and Fritsch, Oliver. (2009). Environmental Governance: Participatory, Multi-level - and Effective? Environmental Policy and Governance, 19.

Office of the Auditor General Canada. (2011). "Who We Are." Retrieved from http://www.oagbvg.gc.ca/internet/English/au_fs_e_370.html

Office of the Auditor General Canada. (2013).’Commissioner of the Environment and Sustainable Development." Retrieved from http://www.oagbvg.gc.ca/internet/English/cesd_fs_e_921.html

Ontario Ministry of Natural Resources. (2013). "Conservation Authorities". Retrieved from http://www.mnr.gov.on.ca/en/Business/Water/2ColumnSubPage/STEL02_163413.html

Qu, Sandy Q., and Dumay, John. (2011). The qualitative research interview. Qualitative Research in Accounting and Management, 8(3).

Parekh, Bhikhu. (2004). Putting civil society in its place. In Glasius, M., Lewis, D. \& Seckinelgin, Hakan (Eds.) Exploring Civil Society: Political and Cultural Contexts (1423). New York: Routeledge.

Paris, Max. (2012, May 29). Fisheries Act changes questioned by former ministers. CBC News. Retrieved from http://www.cbc.ca/news/politics/fisheries-act-changes-questioned-byformer-ministers-1.1208106

Partners in Project Green. (n.d.). "About Us.” Retrieved from http://www.partnersinprojectgreen.com/about-us

Potoski, Matthew; and Prakash, Aseem. (2005). Green clubs and voluntary governance: ISO 14001 and firms' regulatory compliance. American Journal of Political Science: 49(2), 235 -248 .

Raymond, Leigh. (2002). Localism in environmental policy: New insights from an old case. Policy Sciences, 35: 179 - 201.

Rhodes, R.A.W. (1996). The new governance: Governing without government. Political Studies, XLIV: $652-667$.

Rose, Richard. (1991). What is lesson drawing? Journal of Public Policy: 1(11).

Rosenbloom, David, and Gong, Ting. (2013). Coproducing "Clean” Collaborative Governance. Public Performance and Management Review, 36(4): 544 - 561.

Sarnia This Week. (2013, February 14). Open houses on contaminated sediment in the St. Clair. Sarnia This Week. Retrieved from http://eedition.sarniathisweek.com/doc/Sarnia-ThisWeek/sarniathisweekfeb142013/2013021101/35.html\#34

Scholte, Jan Aart. (2002). Civil Society and Democracy in Global Governance. Global Governance, 8: $281-304$.

Sproule-Jones, M. (1999). Restoring the Great Lakes: Institutional analysis and design. Coastal Management, 27: $291-316$. 
Steen-Johnsen, Kari; Eynaud, Philippe; and Wijkstrom, Filip. (2011). On Civil Society Governance: An Emergent Research Field. Voluntas (22): 555 - 565.

Steurer, Reinhard. (2010). The role of governments in corporate social responsibility: characterizing public policies on CSR in Europe. Policy Sciences, 43, 49 - 72.

Steurer, Reinhard. (2013). Disentangling governance: a synoptic view of regulation by government, business and civil society. Policy Sciences: $1-24$.

Tandon, Rajesh. (2002). Civil society and good governance. Media Asia, 29(1).

Tollefson, Chris; Zito, Anthony; and Gale, Fred. (2012). Symposium Overview: Conceptualizing New Governance Arrangements. Public Administration, 90(1): 3 - 18.

Toronto and Region Conservation Authority (TRCA). (n.d.). “Ontario’s Conservation Authorities." Retrieved from http://rca.on.ca/about/conservation-ontario-otherconservation-authorities.dot

Toronto and Region Remedial Action Plan. (2010). "Status of Beneficial Use Impairments." Retrieved from http://www.ene.gov.on.ca/stdprodconsume/groups/lr/ @ene/@resources/documents/resource/stdprod_087419.pdf

Trubek, D. and L. Trubek. (2007). New Governance and Legal Regulation: Complementarity, Rivalry or Transformation. Columbia Journal of European Law, 13: 542 - 564.

Tully, K., and Mattson, M. (2004). Good environmental policy leads to good public health policy: A lesson from the grassroots. Healthcare Quarterly, 7(4): 71 - 74.

United Nations. (1987). "Report of the World Commission on Environment and Development." Retrieved from http://www.un.org/documents/ga/res/42/ares42-187.htm

United States Environmental Protection Agency (U.S.EPA)(2012). Great Lakes Water Quality Agreement. < http://www.epa.gov/glnpo/glwqa/>

United States Environmental Protection Agency (U.S EPA). (2013). “EPA History". Retrieved from < http://www2.epa.gov/aboutepa/epa-history $>$

U.S. Environmental Protection Agency (U.S. EPA). (2013b). "Environmental Management Systems.” Retrieved from http://www.epa.gov/ems/\#iso14001

U.S. Steel Canada. (2006). "Our Operations”. Retrieved from http://www.hamiltonsteel.ca/hamiltonsteel/operations.asp

U.S. Steel. (2012). “Environmental Stewardship.” Retrieved from http://www.ussteel.com/uss/portal/home/aboutus/environment

Van Dongen. (2012, August 13). Councilors delay Woodward treatment plant expansion. The Hamilton Spectator. Retrieved from http:/www.thespec.com/news-story/2254062councillors-delay-woodward-plant-expansion/ 
Water Canada. (2013, June 20). Coca Cola invests in Toronto Wetland Restoration Project. Water Canada. Retrieved from http://watercanada.net/2013/coca-cola-invests-in-torontowetlands-conservation-project/

Weiss, E.D. (1989). New Directions for the Great Lakes Water Quality Agreement: A Commentary. Chicago-Kent Law Review, 65: 375 - 386.

Webb, Kernaghan. (2004). Voluntary Codes: Private Governance, the Public Interest, and Innovation. Carlton Research Unit for Innovation, Science, and Environment.

Webb, Kernaghan. (2005). Sustainable Governance in the Twentieth Century: Moving Beyond Instrument Choice. In Eliadis, P., Hill, M., \& Howlett, M. (Eds.), Designing Government: From Instruments to Governance $(242$ - 280). Montreal \& Kingston: Mcgill-Queen's University Press.

Wilson, Paul. (2013, May 7). Gil was an S.O.B. and now she gets a plaque. The Hamilton Spectator. Retrieved from http://www.cbc.ca/news/canada/hamilton/talk/paul-wilson-gilwas-an-s-o-b-and-now-she-gets-a-plaque-1.1376226

Wood, Stepan (2003). Green Revolution or Greenwash? Voluntary Environmental Standards, Public Law and Private Authority in Canada. In Law Commission of Canada (Eds.) New Perspectives on the Public-Private Divide (123-165). Vancouver: University of British Columbia Press. 